THE STRATEGIC NATURE OF THE WELLINGTON

REGIONAL LAND TRANSPORT STRATEGY 2007-2016

by

Patrick Farrell

Thesis

ENVIRONMENTAL STUDIES 593

[2008]

A 90 point thesis submitted to Victoria University of Wellington, As partial fulfilment of requirements for the degree of Master of Environmental Studies

School of Geography, Environment and Earth Sciences Victoria University of Wellington

[March 2008] 


\title{
THE STRATEGIC NATURE OF THE WELLINGTON \\ REGIONAL LAND TRANSPORT STRATEGY 2007-2016
}

\author{
Patrick Farrell
}

\begin{abstract}
The purpose of the RLTS is to guide the region's transport spending over the next ten years. This study seeks to determine how strategic it is in terms of key environmental, economic and social outcomes: amenity and amenity access, air quality, accessibility, and low-income groups' transport affordability. Strategic is defined as how well the RLTS will function under potential future circumstances and its internal coherency and consistency. The resilience and adaptability of the RLTS to that range of potential futures is also analysed. The RLTS' priority is increasing regional accessibility, however due to 20+ years of underinvestment in the PT infrastructure, especially rail, targets set towards that goal are limited. Amenity and air quality are both considered to not require much intervention, but amenity services would be more adequately served if they were considered on par with air quality. Transport affordability to the community and users, especially low-income groups, was not given warranted attention. Therefore, four out of five of the outcomes appear to be well balanced. The RLTS objectives and outcomes are rather resilient, while the implementation plans are adequately adaptable with annual monitoring reports and final decisions which are also made on an annual basis. However, this can lead to inconsistencies between the Strategy and its implementation plans. The RLTS is therefore starting to head in a more sustainable direction, but the internal coherency and consistency is somewhat lacking.
\end{abstract}

Key words: RLTS; Wellington; transport; land use; urban design; accessibility; affordability; resilience; adaptability 


\section{$\underline{\text { Acknowledgements }}$}

I would like to thank my supervisor Associate Professor Ralph Chapman for reading all my drafts and his patience with all the impromptu question sessions.

Thanks to my colleagues Sara Blank, Amelie Goldberg, Tushara Kodikara, Grace Leung, Nick Preval, and Hayley Vujcich.

To my parents for supporting me while I've been in New Zealand. To Stafford House, Weir House, as well as Phil, Michelle, and Benn Crawford: thanks for putting a roof over my head while I wrote this thesis. 


\section{Table of Contents}

Abstract

Acknowledgment

Figures and Tables

List of Abbreviations $\quad$ v

1 Preface 1

2 Introduction 3

3 Aims and Objectives 6

4 Background 7

4.1 Wellington Region 7

4.2 The RLTS 8

4.3 Policy Context 9

5 Methods 12

5.1 Developing a Conceptual Framework 12

5.2 Interviews 12

6 Conceptual Framework 15

6.1 Environmental Outcomes 15

6.1.1 Amenity and Amenity Access

a Environmental Benefits $\quad 16$

b Social Benefits 16

c Economic Benefits $\quad 17$

6.1.2 Air Quality 18

a Measurement of the Effects of Air Pollution 19

b Susceptibility 20

c Health Effects

d Economic Cost 24

6.2 Economic Outcome 25

6.2.1 Accessibility 25

a Connectivity, Proximity and Agglomeration 26

b Sprawl $\quad 27$

c Congestion $\quad 29$

d Summary $\quad 32$

6.3 Social Outcome 34

6.3.1 Low-income Groups' Transport Affordability 34

6.4 Resilience and Adaptability 37

a Development 38

b Implementation and Monitoring $\quad 41$

c Conclusions $\quad 44$

7 Analysis

7.1 Amenity and Amenity Access 45

7.2 Air Quality 48

7.3 Accessibility 51

7.4 Low-income Groups'Transport Affordability 62

7.5 Resilience and Adaptability 64

8 Discussion $\quad 72$ 
8.1 Amenity and Amenity Access 72

8.2 Air Quality 72

8.3 Accessibility

8.4 Low-income Groups' Transport Affordability 77

8.5 Resilience and Adaptability 79

9 Conclusion $\quad 82$

$\begin{array}{ll}\text { References } & 87\end{array}$

Appendix

$\underline{\text { Figures }}$

1: The Strategic Regional Transport Network

Tables

1: Descriptive statistics $\mathrm{PM}_{10} \mu \mathrm{g} / \mathrm{m}^{3}$ (24-hr average) 48

2: Descriptive statistics CO $\mathrm{mg} / \mathrm{m}^{3}$ (8-hr moving mean) 48

3: Descriptive statistics $\mathrm{NO}_{2} \mu \mathrm{g} / \mathrm{m}^{3}$ (1-hr average) 48 


\section{$\underline{\text { List of Abbreviations }}$}

$\begin{array}{ll}\text { AA } & \text { Automobile Association } \\ \text { AMR } & \text { Annual Monitoring Report } \\ \text { the Bill } & \text { Land Transport Management Amendment Bill } 2007 \\ \text { CBD } & \text { Central Business District } \\ \text { CCTO } & \text { Council Controlled Trading Organisation } \\ \text { CO } & \text { Carbon Monoxide } \\ \text { EPR } & \text { Environmental Performance Review } \\ \text { Greater Wellington } & \text { the Wellington region } \\ \text { GWRC } & \text { Greater Wellington Regional Council } \\ \text { Land Transport NZ } & \text { Land Transport New Zealand } \\ \text { LGA } & \text { Local Government Act 2002 } \\ \text { LTA } & \text { Land Transport Act 1998 } \\ \text { LTCCP } & \text { Long-Term Council Community Plan } \\ \text { LTMA } & \text { Land Transport Management Act 2003 } \\ \text { NIMT } & \text { North Island Main Trunk rail line } \\ \text { NO } & \text { Nitrogen Dioxide } \\ \text { NZTS } & \text { New Zealand Transport Strategy 2002 } \\ \text { PCC } & \text { Porirua City Council } \\ \text { PM } 10 & \text { Particulate Matter } \\ \text { PT } & \text { Public Transport } \\ \text { PTOP } & \text { Public Transport Operational Plan } \\ \text { the PT Plan } & \text { Regional Public Transport Plan } \\ \text { RCP } & \text { Regional Cycling Plan } \\ \text { RLTC } & \text { Regional Land Transport Committee } \\ \text { RLTS } & \text { Regional Land Transport Strategy 2007-2016 } \\ \text { RMA } & \text { Resource Management Act 1991 } \\ \text { RPP } & \text { Regional Pedestrian Plan } \\ \text { RPS } & \text { Regional Policy Statement 1995 } \\ \text { RTP } & \text { Regional Transport Programme } \\ \text { SH } & \text { State Highway (either 1 or 2) } \\ \text { TA } & \text { Territorial Authority } \\ \text { TDM } & \text { Travel Demand Management } \\ \text { Transit } & \text { Transit New Zealand } \\ \text { WCC } & \text { Wellington City Council } \\ \text { WCP } & \text { Western Corridor Plan } \\ \text { WHO } & \text { World Health Organisation } \\ \text { WRS } & \\ \text { WTSM } & \\ & \text { Wellington Regional Strategy } \\ & \end{array}$




\section{1: $\underline{\text { Preface }}$}

Originally, this thesis was going to be entirely different. The notion of writing a thesis on transport and land use issues was a seed idea, left over from my original proposal written in January 2007. That proposal was rejected by my supervisor because it was too ambitious and would not be feasible at a Master's level. A focus on transport and land use integration in Wellington was suggested and agreed upon by both my supervisor and myself - mostly because I would be in Wellington while writing it. At the time, the Wellington Regional Land Transport Strategy 2007-2016 (hereafter known as "the RLTS") which is the primary document concerned with the future of transport in the Wellington region, was in draft form and open to public consultation. This provided an opportunity to write a relevant and timely thesis centred on questions concerning the integration of the RLTS with other policies at multiple political levels. This meant that my thesis would necessarily be broad, rather than deep, in its analysis.

In the beginning, my thesis was concerned with only a vague notion of the sustainability of the RLTS. Narrowing the focus down to a manageable level was a difficult and laborious conceptual task. My interpretation of policy sustainability, in a strategic context, is centred on resilience to slow change and shocks, and a system's adaptive capacity for those same changes and shocks. The central question became how the RLTS would respond if reality did not match with the predictions made during the RLTS's development. The title of my thesis, therefore, was settled early on in the conceptual phase.

A new proposal was written and a conceptual framework put together. The conceptual framework provides the necessary scientific backdrop for the analysis as well as highlights several benefits and issues involved with each focus area. It also contains policy and method recommendations from the literature which, when taken together, describe an ideal version of policy development and strategic objectives. It is against this backdrop that the RLTS is analyzed in this study. A number of articles covering a wide range of potential transport and land use issues were given to me by my supervisor as a starting point. From there a list of several environmental, economic, and social topics were written out and discussed. 
At the start, the environmental outcomes considered most relevant to the RLTS, and of the most interest, were amenity access, air quality, and noise pollution. Amenity was considered an environmental outcome as it was seen as a quality of the surrounding landscape which the RLTS could have a significant impact on independent of the other primary land use legislation: the Regional Policy Statement 1995. The economic outcomes were mobility, congestion, accessibility, and connectivity. The social outcomes considered were health and well-being outcomes - including physical activity, low-income groups' transport affordability, disabled groups' transport accessibility, and community severance. Resilience and adaptability cross-cuts the outcomes and is considered central to the notion of a strategy. Therefore, it was decided that resilience and adaptability would be a separate section. The process section was divided into modelling selection, the level of transparency, consultation, and transitional steps of implementation. 


\section{2: Introduction}

Transport and land use issues are of huge consequence for a variety of reasons. For one, use of the transport system is a significant component of daily social and economic interactions. Land use and its regulation influences where services, businesses and residents are located, affecting the travel times - and thus the transaction costs - of those interactions (Vuchic, 1999). Sprawling land use development and the network of motorways that support and depend upon it raise infrastructure costs and make life more expensive (Litman, 1997). There are also a range of environmental and social effects of land use and transport interactions. For example, transit orientated design means cleaner air than auto-dependent development (Frank, 2000). Moreover, there is a risk that sprawling land development around cities may accentuate the isolation of low-income groups by concentrating affordable housing in already poor, higher crime areas. The powerful local governments of suburban areas resist the siting undesirable development like low-income housing - within their jurisdictions (Downs, 1999; Dunphy, no date).

In asking how strategic the RLTS is, this project seeks to determine how well the strategy will function under a range of potential future circumstances and whether or not it is internally coherent and consistent. However, in order to analyse the strategic nature of a policy approach, there has to be consideration of topics which the strategy is holding in tension and balance. This is compatible with concepts surrounding co-evolution in transition management (Kemp et al., 2006). Carbon emissions was one of the major topics the strategy will have to consider. However, carbon emissions were disregarded immediately because a fellow master's student is concurrently writing a thesis on the impact of the RLTS on Wellington's carbon emissions.

In order to limit the scope of the thesis to a representative set of key topics, a vetting process determined what the focus would be within the various environmental, economic, and social outcomes. Eventually, the environmental outcomes that made the cut were amenity access and air quality. These were chosen because they are more connected to natural resources and systems while noise is largely an anthropogenic issue where the RLTS is concerned.

The economic outcomes of congestion reduction and mobility, as well as accessibility and connectivity issues, were combined together into two sections. This was 
done to take advantage of the conceptual symmetry within the two groupings. While researching the literature, it became problematic and cumbersome to keep the economic outcomes separate so they were combined under the overall heading of accessibility which appeared in the literature to be the best encompassing concept. It was decided to concentrate on commuter vehicle use and not include freight traffic because I considered commuter vehicles to be more strategically relevant to discussions on public transport as well as walking and cycling.

The key social outcome selected for analysis was affordability, especially lowincome groups' transport affordability. Community severance was downsized and relegated to the accessibility section because of its relationship with connectivity issues. Health and well-being concerns were addressed in the amenity access and air quality sections; the other aspects were considered less central to the purpose of this study. Facilities access for disadvantaged groups appeared to be a stand-alone issue, and, while not unimportant, did not appear to have many conceptual connections with the other sections, and so was excluded from study. Also, in a strategic context, transport affordability seemed to be the more pressing issue within the rest of the conceptual framework. For example, the public transport system could be very reliable, well run, and comfortable; but if is not affordable - especially to those living on low and fixed incomes - then it would not adequately serve the greater social welfare.

The issues to be discussed in the process section were distilled to futures thinking/models, horizontal integration, transparency, consultation, and implementation. Horizontal integration was included to reflect the internal structure of the RLTS and its relationships with other high level regional strategies - namely the Wellington Regional Strategy and the Regional Policy Statement. However, to further limit this study to a manageable size, the process section was assimilated into the resilience and adaptability section due to the high degree of overlap between the two. The distribution of these focus areas across the environmental, economic and social fields as well as the specific topics covered in each area are meant to be sufficiently diverse to gauge how the RLTS balances competing objectives.

The resilience and adaptability section thus focuses on policy development, implementation, and monitoring stages of the policy cycle. Transparency and 
consultation issues are important to all three stages. Futures thinking/models are a primary component of policy development. Horizontal integration of individual policies and programmes is a key part of both policy development and potential implementation. It has also become clear that any focused analysis of RLTS implementation is virtually impossible since only one Annual Monitoring Report (2006/2007) has been published during the writing of this study, and that report was based on the previous RLTS from 1999. 


\section{3: $\underline{\text { Aim and Objectives }}$}

The aim of this study is to determine the extent to which the RLTS is a strategic document in terms of key environmental, economic, and social sustainability outcomes determined by the author. Strategic in this sense means, in brief, how well the RLTS will function under a range of potential future circumstances and whether it is internally coherent and consistent. This definition of strategic is consistent with the summary of the long-term concepts surrounding transition management found in Kemp et al. (2006), which the author believes lies at the core of a 'strategy'. In order to determine this several potential outcomes of the RLTS will be analysed as assessed against each other. The potential outcomes of the RLTS are too numerous for this study to consider all of them. Therefore, the environmental outcomes focus on amenity access and air quality. Accessibility in the forms of mobility, congestion reduction, and connectivity constitute the economic focus. The key social outcome is low-income groups' transport affordability.

The resilience and adaptability of the RLTS are core sustainability characteristics. Resilience will be gauged by comparing the policy processes of modelling scenario construction, consultation, and progress monitoring with key recommendations from the literature. To determine this, the RLTS outcomes will be assessed against key findings from the literature. Funding priorities and implementation plans will be matched against the strategic outcomes to establish whether they complement each other. The adaptability of the RLTS will also be assessed in terms of how well the Strategy is likely to reflect changing global, regional, and local conditions that may, or may not, have been foreseen. 


\section{4: Background}

\section{1: Wellington Region}

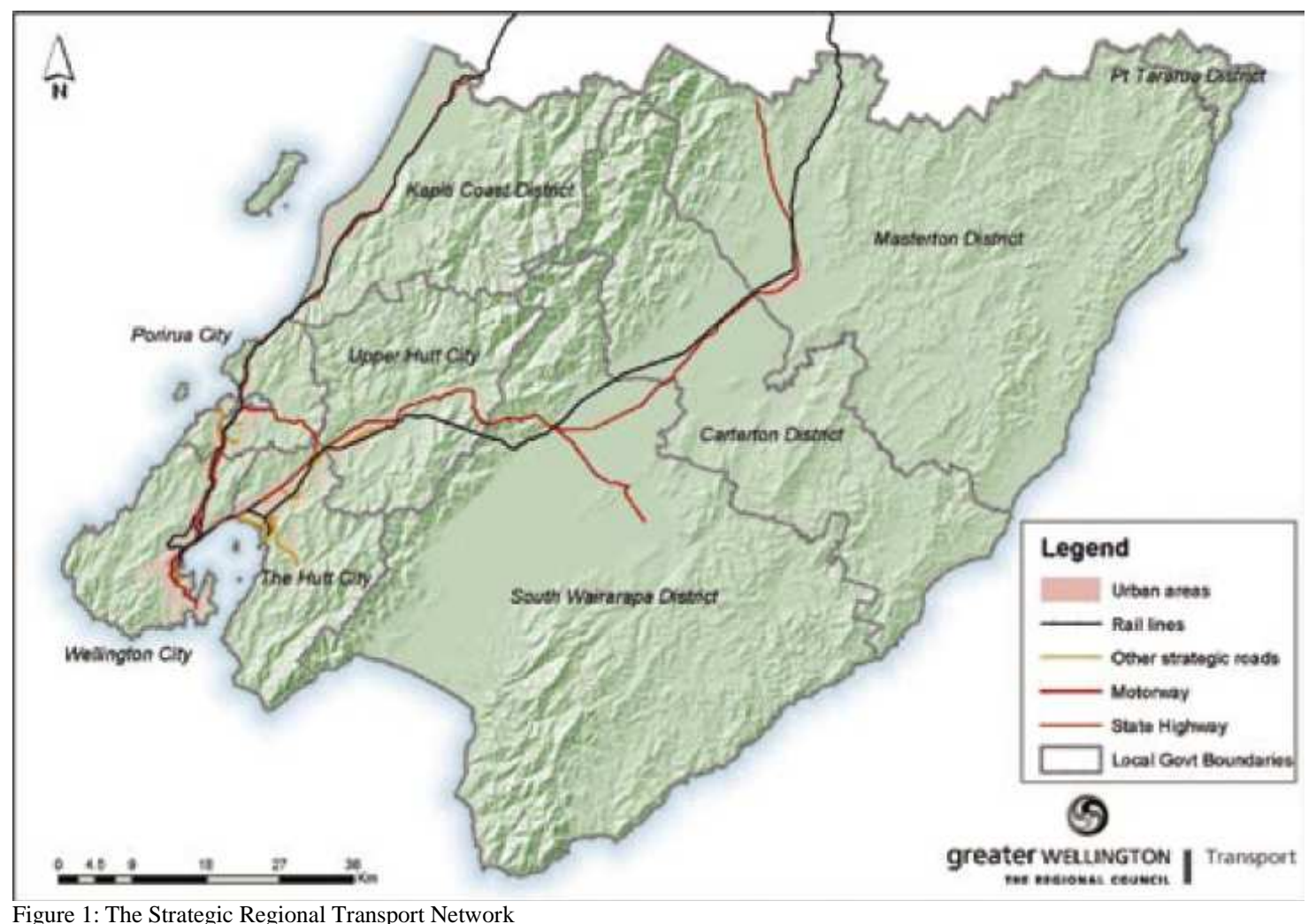

Figure 1: The Strategic Regional Transport Network

The Wellington region (Greater Wellington), as seen above in Figure 1, has a population of about 445,400. It covers an area of 813,005 hectares (GWRC website, accessed 10/2/08) and contains nine territorial authorities (TAs): Carterton District, Kapiti Coast District, Masterton District, Porirua City, South Wairarapa District, Tararua District, The Hutt City, Upper Hutt City, and Wellington City (RLTS p. 7). The three key transport pressures identified in the RLTS (pp. 8-10) are a growing population, growing economy, and the increasing demand for travel. Approximately 112,000 people work in Wellington city, with the majority - 70,000 - working in the city centre (WCC, 2007)

Figure 1 displays the two main transport corridors that service the region. The Western Corridor which is serviced by State Highway 1 (SH 1) and the North Island Main Trunk (NIMT) rail line. Both enter the region in the north near Otaki. State Highway 2 (SH 2) and the Wairarapa Line railway constitute the other main transport corridor. They enter the region north of Masterton, and run through Carterton, Upper 
Hutt, and Hutt City before merging with SH 1 and the NIMT at Ngauranga. SH 1 then proceeds through Wellington City, connecting the Central Business District (CBD) and the Wellington Regional Airport. State Highway 58 serves as a major east/west link between SH 1 and SH2 above Porirua and Lower Hutt. Around 35 million passenger journeys are made on the region's public transport system each year (GWRC website, accessed 10/2/08).

\section{2: The RLTS}

The Wellington Regional Land Transport Strategy was adopted in July 2007. It was produced with advice from the Regional Land Transport Committee (RLTC), established by section 178 of the LTA 1998. This Committee is responsible for approving the RLTS for consideration and adoption by the full regional council, among other things such as varying the RLTS and advising on other transport matters. Its membership includes five members from the regional council, the mayors of eight TAs, five representatives of the RLTS objectives, and one member representing ONTRACK, Land Transport NZ, and Transit New Zealand respectively.

The vision of the RLTS is to provide "an integrated land transport system that supports the region's people and prosperity in a way that is economically, environmentally and socially sustainable" (RLTS p. 6). In order to achieve this, the RLTS has six strategic objectives, all of which are relevant to this study. They are: assist economic and regional development, assist safety and personal security, improve access, mobility and reliability, protect and promote public health, ensure environmental sustainability, and ensure that the Regional Transport Programme is affordable for the regional community (RLTS p. 23). Supporting these objectives are numerous outcomes, targets, and policies.

There are seven implementation plans in the RLTS, five of which are directly relevant to this study. They are the Travel Demand Management (TDM) Plan, Cycling Plan, Pedestrian Plan, Passenger Transport Plan and Operational Plan, and the Regional Rail Plan. The four corridor studies - Western Corridor, Hutt Corridor, Wairarapa Corridor, and the Ngauranga to Wellington Airport Corridor - are also directly relevant. 
The RLTS also describes its view of the roles each transport mode plays within the region. The perceived amount of available funding, different types of funding, and the known funding gaps are also outlined. Finally, policies for the monitoring, evaluation, and review of the RLTS are illustrated. The rest of the document details the Implementation Plans, Regional Passenger Transport Plan, Passenger Transport Operational Plan, Corridor Plans, and the Regional Transport Programme.

\section{3: Policy Context}

The regional council is required under section 175(1) of the Land Transport Act (LTA) 1998 to produce a regional land transport strategy for the region. The LTA was later amended by the Land Transport Management Act (LTMA) 2003 to "take into account" assisting economic development, safety and personal security, improvements in access and mobility, protection and promotion of public health, and to ensure environmental sustainability (LTMA Schedule 6, p. 106). The LTMA 2003 also amended the LTA 1998 to "take into account" the National Energy Efficiency and Conservation Strategy (LTA s. 175(2c)).

The New Zealand Transport Strategy (NZTS) 2002 states central government's overall vision for transport: that it be "affordable, integrated, safe, responsive and sustainable" (NZTS p. 4). This language is echoed in section 175(2a) of the amended LTA 1998. The NZTS states that achieving its vision "will require a transport system that is efficient, affordable, flexible, innovative and resilient" (NZTS p. 4). The five objectives of the NZTS were incorporated into the LTMA 2003, which then amended the LTA 1998 (LTA s. 175(2b)). The NZTS also makes clear that the transport system is a service, not an end in itself, which facilities social and economic interactions (RLTS p. 66). The RLTS is committed to "not be inconsistent with" the NZTS in section 175(4) of the LTA 1998.

Land Transport New Zealand (Land Transport NZ) was formed in 2004 by combining Transfund New Zealand and the Land Transport Safety Authority, deriving its role and responsibilities from the LTMA 2003 (s. 68(1)). Its purpose is to "allocate resources and to undertake its functions in a way that contributes to an integrated, safe, 
responsive, and sustainable land transport system." These resources are distributed through the National Land Transport Programme. Land Transport NZ distributes the vast majority of the transport funding from the national land transport account. These funds include National, Regional, and Crown funds. The remaining Local funds are provided from regional and local rates, as well as individually paid fares (RLTS p. 51).

Transit New Zealand (Transit) is a road controlling authority that designs, constructs, and manages the state motorways, among other things (LTMA s. 78). Transit's Strategic Plan 2004 “informed” the development of the RLTS (RLTS pp. 68-9). Both Land Transport NZ and Transit are required to "take into account" relevant RLTSs when preparing their land transport programmes (LTMA s. 12(5)).

Through the Resource Management Act (RMA) 1991, regional councils are to provide for the "strategic integration of infrastructure with land use through objectives, policies and methods" (RMA s. 30(1gb)). The RMA 1991 requires that regional councils produce a Regional Policy Statement (RPS) in order to promote the sustainable use of the region's resources (RMA s. 59). The RLTS "may not be inconsistent with" the RPS under force at the time of its development (LTA s. 175(3)). The current Wellington RPS was approved in 1995 and is currently under review as of this writing (RLTS p. 66). The new draft RPS was released for public consultation until 16 May 2008 (GWRC website, accessed 13/3/08).

The Wellington Regional Strategy (WRS) 2004 is primarily a sustainable economic development document written by the regional council in conjunction with the nine city and district councils that make up the greater Wellington region. While there is no statutory relationship or responsibilities between the two, the WRS did "inform" the RLTS's development (RLTS p. 68). In addition to that, the RLTS needs to be consistent with the regional council's Long Term Council Community Plan - LTCCP (RLTS p. 68). A June 2007 amendment to the regional LTCCP makes the regional council the "keeper of the WRS" (regional LTCCP amended intro.), furthering the integration between the RLTS and the WRS. In fact, the completion of the RLTS was delayed in order for the WRS to be finalised (RLTS p. 5).

LTCCPs are required under section 93 of the Local Government Act (LGA) 2002. Section 93(6) dictates the purposes of an LTCCP, some of which are to describe the 
activities, the outcomes, and to provide integrated decision-making. While an RLTS is not required by statute to be consistent with any LTCCP, section 80(1) states that any inconsistency must (a) be identified, (b) have a reason provided for being inconsistent, and (c) must be accommodated for by an amendment to the plan or policy it is inconsistent with. This applies to the territorial authority LTCCPs, the regional Annual Plan, and the TA Annual Plans as well.

In October 2007 the Land Transport Management Amendment Bill 2007 was tabled in Parliament. This new piece of legislation will dramatically alter the context of transport planning and funding going forward. The press release issued with the legislation's tabling outlines the proposed reforms. The Minister of Transport must issue a Government Policy Statement that includes Government's overall short/medium term priorities and funding ranges by mode for the first six years, and a funding forecast for the next four years.

Land Transport NZ and Transit will be combined into one Crown entity: the New Zealand Transport Agency. Regional Land Transport Programmes - which will include State highway projects, local roads, public transport, walking and cycling projects, and travel demand initiatives - will be the only means by which "activities" will be included in the National Land Transport Programme; and therefore funded. These new Regional Land Transport Programmes will be renewed every three years.

The membership of RLTCs will be amended to include two representatives of the regional council, a representative from each TA within the region, a representative for each of the five NZTS objectives listed above, one representative from the new New Zealand Transport Agency, and one representative to speak for cultural issues. The regional councils will also gain the ability to charge a regional fuel tax to aid the funding of regionally significant capital projects; and the planning horizon for an RLTS will increase to 30 years. 


\section{5: Methods}

The methods used in this thesis were qualitative in nature. The following two subsections detail how a conceptual framework was established and applied to a reading of the relevant literature, and the purpose and procedure of several interviews that were undertaken. Both the conceptual framework and the attendant reading of the literature along with the substance of the interviews were utilised in the analysis of the RLTS along the lines specified in the previous Aim and Objectives section.

\section{1: Developing a Conceptual Framework}

The purpose of this research stage was to locate and analyse scientific journal articles and other scholarly reports on each of the chosen focus areas (amenity, accessibility, etc.). The primary search engine used for articles to classify the conceptual framework was Web of Science, which is a part of the larger Web of Knowledge database available through the Victoria University Library. Google Scholar was also used at several points to bolster certain sections, but rarely added much. Early in the process other databases were also used, including Emerald and EBSCO; but these never provided information that was unavailable through Web of Science. All articles were organized by focus area and analyzed to extract key points and conclusions. Each section of the conceptual framework was researched, analysed, and written separately in the order they appear below.

The analysis of the literature was a prolonged task, given the broad scope of the study. The structure of the analysis involved extracting themes and key points from the articles. These themes and points were then collated and organized in such a way to construct a representative summary of the scientific research that is relevant to the individual focus areas. Included in these summaries are outlines concerning the importance, benefits, and costs (social and economic) of each of the focus areas. General and specific policy recommendations discussed in the research have been included, where relevant, as part of the conceptual framework. The conceptual framework, therefore, represents author positionality on the focus areas, and is not only a literature review. 


\section{2: Interviews}

This stage of the research required approval from the Human Ethics Committee at Victoria University, which was granted on 21 September 2007. The purpose of these interviews was to gather qualitative information on the professional views of people involved in the development of the RLTS. The interviews were semi-structured in nature and included all of the focus areas in each interview. The semi-structured format was chosen because it allowed participant expertise to determine the relative weight of the individual focus areas in each interview. The key aim of the interviews was to gain coverage of (a) the RLTC and Public Transport Committee, (b) Wellington City Council (WCC), and (c) stakeholder groups.

Most of the participants were employees of the regional council. Many were members or alternates on the Regional Land Transport and the Passenger Transport Committees. An effort was made to contact some stakeholder groups that were not directly involved in the development of the RLTS but was without success. No effort was made to contact central government or Crown agencies because policies and targets at the central government level are only relevant to this study in the context of the RLTS legislative framework.

The primary method of participant recruitment was purposive sampling to select a range of interviewees that covered the key strategic focus areas. A contact within the regional council helped narrow the search by providing the names of the department heads who were involved in the RLTS; my supervisor also helped with key stakeholders, names, and contact information. Others were recommended by participants during their interviews. Key points and topics from each interview were used to inform and enhance the analysis of the RLTS.

Other research options considered, and then rejected, were focus groups and questionnaires. The focus group option was discarded because public opinion was not considered necessary for this study's analysis. The questionnaire format was also rejected as it was too inflexible and concern was expressed over a questionnaire's ability to properly gather detail of participant professional viewpoints. 
A total of 9 interviews were conducted during November and December of 2007. The participants included Joe Hewitt, the Manager of Transport Strategy Development at the regional council; Mike Mellor, the environmental sustainability representative on the RLTC; Brent Efford of Transport 2000+ and the former environmental sustainability representative; Terry McDavitt, the former Chair of the RLTC; Brian Baxter, the Manager of Design and Development in the Public Transport Division of the regional council; Celia Wade-Brown, City Councillor and leader of the Environment Portfolio of the WCC; Peter Glensor, Chair of the Transport and Access Committee of the regional council and of the Hutt Valley District Health Board; and Jill Beck, Manager of Transport Strategy Implementation at the regional council. Also interviewed was an officer of the NZ Automobile Association who preferred not to be named in this study. 


\section{6: Conceptual Framework}

The conceptual framework is divided into three sections along environmental, economic and social themes. Also included is an analysis of the literature on resilience and adaptability and how those two concepts relate to transport infrastructure.

\section{1: Environmental Outcomes}

Two environmental outcomes were identified as measures to gauge the strategic nature of the Wellington RLTS. They are Amenity and Amenity Access as well as Air Quality. No summaries are provided at the end of each subsection as they were deemed unnecessary to determine the key concepts of the environmental outcomes.

\subsection{1: Amenity and Amenity Access}

Amenity values are defined in the Resource Management Act 1991 as "those natural or physical qualities and characteristics of an area that contribute to people's appreciation of its pleasantness, aesthetic coherence, and cultural and recreational attributes" (s2 RMA). Inherent in this definition is the notion that amenity exists in public space, be it publicly or privately owned (Woolley et al., 2004), which is set aside for people to congregate, use and experience. Definitions of public space vary greatly (Carmona and Magalhaes, 2006) and the amenity they offer is described from different perspectives - from non-use values of economics (Mallawaarachchi et al., 2006; Lafforgue, 2005) to ones based on empathic public perception of their surroundings (Bell et al., 2000) to feelings imprinted on the human psyche from the surrounding environment (Jim, 2004; Coppack, 1988). What is consistent is that amenity is an intangible quality of the physical environment that lends itself to a sense of higher quality of life.

This higher quality of life includes various environmental, social and economic benefits to the public. The public spaces that provide these benefits can be separated into recreational, sentimental, and civic areas. Examples of places that offer recreational amenity consist of nature conservation parks, open-space parks, playgrounds and sports fields. Sentimental amenity arises from cultural and historic connections with places of 
civic or ancestral pride. Public spaces like schools, hospitals, and even sidewalks and other human infrastructure have their own amenity values. These civic areas also include any place where public functions might be held like city squares, recreational centres, concert halls, etc.

The amenity values can be seen in the high desirability of urban populations for the benefits these areas provide (Coppack, 1988). Some people are even willing to accept lower incomes in order to live near areas of high amenity value (Schmidt and Courant, 2006). Accessibility is the key to democratic distribution of amenity benefits. However, people will skip the closest public spaces if those areas are in poor condition. Instead preferring high quality, well managed spaces that are farther away - but still accessible (Jim and Chen, 2006). The quality of public space is determined by good initial design, well placed infrastructure (paths, playgrounds, floral arrangement, etc.), and a high standard of upkeep (Solecki and Welch, 1995; Hayward and Weitzer, 1984). Including the public in the definition, management, and monitoring of urban amenity is an important way of ensuring the use of public space and the equitable distribution of its amenity benefits (Marcouiller et al., 2004; Bell et al., 2000).

\section{(a) Environmental Benefits}

Important environmental benefits derived from well-managed public space arise with greenspace areas such as ecological conservation and open-space parks which provide sanctuaries for wildlife (Woolley et al., 2004). Conservation areas provide the best space for ecosystems to function without much human intervention, increasing the biodiversity of the area (Dwyer and Childs, 2004). Trees in these parks provide shade which lowers local temperatures, even if the park is relatively small. These lower temperatures help to mitigate the heat island effect of the paved urban landscape (Wilby and Perry, 2006; Woolley et al., 2004). The thermal differential also creates cool "park breezes" into surrounding areas which people find pleasant and also reduces air pollution (Woolley et al., 2004).

Parks can also absorb pollution by transforming brownfield sites into greenspaces for conservation or recreational purposes; although a careful choice of species is necessary if the brownfield is contaminated by heavy metals (Freitas et al., 2004). Greenspace areas also provide benefits such as storm water storage (Dwyer and Childs, 
2004) which helps with flood control (Netusil, 2005). The amenity values people experience from these greenspaces also make them more likely to take an active interest in protecting the environment (Lafforgue, 2005) even if those areas are distant but still perceived as accessible (Schmidt and Courant, 2006).

\section{(b) Social Benefits}

The higher living standard is also expressed in the many social benefits from amenity areas. Well maintained amenity areas from parks to civic squares provide places for neighbours to go and get to know one another, increasing the social cohesion of the neighbourhood (McCarthy, 2006). General use of public spaces and outdoor community functions held in open spaces has been shown to build stronger communities by increasing civic pride (Jim, 2004; Woolley et al., 2004). These functions also allow ethnic and cultural minorities of the community to express their respective heritages (Woolley et al., 2004). Casual use of public spaces can also increase communication amongst neighbours of different backgrounds, reducing ethnic tensions and suspicions within the community (Woolley et al., 2004; Ellaway et al., 2001).

Safety is a large component of social amenity values. Well maintained gardens and parks (Woolley et al., 2004) as well as better lit public facilities like bus stops and walkways (LSW, 2007; Willis et al., 2005) increase the sense of safety and thus increase use of those facilities. With more people going to parks and using other public facilities 'natural surveillance' increases, reducing both crime and fear of crime in those areas (Woolley et al., 2004; Burgess, 1988).

Amenity areas, particularly greenspaces, are a vital part of reducing stress in urban populations by providing places of relief, escape, and respite for those within sight of, or visiting, those areas (Coppack, 1988; Hayward and Weitzer, 1984). As such, they provide general psychological and physical benefits to urban populations (Jim, 2004). Besides reducing stress, amenity areas provide other health benefits by encouraging more physical activity outdoors (Giles-Corti et al., 2005). These include a better immune system, better cardiovascular health, reduced blood pressure (Woolley et al., 2004), lower rates of obesity (Newman et al., 2005), as well as reduced risk of diabetes, certain cancers, osteoporosis, and premature death (Quigley et al., 2006). 
Play outdoors for children has been shown to assist their development, social skills, and learning. Greenspace oriented activities are more beneficial for children in that they stimulate more creative play which improves motor fitness and ability to manage risk. Children reported to have ADHD were also considered to be more manageable during activities involving greenspace (Woolley et al., 2004).

\section{(c) Economic Benefits}

Increasing the amenity value of an area makes it more attractive and has several economic impacts. Natural amenity (parks and recreation) and human-built amenity (museums, iconic structures) increase tourism to those areas (Mallawaarachchi et al., 2006; Marcouiller et al., 2004). The increased 'footfall' - the number of visitors who are potential customers - benefits business by bringing in more customers as well as increasing outside investment in those communities (Woolley et al., 2004). Natural amenity tourism can halt the economic decline of rural areas by promoting the inmigration of urban visitors and retirees looking to live less stressful lives (Marcouiller et al., 2004; Coppack, 1988).

Communities that take advantage of their amenity-rich assets tend to have higher property values than they otherwise would have (Netusil, 2005; Smith et al., 2002). Apart from tourism, communities that increase the surrounding amenity value have a better opportunity to diversify their economy, stimulate local innovation and creativity, and enhance their image through place marketing (McCarthy, 2006). Commercial districts with high amenity values also increase the number of potential customers for local business. Woolley et al. (2004) states that this increased 'footfall' could be up to $40 \%$ more than it would otherwise be with lower amenity values.

\subsection{2: Air Quality}

Degradation of air quality by human activity comes from three primary sources: domestic heating, transport, and industry. This degradation has both short and long term effects on human health and the environment. Vehicle related air pollution and its corresponding health effects have received more focus recently in environmental impact assessments of new road construction projects and have been the subject of an increasing 
number of public awareness campaigns (Fisher et al., 2007). The pollutants that garner international attention are carbon monoxide $(\mathrm{CO})$, nitrogen oxides (NOx), volatile organic compounds (VOC) especially benzene, sulphur oxides (SOx), particulate matter $\left(\mathrm{PM}_{10}\right.$ and $\left.\mathrm{PM}_{2.5}\right)$, and ozone $\left(\mathrm{O}_{3}\right)$ (Hidy, 2002; Bose and Srinivasachary, 1997). The main health risks from these pollutants are respiratory diseases (Seagriff, 1995) and the specifics of each will be discussed below.

\section{(a) Measurement of the Effects of Air Pollution}

Measuring air pollution levels and their associated health effects are very complicated (Hidy, 2002). There are many factors that need to be taken into account since air quality varies greatly over space and time, weather conditions, the types of contaminants, as well as the topography of the given area (Fisher et al., 2007; Beverland et al., 2000). For example, hourly monitoring studies have shown that air pollution peaks after morning and afternoon rush hours, when most people are driving to and from work (Chang and Lee, 2007). The dispersion of pollutants from a source is highly influenced by the weather and climate (Beverland et al., 2000). There are several pollutants that react in the atmosphere in different ways. Mountains and valleys also have an effect on local air quality by confining the pollutants within the area (Calef, 2007). For administration and measurement purposes, areas are divided using emission sources, weather/climate, and topography into individual 'airsheds' in order to map the air quality of a given area (Fisher et al., 2007).

The standard for measuring air pollution and its effects on human health is the dose-response, or concentration-response, relationship (Fisher et al., 2007). $\mathrm{PM}_{10}$ is used as an indicator because it is the most potent pollutant in terms of human health. In brief, this relationship shows that very few people over the age of 30 are affected by low ambient levels of pollution, while virtually everyone over 30 is affected at high levels. The slope of the curve measures the daily morbidity - illness not leading to death - or mortality against daily levels of particulate matter, charting the amount of particulate exposure (dose) to the relative risk of morbidity or mortality in exposed people (response).

That does not mean that there are identifiable individuals who have suffered morbidity or premature mortality due to air pollution (Fisher et al., 2007). Premature 
mortality, in this context, is the average amount of time a person's life is shortened due to the air pollution they were exposed to. This can be a matter of days or weeks, but it also can be months or years, which has considerable economic and social costs. Gender, age, socio-economic status, and climate also influence the relationship (Fisher et al., 2007). Since the dose-response relationship does not track air pollution's effects on children and the very young, it underestimates the overall impact.

The national dose-response mortality relationship for New Zealand is $4.3 \%$ for each $10 \mu \mathrm{g} / \mathrm{m}^{3}$ of $\mathrm{PM}_{10}$ emitted (Fisher et al., 2007). However, there are uncertainties inherent in this relationship (Hutchinson and Pearson, 2004). There are several studies suggesting that New Zealand's dose-response relationship percentage is steeper. The Ministry of Transport (1996) calculated that 399 (95\% confidence interval of 241-566) people suffer premature mortality in New Zealand every year from $\mathrm{PM}_{10}$ vehicle emissions; while 571 people over 30 are estimated to have died prematurely from $\mathrm{PM}_{10}$ emissions from other sources, mainly domestic heating.

Fisher et al. (2007) calculated the national average increase in mortality from air pollution at $4.8 \%$. That means approximately 1 in 20 people die prematurely due to air pollution. It has been suggested that the actual dose-response relationship for New Zealand is between $4-8 \%$ per $10 \mu \mathrm{g} / \mathrm{m}^{3} \mathrm{PM}_{10}$ (Fisher et al., 2007). From these numbers the annual average mortality increase attributable to air pollution in Wellington City was $3.3 \%$. Annual deaths of over 30 s due to vehicle-related $\mathrm{PM}_{10}$ were estimated to be 56 (34-80). For Greater Wellington, the average air pollution mortality increase was estimated at $5.3 \%$.

\section{(b) Susceptibility}

The people who are most affected by air pollution are the elderly, those with existing respiratory and cardiovascular disease, asthmatics, young children, and possibly low-income groups (Fisher et al, 2007). People who have low incomes may be more susceptible because they are more likely to have longer exposure times and be less physically healthy. A growing body of evidence suggests that short and long term health effects may result at low ambient pollution levels, or at least levels below existing health standards. 
Young children are susceptible for a variety of reasons (Fisher et al., 2007). The lungs of children are not completely developed and they breathe in more air per $\mathrm{kg}$ of body weight than adults. Their immune system is immature, so lower doses put their bodies under more stress. Children also tend to have high exposure time to outdoor air pollution because they are more likely to spend a lot of time outdoors. The contaminants listed above also tend to be in greater concentrations closer to the ground.

Transport decisions play a part in pollution exposure, and thus susceptibility. More people driving private vehicles means greater pollution from exhaust fumes. Active modes of transport, such as walking and cycling, emit no pollutants, but can increase exposure time to air pollutants (Diana et al., 2007). Interestingly enough, the air quality inside vehicles, both private and some public transport buses (Chan, 2005), has been shown to be of worse air quality than the outside environment. Therefore, the total exposure from driving and walking an equal distance is about the same (Fisher et al., 2007).

Other confounding factors consist of climatic effects (Beverland et al., 2000), smoking habits, and occupational exposures. Mortality and morbidity rates are affected by the climate in that rates for both increase in very cold and very warm climates (Fisher et al., 2007). Climate not only affects the background mortality/morbidity rates, but also susceptibility to the effects of air pollution (Hidy, 2002). Thus, in the modelling statistics described above, climate can "exacerbate or obscure" the effects of air pollution. Smoking habits act in the same way by damaging the respiratory system, lowering the dose needed to cause the adverse response. Occupational exposures and diseases like influenza can have the same effect as smoking and climate (Fisher et al., 2007).

\section{(c) Health Effects}

Studies indicate that the effects of air pollution are not only acute and short-term, like 'restricted activity' days where in people are absent from work and school, but have cumulative effects over the long term (Fisher et al., 2007). These long-term effects include increasing rates of chronic cardio-respiratory diseases, larger cancer diagnosis numbers, and overall higher mortality (Chaaban, 2001). In fact, Fisher et al. (2007) reported that the long term mortality estimates have been calculated at 5-10\% per 10 $\mu \mathrm{g} / \mathrm{m}^{3}$ of $\mathrm{PM}_{10}$, while over the short term the increase was only $0.5-1 \%$ for every 10 
$\mu \mathrm{g} / \mathrm{m}^{3}$ of $\mathrm{PM}_{10}$, as confirmed by Chaaban (2001). It is unknown why the long term risk factor is much higher than the short term risk. The health effects of particulate matter may be non-linear, or have differences in how they affect the body, or perhaps just because PM air pollution lingers longer than a single day (Fisher et al., 2007).

Over the past few years there has been an increasing amount of research on air pollution's effects on children (Fisher et al., 2007). Concerns are being raised about lung damage and retarded cardiovascular development in young children increasing the risk of chronic cardio-respiratory diseases later in adulthood. Air pollution has also been linked to reduced birth weight and a greater risk of premature delivery. Fisher et al. (2007) reviewed the results of one survey of 3,600 children and found significant reductions in cardio-respiratory function within 500 meters of motorways. This is not surprising since the greatest concentrations of air pollutants are consistently found near roads (Lopez et al., 2005).

Fisher et al. (2007) lists the adverse health effects of each of the criteria pollutants listed above. Carbon monoxide is readily absorbed into the blood stream where it reduces the oxygen concentration the blood can carry throughout the body, impairing organ function including the heart and brain. Carbon monoxide is emitted into the atmosphere primarily through solid fuel burning for home heating and vehicle exhaust (Potoglou and Kanaroglou, 2005). CO emissions have been steadily decreasing due to emissions control systems on newer vehicles (Hutchinson and Pearson, 2004).

Nitrogen oxides are primarily emitted into the air from vehicle exhaust. In fact, one of the nitrogen oxides $-\mathrm{NO}_{2}$ - has been used as the primary indicator for vehicle exhaust pollution. Although domestic and industrial fossil fuel burning does contribute, the transport fleet emits approximately 50\% of the observed levels (Jakob et al., 2006). Indoor concentrations are often greater than the outside. NOx released into the air are largely oxidized into $\mathrm{NO}_{2}$ and are a major component in the formation of photochemical oxidants (ozone) and certain particulates (like nitrates) (Seagriff, 1995). $\mathrm{NO}_{2}$ seems to directly affect the lung, causing inflammatory reactions on the lung's surface (Fisher et al., 2007; Seagriff, 1995).

Volatile organic compounds (VOCs) are a diverse range of hydrocarbons, but benzene is the most important and dangerous (Seagriff, 1995). Its maximum allowable 
level in petrol is now $1 \%$ by volume because it is a carcinogen (Fisher et al., 2007). Sulphur oxides, mostly $\mathrm{SO}_{2}$ but also $\mathrm{SO}_{3}$ in lesser quantities, are gases created from the oxidation of sulphur in fuel. Vehicles are a minor contributor of this pollutant, with the coal fired powerplants and other major coal burners the principal emitters. Sulphur oxides from fuel and coal are partly oxidized again into solid sulphates within the engine or powerplant with the rest being oxidized in the atmosphere (Hidy, 2002). Sulphur oxides are also a potent respiratory irritant. It has been correlated with higher numbers of hospital admissions for cardio-respiratory disease and mortality (Fisher et al., 2007).

There is some debate in the academic literature over how to best measure the health effects of particulate matter. Current methods track $\mathrm{PM}_{10}$ concentrations in the air. Recent studies suggest that $\mathrm{PM}_{2.5}$ is a better indicator of health effects because it is smaller, can penetrate deeper into the respiratory system, and thus have a greater effect. More evidence is emerging, though, that sulphates and strongly acidic particles, both constituents of $\mathrm{PM}_{2.5}$ concentrations, are the best predictors of health effects.

Particulate matter is emitted from vehicles, wood smoke and from industrial sources (Chow and Watson, 2002). However, the potency of all three seems to be statistically the same (Fisher et al., 2007). Particulate matter can accumulate in the atmosphere in two ways. Primary particulates are emitted from their source. Secondary particulates form by the chemical reactions of $\mathrm{SO}_{2}$, nitrogen oxides, and certain organic compounds within the air after they are emitted (Beverland et al., 2000).

Short term health effects include increased daily mortality, higher rates of hospital admissions from exacerbation of respiratory disease, increased bronchodilator medication use, increased prevalence of cough, and a reduction of lung function (Fisher et al., 2007, Chaaban, 2001). Long term health effects of low concentration exposure seem to be an increased mortality rate, and chronic effects such as increased rates of bronchitis and impaired lung function. $\mathrm{PM}_{2.5}$ is also an important environmental factor, after smoking and other potential confounders are adjusted for, in an increased risk of cardiopulmonary and lung cancer mortality (Fisher et al., 2007).

Ozone is the main component of photochemical oxides (smog). $\mathrm{O}_{3}$ is a secondary air pollutant, formed when nitrogen oxides and volatile organic compounds react in the atmosphere in the presence of strong sunlight (Fisher et al., 2007). The primary 
emissions that eventually create ozone are mainly from vehicle exhaust (Chang and Lee, 2007). Due to traffic patterns, suburbs tend to contain higher concentrations of ozone than city centres (Fisher et al., 2007). Ozone exposure contributes generally to both morbidity and mortality rates (Guest et al., 1996). However, like particulate emissions, there are no threshold concentration values for adverse health effects. The toxicity of ozone increases with higher concentrations, longer exposure times, and greater activity level. Substantial short term effects have been shown to occur during exercise with 1 hour's exposure time at concentration levels of $500 \mu \mathrm{g} / \mathrm{m}^{3}$ or higher (Fisher et al. 2007).

\section{(d) Economic Cost}

Air pollution can have a detrimental effect on the growth and health of crops (Hutchinson and Pearson, 2004), and by extension, flora of the natural environment (Taylor et al., 1994). The total cost of air pollution to New Zealand has been estimated in Fisher et al. (2007) to be NZ\$1,139 million per year. This number was calculated by summing the total costs of domestic (\$503.2), vehicle (\$494.6), and industrial (\$141.5) sources of air pollution. Background effects from natural concentrations were not included.

The total costs per source were derived from costs per effect. These effects were premature mortality for $\mathrm{PM}_{10} / \mathrm{NO}_{2}$ and $\mathrm{CO}$, bronchitis, respiratory/cardiac hospital admissions, cancer, and restricted activity days. Indirect costs like doctors' visits and increased medication use were not included because there is not much information on these; however, expectations are that they are minor (Fisher et al. 2007).

The costs in Fisher et al. (2007) were based on 2001 Census statistics. Since then the population of New Zealand has grown by $17 \%$. By factoring in this population growth, the current total cost of air pollution for New Zealand can be estimated to be around NZ\$1,333 million per year. For vehicle related air pollution, this means that the current costs can be estimated to be roughly NZ\$578.7 million. 


\section{2: Economic Outcome}

The Economic Outcome section went through a long process of hybridisation. Ultimately, the concept of accessibility became the most convenient catch-all when separate sections became conceptually untenable. A summary is provided at the end distilling the key concepts from the review of the literature.

\subsection{1: Accessibility}

The literature on accessibility and its constituent concepts (connectivity, mobility, etc.) is rather murky because these terms are often loosely defined, or not defined at all. However, it can be stated that the accessibility of a neighbourhood is determined by its level of connectivity, proximity, and agglomeration. As concepts, it is almost impossible to distinguish between connectivity and proximity (Frank, 2000). Hence, accessibility is often discussed in terms of 'walkability' - or how conducive a neighbourhood is to walking (Cerin et al., 2007).

Connectivity can be separated into two types: the connectivity between neighbourhoods and connectivity within a neighbourhood. Both are determined by layout of the street network and the provision of alternative transit mode infrastructure (Song and Knaap, 2004). Proximity is the distance travelled between residential units and potential destinations. Agglomeration has to do with the level of mixed use and commercial and population density of the neighbourhood (Vuchic, 1999). Accessibility is therefore measured as the average distance between residential units and places where people need to get to, such as commercial districts, public parks, and public transport nodes. Lowering the distance needed to travel increases the level of accessibility between and within neighbourhoods (Song and Knaap, 2004).

Sprawl and congestion diminish a neighbourhood's accessibility. Both are determined by spatial and land use planning, government policy, economic forces, technological, social, and behavioural trends (Shiftan et al., 2003). Sprawl is randomized low-density urban and suburban growth on the fringe of built-up areas (Roeseler, 1991). It reduces accessibility by increasing the distances between residential and commercial districts (Horner and Murray, 2003), and reducing connectivity with low density cul-de- 
sac housing development (Frank et al., 2006). Congestion is the result of private vehicle dependence and a lack of other transportation options (Newman et al., 2005). It diminishes accessibility by increasing travel times and reducing mobility (Frank, 2000). Mobility is here defined as the ease and speed with which one can travel to a destination. The effects of sprawl and congestion together are also difficult to separate since land use policies that give rise to congestion are also a significant component of sprawl (Litman, 2006).

\section{(a) Connectivity, Proximity and Agglomeration}

People tend to value time a great deal. This creates certain invariables in how much time people budget for travel (Frank, 2000). On a daily basis, people tend not to travel more than about $1-1.5$ hours per day (Frank, 2000; Marchetti, 1994). That equates to a half hour or so travelling to a given destination, and a half hour home again per day (Newman et al., 2005). The greater the distance that can be covered within that time frame and a higher diversity of potential destinations equates to greater accessibility, connectivity, and mobility (Song, 2005).

Connectivity is mode neutral. Neighbourhoods can be well connected via public transit or a multi-lane motorway (Farmer, 2002; Downs, 1999) and be even more connected by both (Silva, 2000). However, if the flow of traffic on these routes is not smooth, then connectivity is reduced (Artimy, 2007; Litman, 2005). Traffic flow on roads is measured several ways (Artimy, 2007), but to measure connectivity the number of vehicles per hour per lane is the most important relationship (Litman, 2006). Reducing this number increases connectivity by increasing the speed of traffic which results in greater mobility for those travelling (de Corla-Souza and Cohen, 1999; Downs, 1999).

Connectivity within a neighbourhood can be measured as the number of intersections divided by the number of cul-de-sacs plus the number of intersections (Song and Knaap, 2004). More connected neighbourhoods are characterized by straight streets with short block lengths (Frank et al., 2006; Schlossberg et al., 2006). These streets create a grid pattern which makes local trips more direct (Dunphy, no date). Short block lengths in a grid pattern also increase connectivity by increasing the use of active transport modes like cycling and walking (Frank et al., 2006). 
Measures of connectivity are also multi-modal (Frank, 2000), making the distances covered and diversity of potential destinations accessible by public transport, cycling, and walking key variables. Land use policies that promote mixed use and greater population density have been shown to encourage greater uses of public transport as well as active modes (Cerin et al., 2007; Frank, 2000). Therefore, the proximity between housing units and places of work, recreation, shopping, etc. and the agglomeration of these multiple options within people's travel time budget are critical for connectivity (Farmer, 2002). This is especially so for walking, where a pedestrian's range of accessibility is widely considered to be only a quarter of a mile (Frank, 2000). This has several benefits including better public health from exercise and increased neighbourhood amenities (Frank et al., 2006) and improved air quality (Song and Knaap, 2004).

As residential and commercial density increases the demand on the transportation network also rises, which can lead to congestion (Chen et al., 2005). However, several studies have concluded that if those higher densities are associated with greater agglomeration and connectivity the actual vehicle miles travelled will be reduced even though the number of trips increases (Frank, 2000). This is because increasing density tends to create demand for all modes of travel (Song and Knaap, 2004).

\section{(b) Sprawl}

Sprawl is characterized by unlimited outward expansion of development, lowdensity commercial and residential land uses, leapfrog development, powerful local governments, private vehicle dependency, a lack of regional planning, widespread strip commercial development, large economic disparities between neighbourhoods, zoning regulations that divide commercial and housing land uses, and reliance on top-down filtering processes in the siting of low-income housing (Downs, 1999). There are several reasons why sprawl has become the dominant form of development in many Western countries, including New Zealand. It represents a common - albeit challenged - dream of growth and success (Dunphy, no date). It is the result of market failures which do not include the full costs of sprawl such as expanding public services infrastructure, commuting costs, and the loss of agricultural and open spaces (Downs, 1999). Sprawl is also caused by the belief that neighbourhoods of low connectivity and proximity shield 
property values from negative externalities like traffic and noise that accompany nonresidential development (Matthews and Turnbull, 2007).

Accessibility is reduced by sprawl because connectivity, proximity, and agglomeration are all limited. Connectivity is reduced by reliance on arterial roads and the accompanying private vehicle dependence characteristic of sprawl (André and Villanova, 2004; de Corla-Souza and Cohen, 1999). Funding is often expressly allocated for these arterial roads and thus cannot be spent on other transport options. Other transport modes are also often under-funded due to this (Litman, 2005). Arterial roads tend to lack facilities for public transport (Newman et al., 2005) and are not pedestrian or cyclist friendly as well (Cerin et al., 2007). These policies limit connectivity by reducing commuter choice (Litman, 2005).

Proximity is reduced because sprawling neighbourhoods allocate 2 to 3 times more land area per capita for road projects and parking than do multimodal cities (Litman, 1997). Population density is greatly reduced in sprawled areas and fringe developments increase trip length for residents working in the urban centre. It is important to note that sprawl does not necessarily increase trip length for those who live and work in the sprawl area (Sultana and Weber, 2007; Downs, 1999). However, studies have shown that fringe communities have higher transport costs than those who live in more compactly developed areas (Perkins and Hamnett, 2005).

Agglomeration is reduced by zoning laws that divide residential and commercial areas (Sultana and Weber, 2007). These laws may also contain provisions that cause excess parking capacity - sometimes in the range of 50\% extra - that takes up land that could otherwise be put to commercial use and reduces building density (Willson, 1995). Low density residential and commercial development both increase trip length and accentuate peak travel time congestion (Hess et al., 2007; Safirova, 2007).

Community severance, both physical and economic, is another problem. Arterial roads that lack infrastructure and facilities for cyclists and walkers divide otherwise connected communities (Newman et al., 2005; Frank, 2000). Sprawling development is also very expensive, often costing $20 \%$ more than alternative transit modes and compact agglomerated development. These extra expenses use public funds that otherwise could be spent on schools, housing and public services (Downs, 1999). Declining funds to 
maintain transport facilities and lack of transport options leaves many residents in fear of increased isolation and loss of mobility (Dunphy, no date). Diversifying transport options requires strong regional governance and cooperation which is very difficult in sprawling areas characterised by powerful, competing local governments (Shiftan et al., 2003; Downs, 1999) and metropolitan planning organizations focused on particular capital building projects such as road construction (Waddell et al., 2007; Gayle, 2003).

Vehicle dependence, therefore, diminishes community investment and sense of neighbourhood (Newman et al., 2005). Sprawl and competition amongst local governments tend to result in the concentration of little investment in specific poor neighbourhoods with small tax bases - which often also have predominantly minority populations (Downs, 1999). This consolidates social problems of poverty, poor quality and access to public services, decaying infrastructure, and crime in these neighbourhoods which then find it very difficult to increase their standing (Cerin et al., 2007; Downs, 1999; Vuchic, 1999).

\section{(c) Congestion}

For urban planners and transportation engineers, reduced accessibility from congested roadways has been and continues to be a serious problem. The level of congestion is determined by the amount of vehicle activity operating on the capacity of the provided infrastructure (Hensher and Puckett, 2005). If vehicle activity is greater than the capacity of the road, traffic speeds will slow causing congestion (de Palma et al., 2006). If speeds become too slow then drivers will shift to other routes and back again creating an equilibrium effect throughout the road network (de Cea et al., 2005; Downs, 1999). Congestion, therefore, is rarely cured, but it can be managed (de Cea et al., 2005).

Traffic congestion tends to increase with density, trip length, vehicle dependence, and inefficient land use acting in concert with one another (Newman et al., 2005; Shiftan et al., 2003). There is also a strong time-of-day component because congestion is often at its worst when many people are travelling to work in the morning and home again in the evening (Hess et al., 2007).

High residential and commercial density coupled with vehicle dependence forces the increased activity onto the road network (Newman et al., 2005). Trip length is the total distance travelled and the amount of time spent travelling. The longer it is, the more 
likely congestion will occur because there will be more vehicles on the road at any given time (Sultana and Weber, 2007). The structure of the road network also influences trip length. Networks that require vehicles to funnel onto major arterials for trips of any distance increase trip length more than direct routes (Dunphy, no date).

Vehicle dependence causes congestion by limiting transportation choices and increasing the number of vehicles on the road at any given time (Newman et al., 2005). Although purchasing and maintaining a car can be quite expensive, the average variable costs of each trip are very low, mostly lower than a bus fare (Litman, 1997). Private vehicle use is also encouraged by several economic incentives (Shiftan et al., 2003).

Parking is often subsidized while other transit modes are not (Litman, 2005). Commuters often do not pay for parking; however, land owners incur the cost to provide parking space. The result is a subsidy to the vehicle commuter in the form of free parking. Excess subsidized parking encourages vehicle use and dependence, lengthens trips and thus contributes to congestion (Willson, 1995). Insurance, registration, tax and lease fees are often fixed, giving drivers an incentive to maximize their mileage in order to get the greatest return on their vehicle investment. There are also no mechanisms to return the external savings of less vehicle use to the drivers in many jurisdictions (Litman, 2005).

It is difficult to measure land use effects on congestion (Safirova, 2007; Chatterjee and Gordon, 2006). Many different types of models have been used with varying degrees of output quality (Safirova, 2007; Shiftan et al., 2003). Feedback loops that encourage sprawl are often ignored in traditional models used by metropolitan planning organizations when considering road expansion projects. These oversights contribute to an exaggeration of economic and congestion relief benefits of new road projects while undervaluing the benefits of alternative strategies (Waddell et al., 2007; Litman, 2006). There are also still modelling gaps and some congestion characteristics are still poorly understood (Hensher and Puckett, 2005; de Corla-Souza and Cohen, 1999). However, models have become increasing robust over recent years (Waddell et al., 2007). What is known is that the end result of all of these factors is that private vehicle use is under-priced in these models (Downs, 1999) and that leads to excessive use and congestion (Litman, 1997). 
Widespread negative public perception of traffic congestion has in many cases driven government intervention to fund expanded road capacity or, less often, diversify the transportation options of commuters (Lam and Toan, 2006; Horner and Murray, 2003; Gayle, 2003). However, increasing road capacity is not a long-term remedy to congestion. Induced travel - wherein the higher traffic speeds encourage more vehicle ownership and use, and bring in commuters who would normally travel at different times - tend to remove any gains in traffic speeds (de Corla-Souza and Cohen, 1999; Downs, 1999).

However, there is some debate in the academic community about whether congestion is a net cost. The most congested areas also tend to be the most economically vibrant, suggesting that congestion is merely a by-product of a robust economy. Although increased road capacity may not alleviate congestion, it does increase connectivity and road use which, in turn, encourages more economic activity (Farmer, 2002). Other evidence suggests that congestion has unacceptable costs in mobility, time, and pollution emissions resulting in a number of economic, social, and environmental problems (Horner and Murray, 2003; Litman, 1997), most of which are directly connected to sprawl (Sultana and Weber, 2007).

While low transport costs facilitate economic growth (Litman, 1997) underpricing vehicle activity and road access leads to inefficient use, waste and misallocation of resources. Cities that are heavily vehicle dependent have the highest transport costs in proportion to city wealth $-12-15 \%$ compared to $5-8 \%$ of rail-based cities according to Newman et al. (2005). A significant portion of the cost of congestion and sprawl-induced congestion is external (Litman, 1997). Without tolling and other mechanisms in place each driver in congested conditions does not pay for costs borne by the others (de Palma et al., 2006). These costs are mostly in the form of lost time and vehicle operating costs, such as fuel burnt, for other drivers (Schreyer et al., 2004).

Other external costs include higher prices for commercial goods to make up for money lost to subsidized parking, increased local taxes to pay for road services, and lower residential property values from environmental externalities (Litman, 1997). Even if a commuter decides to reduce their driving, or not drive at all, they still pay these external costs (Litman, 2005). This market failure to price external costs induces 
wasteful resource use and negatively affects economic development and general wellbeing (Downs, 1999; Newman et al., 2005).

Vehicle ownership is linked with wealth, but vehicle use is not (Newman et al., 2005). This is partly due to many communities in sprawl areas being only reasonably accessible by arterial roads (de Corla-Souza and Cohen, 1999). While under-pricing vehicle use helps low-income groups in the short run, the resulting sprawl and vehicle dependence increases the per-trip costs, making transport more difficult. By incurring the external costs of congestion while their mobility declines, in a very real sense, low income groups subsidize the vehicle use of their wealthier neighbours (Litman, 1997).

Increasing congestion also has various health effects. Air pollution and accidents on congested roads increase injury and illness rates (Litman, 1997). Vehicle dependence has also been linked to obesity problems in the population by discouraging active transit modes like walking and cycling (Frank et al., 2006; Newman et al., 2005). Increasing type II diabetes rates have also been linked to sprawling communities and vehicle dependence (LSA, 2006).

Congestion has strong environmental effects in terms of air pollution and loss of amenity (Downs, 1999). Vehicle dependence and increased miles travelled create more air pollution from tailpipe emissions (Litman, 2005). Local amenity values are diminished by open space being paved over for road capacity expansion and associated subsequent sprawling development (Bengston and Youn, 2006, Downs, 1999). Amenity is also diminished by the congestion itself from increased noise and air pollution (OECD, 2000).

\section{(d) Summary}

Accessibility is the ultimate goal of urban and transportation planners. Traditionally, planners have sought to increase accessibility with new and expanded road projects. However, the resulting loss of mobility by congestion from private vehicle dependence, sprawling land use, and further induced congestion have all lowered accessibility between and within neighbourhoods. This is because accessibility is multimodal and determined by levels of connectivity, proximity, and agglomeration.

Connectivity is mode neutral, but determined by ease of travel from residential units to commercial districts and public transport nodes (i.e. greater mobility). Internal 
connectivity within a neighbourhood is primarily the result of a greater number of street intersections in a grid pattern. The proximity between residential units and potential destinations increases accessibility and connectivity by bringing them closer together. Agglomeration is the means by which proximity is achieved through mixed-use land development policies that bring a greater diversity of commercial opportunities and transport options within a person's daily travel time budget. This reduces vehicle dependence and vehicle miles travelled by encouraging alternative modes of travel such as public transport, cycling, and walking. These factors indicate that accessibility increases in the long-term only by efficient multi-modal transit systems that balance private vehicle use, public transport, and active modes (Vuchic, 1999).

Several economic, social, and environmental benefits result. More connected neighbourhoods reduce community severance and problems of urban decline and reduced civility. The level of congestion is mitigated, increasing mobility and air quality. More 'walkable' neighbourhoods increases the amount of money dedicated to infill development and local amenities rather than the construction of new disconnected neighbourhoods on the fringe. Greater use of active transport also has several health benefits including reduced obesity and type II diabetes rates, and an increased general feeling of well-being. 


\section{3: Social Outcome}

The affordability of transport for low-income groups was deemed to be the most reliable measure of general transport affordability for both users and the community. No summary is provided as this section was deemed too brief to merit one.

\subsection{1: Low-Income Groups' Transport Affordability}

Effective and affordable transportation is necessary for maintaining a good quality of life (Metz, 2003). Central to the notion of transport affordability is the concept of equity in the form of distributive justice - or the fair distribution of benefits and costs throughout society (Burton, 2000). Since rates of private vehicle use tend to diminish as income levels decrease (Gray et al., 2001) a case can be made that public transport ought to be available and affordable to low-income groups (Câmara and Banister, 1993). The lack of affordable services to low-income groups has been attributed by some to a lack of political clout and influence on development planning (Lau, 1997).

Traditional development strategies are targeted to meet the needs of people with average to above-average incomes (Bostock, 2000). Transport planning is often limited in scope to motorized and peak period transport that undervalues active transport modes and marginalizes the transport needs of low-income groups (Behrens, 2004). These planning policies encourage private vehicle dependence and sprawl which tends to site amenities, health care services, and other potential destinations in ways that suit vehicle owners, while at the same time reduces the funding for public transport (Bostock, 2000). This limits the mobility of low-income groups who cannot afford to use a private vehicle and diminishes their access to facilities for work, recreation, health care, etc. (Lau and Chiu, 2003; Metz, 2003).

The people who tend to make up low-income groups that are studied in the literature are women with small children, elderly people, and members of ethnic minorities (Jarvis, 2005). Many of these groups are relegated to living in areas that have few employment opportunities and poor public transport connections (Behrens, 2004; Câmara and Banister, 1993). This means that low-income groups often have to make longer trips to reach their destinations and thus pay higher fares, proportional to their 
income, for the longer travel distances and one or more interchanges (Câmara and Banister, 1993).

It is very difficult for these groups to afford private vehicles because transport costs are a greater percentage of their income (Tiwari, 2002). The costs of owning and operating a private vehicle can be a large financial burden (Gray et al., 2001) This makes low-income groups reliant on whatever public transport services are made available, regardless of quality (Behrens, 2004) and on active transport modes whether adequate infrastructure is in place or not (Tiwari, 2002). A lack of connections between public transport modes and pricing regimes can make public transport use about as expensive as operating a private vehicle, which can preclude usage among low-income groups (Charoentrakulpeeti et al., 2006). In fact, some see public transport as a luxury service due to usage costs (Bostock, 2000).

Other factors that tend to discourage public transport usage by low-income groups are the concession fare policy, frequency and reliability of the service, attitude of staff, network planning, and district monopolies on service and facilities (Lau, 1997). Concession fares are often offered for elderly passengers (Metz, 2003) but are not offered for other low-income groups. Low frequencies of stops can overcrowd buses and lead to poorer service. Network planning tends to focus faster and more reliable public transport services in city centres which serve people of average and above incomes; and local monopolistic operators rarely coordinate effectively (Câmara and Banister, 1993).

Walking has been hailed as a means of decreasing obesity and diabetes rates in society (Metz, 2003; Bostock, 2000). However, people living on lower incomes can effectively be forced to walk (Tiwari, 2002), sometimes even large distances, if public transport is erratic or costs are too high (Bostock, 2000). Walking is typically not analysed in-and-of-itself in transport models, but is conceived as the beginning and end legs of public transport and private vehicle trips. The importance of walking, especially for low-income groups, is not revealed - and sometimes deliberately disregarded - in these models and therefore tends to be neglected in planning and designing improvements (Behrens, 2004). Excessive walking can cause fatigue and unnecessary stress, especially among low-income mothers with young children. Walking to avoid the cost of public 
transport also reduces mobility by reducing the trip distance that can be reasonably covered (Bostock, 2000).

Transport is also not just a means of getting from an origin to a destination. There are several benefits of enhanced mobility such as enhanced social interaction, psychological boosts from being active, exercise (Metz, 2003), and better access to health services (Bostock, 2000). Transportation infrastructure and services facilitate economic activity opening up new opportunities, enhancing personal mobility and making resources more available. This, in turn, lowers transaction costs, expands trade, integrates markets, and strengthens effective competition which eventually increases income and welfare throughout society. Economic development and poverty reduction are therefore not possible without efficient, affordable transport (Fouracre et al., 2007).

However, low-income households tend to make shorter trips to seek jobs, visit friends, or to take part in other social and economic activities (Lau and Chiu, 2003). The proportion of trips made for services like healthcare or for job seeking are higher among low-income groups, while the proportion of trips for work and educational activities remain fairly constant across different income levels (Behrens, 2004).

Of the three main modes of public transport - heavy rail, light rail, and bus services - bus services have the potential to show the most promise in providing affordable and convenient transport for low-income groups. This is because buses can form a system-wide network of services, rather than corridor service like rail modes, and require less investment in construction and operational costs as well as lower subsidies per passenger (Hensher, 2007). Services to low-income areas that are traditionally neglected can be funded through congestion pricing policies (Eliasson and Mattsson, 2006) and carbon taxes (Speck, 1999). However, a carbon tax could hurt low-income groups by increasing fuel costs that may not be entirely offset by public transport subsidies (Speck, 1999).

Other options include fare structures that do not penalize interchanges, priority bus lanes, coordination between the different modes of public transport and operators, and better fleet maintenance (Câmara and Banister, 1993). Concessionary fares can also be expanded to include more low-income groups (Whitley and Prince, 2005; Metz, 2003). Public transport costs can also be reduced by implementing more compact and mixed 
land use (Lau, 1997). Although this option is more controversial, studies have shown that mixed land use increases public transport patronage (Burton, 2000). In short, these quality improvements in public transport services are likely to preferentially benefit lowincome groups.

\section{4: Resilience and Adaptability}

Most of the literature on resilience and adaptability focuses on social-ecological systems in the context of sustainable development (Folke et al., 2005; Kemp et al., 2005; Adger, 2006; Plummer and Armitage, 2006; Brock and Carpenter, 2007; Nooteboom, 2007). While not directly intended to describe transport and land use systems the literature on resilient and adaptive policy and strategic development, implementation, and monitoring does appear transferable in theory and practice. As in social-ecological systems, resilience in transport and land use systems is characterised by the magnitude of shock that the system can absorb before it breaks down (Folke et al., 2007), the ability to adapt to new circumstances and maintain function (Adger, 2006), as well as the system's ability to shape change within itself (Folke et al., 2005). Policy and strategic adaptability is largely a question of "adaptive capacity" which Brooks et al. (2005) define with a quote from the IPCC: "The ability of a system to adjust...., to moderate potential damages, to take advantage of opportunities, or to cope with the consequences." Conversely, vulnerability is defined in Adger (2006) as "the state of susceptibility to harm from exposure to stresses associate[d] with environmental and social change and from the absence of capacity to adapt."

As concepts, resilience and adaptability are centred on risk and change. Risk is a probabilistic function of hazard and vulnerability - the more vulnerable a system is, the greater the risk of a hazard leading to an undesirable outcome (Brooks et al., 2005). Risk, however, is not easily measured. Perception of risk is subjective in terms of both the internal feeling of vulnerability and on what external object, structure, system, etc. is the focus of the perceived risk (Adger, 2006). Change operates on various timescales (Brooks et al., 2005) and orders of scale (Plummer and Armitage, 2006); it therefore can be gradual and incremental, or it can be abrupt. Change is usually exogenously driven 
but mediated by positive feedback loops that amplify each other with each cycle, while negative feedback tends to keep the status quo by cancelling itself out (Nooteboom, 2007). Systems that are resilient and adaptable can go through short and long term change, and manage risk while retaining the same function, structure, identity, and feedbacks (Folke et al., 2005). When transformative change is inevitable, resilient systems contain the necessary components to renew and reorganize without loss of functionality or services (Folke et al., 2002).

\section{(a) Development}

Effecting change toward desired outcomes and the management of risk is the purpose of governance. Governance is a concept that encompasses various processes and procedures through which people effect change and the extent to which all actors adhere to the enacted policies. These processes and procedures are political and can include deliberation, negotiation, self-regulation, or an authoritative direction (Kemp et al., 2005). Differences in power and values across stakeholders mean that conflict is inherent whenever a political choice must be made (Dietz et al., 2003). These differences can be determined by the institutional structure of governance (Lejano et al., 2007) or by diverse reactions to complex systems which, according to theory, are distinguished by adaptive cycles nested in different scales of organization that result in uncertainty, non-linearity, and self-organization (Plummer and Armitage, 2006). Effective governance seeks to minimize the disruptions from conflict in the development and implementation of policy (Dietz et al., 2003).

The level of conflict is, for the most part, inversely proportional to the resilience of the social institutions of governance. According to Folke et al. (2005) the sources of resilience in social systems are social capital and social memory. Social capital is based on trust and networks of communication among involved stakeholders. Trust leads to reduced suspicion and apprehension amongst stakeholders (Fang et al., 2006). Good lines of communication facilitate mutual understanding amongst stakeholders and lead to greater institutional learning. Institutional learning is based on the uptake of new discoveries into the institutions and models being considered (Brock and Carpenter, 2007). The four crucial factors listed by Folke et al. (2005) for institutional learning to deal with complex systems are learning to live with change and uncertainty, combining 
different types of knowledge for learning, creating opportunity for self-organization, and nurturing sources of resilience for renewal and reorganization. The structure of institutions is not only made of rules, positions, and resources but also by vision, purpose, and collective stories and meaning built from trust and strong internal and external social links (Folke et al., 2005).

Social memory provides context for policy and management decisions. It is the collective experiential memory of the various involved stakeholders that guide decision making. This stored experience of prior successful adaptations helps to deepen shared values among stakeholders because it is actualized through debate in which each stakeholder brings their own framework of accumulated experience to the table. The knowledge that these stakeholders bring ranges from scientists with specialist expertise, managers who have worked within the governing institutions, and other groups with experience and expertise of their own. New and innovative ideas that emerge from this debate are therefore rooted in the experiential memory of the institution and stakeholders (Folke et al., 2005). These new ideas will, hopefully, improve the resilience of governance by increasing the capacity to handle change (Folke et al., 2007). There are, however, potential problems. Some stakeholder interests might only be represented indirectly, or not at all; and groupthink and collective misjudgement are both possibilities (Nooteboom, 2007). Debate may also raise barriers to action and encourage collusion amongst select interests for advantage if different value systems and worldviews are unable to find common ground. Opinion shifts can also be inhibited by powerful and credible interests who may impose their own grid on social memory, or by competition with other issues for attention (Folke et al., 2005).

The other part of governance is the level of compliance with policies. Levels of compliance vary due to perceptions of legitimacy and accountability, types of institutions, and organisational scales. Legitimacy and accountability issues are very important when discussing compliance (Folke et al., 2005). A lack of legitimacy leads to conflict over authority and policy. This is especially true if input from stakeholders representing certain interests is marginalised (Kemp et al., 2005). Accountability is very important in governing institutions because it is a characteristic that promotes confidence and trust among those involved (Folke et al., 2005; Kemp et al., 2005). Confidence and trust can 
be fostered in accountable governance regimes because there is less risk of opportunism and less room for scepticism (Nooteboom, 2007). Transparency is a vital characteristic of accountability because it creates avenues for constructive criticism, limits opportunism, and encourages cooperation and interdependency (Kemp et al., 2005; Nooteboom, 2007).

Types of governance regimes range from formal structures to informal arrangements (Dietz et al., 2003). Formal governance structures are based in legislation and usually include centralised bureaucratic decision making methods (Folke et al., 2005). These centralised government bodies have critical roles in coordinating and initiating actions, as well as legitimising and entrenching decisions once made (Kemp et al., 2005). Formal institutions operate using legally-defined rules and regulations that prescribe the roles and interactions of involved parties (Young, 2006). Informal structures are based in social networks and traditional customs, including habits and routines (Kemp et al., 2005). Consequentially, these informal networks tend to have high levels of transparency and compliance (Young, 2006). These networks play a critical role in insuring all involved parties act coherently, effectively, and with some efficiency (Kemp et al., 2005).

Informal social networks are more amenable to rapid change because they tend to be more accommodating to novelty than centralized bureaucracies (Folke et al., 2005). However, this flexibility can blur formal lines of authority and thus hinder accountability (Lejano et al., 2007; Folke et al., 2005). Leadership from formal institutions, with clear lines of accountability, is required to provide a coherent vision of, and coordinate action towards, a desired future within the local context (Folke et al., 2005).

Risk and change can occur at multiple scales - from global to regional to local levels (Folke et al., 2007). In order to be effective, governance must be concentrated at the correct scale, but involve all appropriate scale levels (Dietz et al., 2003; Folke et al., 2005). Cross-scale governance can result in patterns of dominance, separation, merger, or negotiated agreement depending on the amount of social capital and network communication (Young, 2006). Informal institutions tend to operate at the local scale, but the informal methods do not translate well into the higher level where more formal institutions are more common (Young, 2006). Dominance occurs when the formal, higher level institutions attempt to impose regulations onto the local scale, often resulting in the degradation of these local informal institutions (Folke et al., 2005). These 
regulations usually have little credibility with local people, and thus compliance is relatively low (Dietz et al., 2003). Multiple forms of separation are possible. There can be the separation of issues which are managed independently of one another (Nooteboom, 2007). Separation can also be a lack of a common understanding among stakeholders focused on their own vested interests (Adger, 2006). Finally, there can be a lack of integration of strategy and policy across multiple levels of governance (Young, 2006). These separations usually hurt the rate of compliance (Dietz et al., 2003; Adger, 2006; Young, 2006). On the other hand, mergers may form, or negotiated agreements may be struck, when stakeholders at multiple scales coordinate actions and share common goals (Folke et al., 2005).

\section{(b) Implementation and Monitoring}

Conventional formal governing techniques tend to rely on bureaucratic decision making and top-down regulatory governance procedures (Bryner, 2006). These practices tend to be modernist in the sense that they operate as if the world was a machine, and therefore predictable through reductionism and the scientific method (Plummer and Armitage, 2006). This line of thought fails to include politics and other social dynamics, and therefore creates several problems (Bryner, 2006). Formal institutions tend to have scientific experts and bureaucrats create frameworks for discussion which are then brought to outside groups for consultation. In this way, formal institutions use stakeholder consultation to legitimise policies without empowering the stakeholders to provide meaningful input (Folke et al., 2005). This allows certain interests with deeper connections within the institution to influence policy development in ways that groups lacking this privilege cannot (Brock and Carpenter, 2007). Remedying political dispute can become costly in terms of money and social capital, but can also lead to "negotiated knowledge" or "serviceable truth" in order to obtain compromise (Nooteboom, 2007). With stakeholders primarily concerned with their own vested interests it can become very difficult for new and innovative ideas to get accepted (Folke et al., 2005; Lejano et al., 2007). In this regard, formalized bureaucracies, which can include participating stakeholders as well, are typified by slow institutional learning (Nooteboom, 2007). Integration of policy and strategy is also difficult in a bureaucracy where fragmented 
approaches to decision making are common due to the influence of vested interests (Nooteboom, 2007).

The result of all these barriers is that conventional centralized means of governance are seldom adequate to properly govern complex systems (Plummer and Armitage, 2006). These complex systems require a different approach which can offer what Nooteboom (2007) called "requisite variety" in strategy and policy. Requisite variety is defined as the capacity to foresee future changes, command a range of proactive responses, and the institutional and infrastructural flexibility to adopt necessary future adaptations. The importance of requisite variety is to avoid being trapped in suboptimal policies or strategies (Brock and Carpenter, 2007). The governance process that is best able to provide requisite variety is called several things in literature: adaptive governance (Folke et al., 2005), adaptive management (Adger, 2006), and adaptive comanagement (Olsson et al., 2004). All three are based on the precautionary principle and the community-based principle. The precautionary principle states that if an activity threatens harm to human health or the environment, mitigation measures should be taken despite some scientific uncertainty (Fang et al., 2006). The community-based principle calls for public participation in decision making and contextualisation of governance policy and strategy to fit local circumstances (Fang et al., 2006; Lejano et al., 2007). Transition management is the incremental process used to bridge the gap between topdown conventional governance and the more democratic adaptive management (Kemp et al., 2007).

Adaptive governance/management that is successful under uncertainty needs to build knowledge and understanding, develop practices that interpret and respond to feedback, and support flexible institutions (Olsson et al., 2004). Building knowledge requires an institution that is capable of learning. Experimentation and innovation, or learning-by-doing, is how an institution builds its knowledge base (Folke et al., 2002). This is called adaptive learning, and it helps develop capacity to quickly respond to change (Brock and Carpenter, 2007). Practices that interpret and respond to feedback require robust modelling practices and strong public participation. Modelling uncertainty can cause the enactment of sub-optimal management strategies (Brock and Carpenter, 2007). In order to avoid this, empirical observations from all scalar levels (Dietz et al., 
2003) and other stakeholder groups should be included in building the modelling parameters to make them comprehensive (Schoemaker, 1995). Also, modelling procedures should not just focus on extrapolating current trends into likely futures. Backcasting procedures allow leadership and vision to come to the fore by describing a desired future and then interpreting the events and trends needed to achieve that desired future (RIVM report). Kemp et al. (2005) outline four reasons why stakeholder involvement is important: it (1) enhances legitimacy, (2) helps reduce risk of conflict, (3) offers additional sources of ideas and information for learning, and (4) people and organizations learn through involvement. These stakeholder groups range from businesses to civil society groups, civilians, and formal government institutions. The hard part is getting all these actors to act coherently, effectively, and efficiently (Kemp et al., 2005).

Awareness of interdependency amongst stakeholders is often what leads to cooperation (Nooteboom, 2007). This cooperation often leads to better policy and strategic integration through an acceptance of common objectives, elaboration and selection of options from the modelling, and consistent implementation (Kemp et al., 2005). Local informal institutions also benefit from added support and legitimacy by being nested in formal structures operating at larger scales (Folke et al., 2005). There are potential problems though. Adaptive management has no legitimacy of its own, and must be convincing on the argument alone (Nooteboom, 2007). Adaptive management also requires the devolution of power away from centralized bureaucracies with clear structural hierarchies into multiple bodies. This is why the term adaptive co-management is often used. While this democratization of power aids institutional flexibility it also confuses the lines of accountability and authority (Folke et al., 2005). Adaptive management procedures have also been slow to deliver results, causing several commentators to declare adaptive management a failure. However, Folke et al. (2007) disagrees, suggesting that the argument is based on too narrow a view, and excludes the learning and build-up of social capital in many adaptive management projects.

Adaptive management is not a simple linear process (Shindler et al., 1999). It involves multiple policy cycles and requires similar levels of cooperation and stakeholder investment throughout (Brock and Carpenter, 2007). Monitoring processes provide 
feedback on how circumstances have changed and how they may continue to change in the future (Folke et al., 2005). Monitoring the progress of adaptive management procedures is difficult because it must include social aspects, such as increased trust among stakeholders, in order to provide the full picture (Shindler et al., 1999). Plummer and Armitage (2006) point out that there is a gap in the literature when it comes to monitoring and evaluating adaptive management projects. Monitoring, stakeholder involvement, and integration of institutions and policies all help fulfil Olsson et al.'s (2004) third criterion of success which is stakeholder and public support of flexible institutions.

\section{(c) Conclusions}

The above concepts appear transferable from the literature on resilience of socialecological systems to the arena of transportation infrastructure and policy. Adaptive management procedures provide the best method for attaining resilient and adaptive governance of transport and land use systems. Conventional formal governance is not superior because of a lack of flexibility, slow institutional learning, and poor contextualisation to fit local conditions and informal institutions. Learning by doing, extensive stakeholder involvement, and a high degree of policy and strategy integration make adaptive management the better option. It is not a panacea because adaptive management is not immune to controversy or failure. Successful adaptive management must include factual scientific knowledge built into robust modelling procedures that do not just forecast potential futures based on current trends, but provide a platform for leadership and future vision. Leaders governing with adaptive management procedures must strive to build trust and social capital amongst the various stakeholders by strengthening democratic decision making and avoiding the entrenchment of vested interests. This will increase the legitimacy of and compliance with the agreed upon policy or strategy. 


\section{7: $\underline{\text { Analysis }}$}

This chapter and the discussion will follow the order of the conceptual framework. The analysis combines information gleaned from the RLTS and its underlying implementation and corridor plans along with answers to interview questions to illuminate the focus areas of this study. The interview participants are detailed on page 14. The purpose of the analysis is to compare the transport and land use system in Greater Wellington in as much detail as possible against the themes and key points of the literature reviewed in the conceptual framework. When not directly quoted, the interview references are meant to serve merely as an indicator to support the assertion made.

\section{1: Amenity and Amenity Access}

Greater Wellington has many amenity areas. The regional council manages 50,000 hectares of regional parks and forests according to its website. The eight territorial authorities (TAs) also preside over numerous parks and botanical gardens. The airport and Wellington Hospital, as well as Wellington's waterfront area, the Te Papa museum, and the Civic Square are examples of amenity areas, albeit all within the boundaries of WCC. The strategic outcomes of the RLTS and the implementation plans beneath it have a direct effect on the accessibility of these amenity areas.

However, a region's amenity is not isolated to individual, defined areas. Neighbourhoods and streets, as well as the transport service itself, are of amenity value as well. The NZTS states that streets where people can easily walk and congregate tend to be associated with healthy communities (p. 27). This is echoed in the Urban Design Protocol (p. 16). "Streets ought to be about sitting and having coffee, they ought to be about children crossing to the nearby school, they ought to be about just places that are attractive in their own right," says Celia Wade-Brown.

Long-distance journeys should not automatically receive priority over shortdistance ones (Celia Wade-Brown). Streets with high amenity values also tend to be traffic calmed - a function of the Travel Demand Management (TDM) Plan - and pedestrian and cyclist friendly. As such, there is a close relationship between the TDM Plan and the Cycling and Pedestrian Plans (Jill Beck). "It's not just about cramming 
more people in," Celia Wade-Brown continues, "it's about making it more attractive: having more trees, having better play spaces, as well as having better transport as well."

Having clean, modern buses and train cars that can comfortably situate their passengers is also an amenity concern; as well as a means of encouraging more public transport (PT) usage (Brent Efford; Celia Wade-Brown). The importance of this was demonstrated in 2006 when increasing fuel costs drove up the mode share of PT by 11.6\% (AMR 06/07 p. 10) and the system could not handle the increased demand. Brian Baxter puts it this way: "Some people tried to ride on the trains, found it was not very pleasant because it had stains and it was a bit crowded, so they went back to their cars. It'll be a little bit longer before we can attract them back again." The bus operators are brand-naming their bus services in different areas in the hope that people will identify more with their bus services. For example, the New Zealand Bus company services running in Wellington City are under the Go Wellington or Stagecoach brand (Brian Baxter).

The health benefits of amenity that encourages physical activity and social interaction were also addressed in the RLTS. "We [the RLTC] took social participation and access as a part of health; so it's almost community well-being rather than individual well-being, and that became particularly important," says Terry McDavitt. Peter Glensor also initiated a 4-way Memorandum of Understanding between the regional council, Upper Hutt and Hutt City Councils, and the Hutt Valley District Health Board that focused on three areas of community well-being: deprived areas, children and young people, and physical activity. The physical activity section involved strengthening cycle and pedestrian access and increasing the use of greenspaces. Brian Baxter also comments that "there's been quite a push to get a connection between Lower Hutt and Wellington Hospital because of the ways hospitals are reorganising these days"; and the AA mentioned that the connections between the Hutt and Wellington Hospital were not good. In an attempt to solve this, the Transport and Access Committee extended bus route 83 in a four month trial service from the Hutt Valley to the Hospital (GWRC Report 08.41).

However, all the actions described above are below the level of the RLTS strategic objectives. Amenity and amenity access were not a priority for the RLTC in its meetings (Joe Hewitt). The word 'amenity' itself is only fleetingly mentioned in the 
RLTS. There are no outcomes, targets, or policies that directly relate to amenity. The two main reasons for this are that the RLTC believed amenity and amenity access would be increased by default through interventions that would increase regional accessibility generally and that amenity was more of a TA concern. "Following through [with the RLTS] would tend to result in better amenity because of the emphasis on more sustainable modes, which tend to be more amenable sort of modes," says Mike Mellor. Brian Baxter added that the linkages between the modes were getting better, and that new roads often have facilities and dedicated space for alternative modes.

Mike Mellor notes that "the RLTS is a regional document and when you get down to accessing individual places you're talking largely about local issues, so that's territorial authorities." Terry McDavitt also explains that it is not the regional council's place to govern the local roading network, and so therefore, local amenities are largely out of the RLTC's brief. "There are regional amenities [such as the airport, Hospital, CBD, SH 1, etc.], and the regional council can only look out for them."

The result is that few specific amenity provisions make it into the implementation and corridor plans. Mike Mellor illustrates this point when saying, "Most of the stations up the Hutt Valley have got grotty subways underneath them and are hard to find and just generally are not particularly inviting places.” The Hutt Corridor Plan does not mention railway station refurbishment in its needs and issues section. The Porirua City Council, in the Western Corridor Plan, does have a project to "upgrade" the Porirua Rail Station. However, that project is not to take place until after 2016. So far, as Celia Wade-Brown explains, everybody thinks someone else is responsible: "Because the land ownership [is not clear] and the district plans and so on are not helpful to that [better amenity] outcome, it doesn't happen."

The TDM Plan is most likely the principal means through which amenity will be increased. Integrated transport and land use provisions - while only able to be advocated for in the RLTS - along with a close relationship between the TDM and the Cycling and Pedestrian Plans, will perhaps influence TAs to adopt amenity increasing measures. However, there is no statutory authority attached to the programmes of the TDM Plan as they are all currently voluntary, and legal precedent exists for land use provisions in district plans to be only responsible to the RPS (Jill Beck; ARC vs. NSCC, 1995). Since 
Wellington's RPS is currently under revision, the strength of the land use provisions cannot be assessed. The current RPS has a policy to promote "enhancing and protecting amenity values" (RPS 14.4(8(2) p. 254). Where the RLTS is concerned, the RPS states that "the appropriate means" of implementing the amenity policy are the TA District Plans (p. 259).

\section{2: Air Quality}

Greater Wellington monitors three air pollutants: particulate matter $\left(\mathrm{PM}_{10}\right)$, carbon monoxide (CO), and nitrogen dioxide $\left(\mathrm{NO}_{2}\right)$ (AMR 06/07 p. 48). It operates one permanent monitoring site at the Vivian/Victoria Street intersection in the Wellington City centre, and two mobile units at Melling and Ngauranga. The New Zealand national air quality standards mirror WHO guidelines (Fisher et al., 2007). The national standard for $\mathrm{PM}_{10}$ in NZ is $50 \mu \mathrm{g} / \mathrm{m}^{3}$ over a 24 hour period and an annual average of $20 \mu \mathrm{g} / \mathrm{m}^{3}$. For CO the standard is $10 \mathrm{mg} / \mathrm{m}^{3}$ as an 8 hour moving average, calculated on the hour. For $\mathrm{NO}_{2}$ the standard is a concentration of $200 \mu \mathrm{g} / \mathrm{m}^{3}$ as a 1 hour average $(06 / 07$ AMR pp. 48-49).
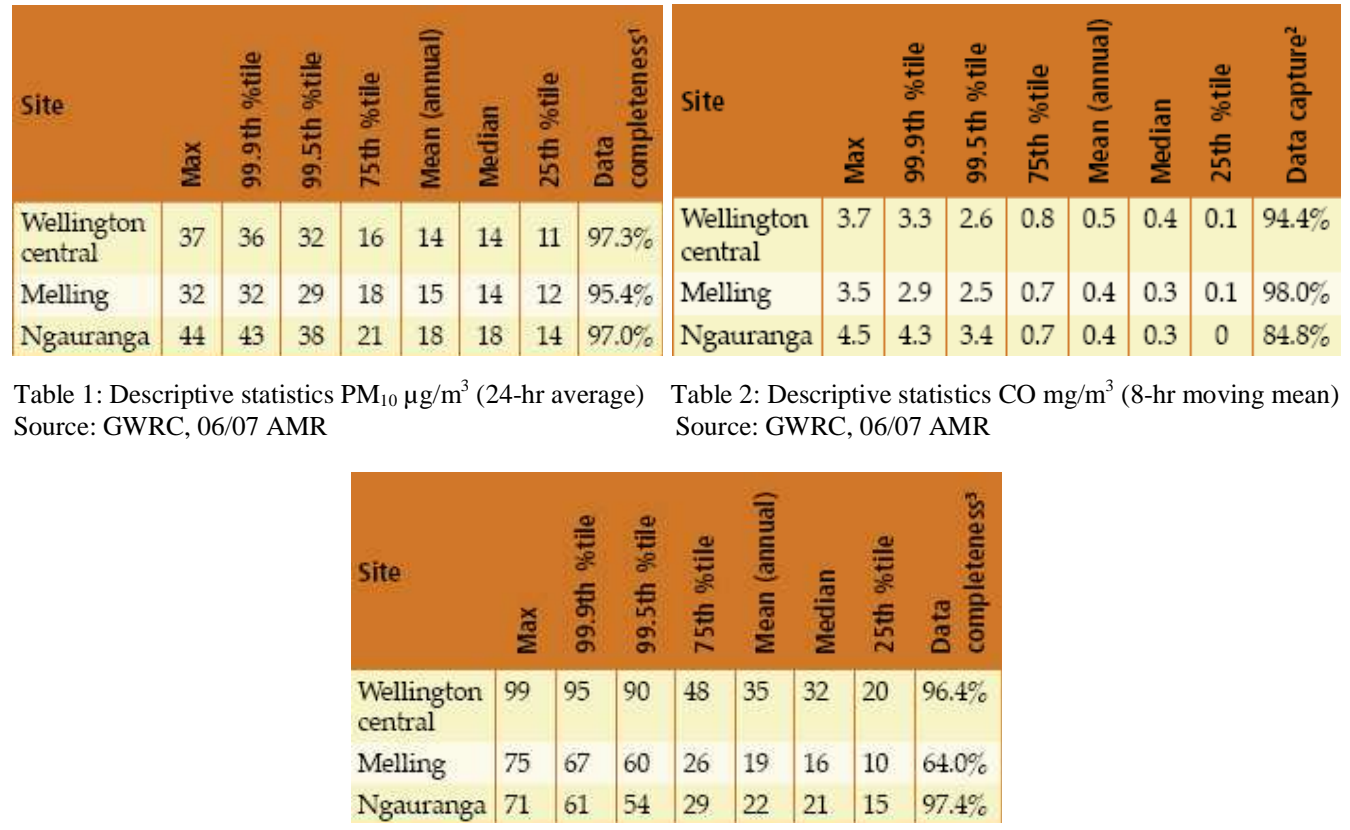

Table 3: Descriptive statistics $\mathrm{NO}_{2} \mu \mathrm{g} / \mathrm{m}^{3}$ (1-hr average) Source: GWRC, 06/07 AMR 
Table 1 shows the maximum concentrations recorded in the 06/07 AMR were 37 $\mu \mathrm{g} / \mathrm{m}^{3}$ for Wellington, 32 for Melling, and 44 for Ngauranga. The annual mean of $\mathrm{PM}_{10}$ at Wellington central was $14 \mu \mathrm{g} / \mathrm{m}^{3}, 15$ at Melling, and 18 for Ngauranga. Table 2 displays the CO the Wellington centre, Melling, and Ngauranga monitoring stations recorded a maximum $\mathrm{CO}$ concentration of $3.7,3.5$, and $4.5 \mathrm{mg} / \mathrm{m}^{3}$ respectively. The annual mean value for Wellington central was $0.5 \mathrm{mg} / \mathrm{m}^{3}$ while Melling and Ngauranga each recorded a mean of 0.4 . Table 3 shows the $\mathrm{NO}_{2}$ maximum values recorded by the monitoring stations were all well below this standard. Wellington central only measured a $99 \mu \mathrm{g} / \mathrm{m}^{3}$ high, while Melling and Ngauranga measured a maximum value of 75 and 71 respectively. The annual mean for $\mathrm{NO}_{2}$ in Greater Wellington was recorded as 35, 19, and $22 \mu \mathrm{g} / \mathrm{m}^{3}$ for Wellington central, Melling, and Ngauranga.

These monitoring stations were set up specifically to monitor areas where transport was the likeliest cause of polluting emissions. For the 06/07 AMR review period there were no breaches of national standards. Carbon monoxide and nitrogen dioxide levels never reached alert levels. An alert level is $66 \%$ and above of the national air quality standards (AMR 06/07 p. 48). For $\mathrm{PM}_{10}$, Wellington central had 2 day where alert levels were reached, and Ngauranga had 6 days of alert levels.

Since there were no breaches of national air quality standards and very few alert days, air quality is not seen as an issue that requires intervention by the regional council through the RLTS. "I accept the conventional wisdom that the wonderful fresh air blowing through Wellington means that air quality is not a big issue for us," says Peter Glensor. The other reason is that fleet upgrades, new technology, and improving fuel standards will better the air quality - or at least negate any effects from projected vehicle use and travel time increases - in virtually any business-as-usual scenario (Joe Hewitt). For these reasons, issues around air quality were of low priority in RLTS development phases.

However, the methods used for monitoring air quality by the regional council have been challenged as inadequate. The fact that there is only a single monitoring station for Wellington City was brought up in several interviews as a problem (Brent Efford; Peter Glensor; Celia Wade-Brown). However, the biggest complaint was the positioning of the monitoring station at the Vivian/Victoria Street intersection. "That's in 
a very open, well ventilated place, open to the North/South winds... and also it's in a spot where now the traffic on that part of [Vivian] Street goes in the other direction," says Brent Efford. He went on to say that "they're [the regional council] not measuring in the places where the human impact is greatest." Celia Wade-Brown commented that it would be good to monitor local roads where "you've got quite a lot of low quality vehicles going through." She characterised these low quality vehicles as "some of the old diesel buses... people's old Subarus from the 1990s... a lot of Japanese imports." Mr. Efford added that he believed some form of air quality monitoring should be instituted along the "canyon-like streets around Willis Street and Lambton Quay."

The Environmental Performance Review (EPR) of the draft RLTS stated that the Vivian/Victoria site was chosen as it was the most likely place where transport emissions would be at their greatest concentration in the city. Joe Hewitt elaborates on this when he says, "the regional council took quite a wide assessment of air quality monitoring prior to the establishment of that Vivian/Victoria site," and that it "showed that the worst site in Wellington was the Vivian/Victoria area because of the canyons on a clear, fine day, no wind blowing around - you get problems." Brent Efford says that he "wasn't surprised" the station showed a reduced amount of emissions because the Inner City Bypass was constructed after the monitoring station was installed. The Bypass reduced stop/start motoring along that part of Vivian Street, making a build-up of exhaust emissions less likely.

Terry McDavitt explained that the regional council did not monitor air quality along Willis or Lambton, for example, because they were local roads and therefore outside of regional jurisdiction. Or, as he puts it, "the [WCC] would have several fits, turn around and have another one if we dared to wander into [WCC] territories. The end result being, unfortunately, that neither do we get the results of any [WCC] air monitoring - because they don't have any." Page 61 of the RLTS has a list of the arterial roads, designated by WCC, on which the regional council could possibly make a case for establishing an air monitoring station. However, Mr. McDavitt also pointed out that every monitoring site costs approximately $\$ 80,000$ which, traditionally, the transport division of the regional council is expected to pay. 
The areas with the worst air quality in Greater Wellington, according to the EPR, are Wainuiomata, Upper Hutt, and the Wairarapa. However, the air quality problems of these places is largely due to domestic heating sources (EPR p. 10; Joe Hewitt), and therefore, not an appropriate issue for the RLTS to address. Within the RLTS, there is a policy (8.4.b) which states that the RLTS will "support continuous improvements in air quality through reduction in harmful vehicle emissions." However, there are no set targets attached to this policy in the RLTS, nor any in the Implementation Plans. There are also no key outcomes or related outcomes (RLTS p. 24) that the air quality improvement policy directly relates to. Instead, the RLTS relies upon the regional council's LTCCP to provide a target: "no recorded instances when air pollution reaches the 'alert' level of the national ambient air quality guidelines" by 2016 (LTCCP p. 28). The RLTS is also deemed not inconsistent with the Regional Air Quality Management Plan (RLTS p. 67), which was prepared under the RPS.

\section{3: Accessibility}

Improving regional accessibility was the main goal of the RLTC (Joe Hewitt). Accessibility can be improved by two principal means. The first method is giving commuters more choice in their mode of transport by providing for multi modal transport infrastructure. The other means is by increasing the proximity between where people live and where they want/need to get to by promoting mixed-use urban design. These two means are meant to redress the two main factors that tend to reduce accessibility: congestion and sprawl. The implementation and corridor plans beneath the RLTS describe several projects and programmes that are supposed to help increase accessibility, insofar as they are not inconsistent with the desired outcomes and targets of the RLTS.

To accomplish this objective, the RLTS has several outcomes and targets dedicated to accessibility that are relevant to this study. The relevant RLTS key outcomes and targets are increased peak period passenger transport mode share (1.1); the target is 25 million PT peak period trips per annum (21\% of all journey to work trips) in 2016 - up from 18.3 million (17\%) in 2005/06. The second key outcome is increased mode share for pedestrians and cyclists (2.1) with a targeted increase from 13\% in 2006 
to $15 \%$ in 2016 . Reduced severe road congestion is outcome 4.1 which has a 2016 target of average congestion below 20 seconds of delay per km travelled on selected roads; this down from 21 seconds in 2006. The final desired key outcome is improved land use and transport integration (6.1) with the target of all large subdivisions and developments to include appropriate provision for walking, cycling and PT. There are also several related outcomes detailed on the next page of the RLTS (p. 28).

The two plans that most directly affect modal shift are the Regional Passenger Transport Plan (the PT Plan) and the Passenger Transport Operating Plan (PTOP). Currently, private vehicles account for about $76 \%$ of all weekday trips, according to the transport model used for the RLTS, and $68 \%$ of all journey to work trips in the region (RLTS p. 28). The RLTS (p. 38) states that the RLTC anticipates that private vehicles will continue to be the dominant mode of transport over the timeframe of the Strategy. "PT only works when you've got a lot of people generally going to the same place from similar origins to similar destinations," says Joe Hewitt.

There are several barriers to modal shift that were described over the course of the interviews, with Brent Efford having the most to say. There are few economic incentives by way of congestion charging and fuel taxes. There is no infrastructure for real-time information systems which informs commuters at the train station or bus stop the estimated arrival time for specific buses or trains. An integrated ticketing system, which allows commuters to purchase a single ticket for train trips and/or any bus(es) that they may have to catch, has not been established. Many of the buses and train carriages are old and not very pleasant, which is described in more detail in the amenity section. There are also issues with the reliability of the PT network - scheduling, break-downs, and other hold-ups - creating uncertainty about arrival and departure times. Brian Baxter added the notion of convenience: that the closer a PT network gets to the door-to-door service that private vehicles offer, the more attractive it will be.

The role of PT, according the RLTS (p. 39), is to "provide an alternative to private cars, particularly for longer journeys where active modes are less attractive." This thesis focuses on two forms of PT: rail and bus. The PT Plan defines the role of rail as providing "safe and efficient movement of many people at a time over medium to long distances, particularly for access between regional centres and commuting to and from 
the Wellington CBD" (p. 1). Currently, the rail stock consists of 88 Ganz Mavag electric multiple unit cars from 1982, 36 English Electric cars purchased in 1955, 15 locomotivehauled carriages used on the Wairarapa line, and 8 extra cars used on the Palmerston North "Capital Connection" service from the 1970s (PT Plan, p. 22).

Clearly the rail stock is outdated and requires replacement. An older PT fleet is not as attractive to commuters as newer private vehicles. The Medium Term Rail Improvement Plan allocates NZ\$280 million to rolling stock and associated works, \$180 million to track upgrades, and $\$ 30$ million to station upgrades (PTOP p. 14-15). The improvements in rolling stock consist of 18 new carriages for the Wairarapa line, which replaces the current 15 while adding 3 more. Brian Baxter stated that usage is up already on the Wairarapa line due to the new trains. The other major procurement is 70 new Electric Multiple Units which will be delivered starting in 2010.

These new trains will, hopefully, prevent reliability problems from breakdowns as well as increase the amenity values of the carriages. There are also several infrastructure improvement plans designed to increase the quality and reliability of the rail service. In the short to medium term, the Western Corridor Plan outlines plans to establish the Lindale and Raumati Rail Stations, and double track a section of rail line from McKays to Lindale. In the long term, beyond 2016, the Plan identifies electrification of the NIMT through to Waikanae. There will also have to be several other upgrades to the station platforms and tunnels in order to accommodate the new trains (PTOP p. 15).

The other major rail infrastructure projects are proposed in the Ngauranga to Wellington Airport Corridor. These include adding a third track through what's known as the Kaiwharawhara Throat into Wellington Rail Station to reduce delays. Currently, as Brian Baxter described it, there are several lines that go out to Johnsonville, up the Kapiti Coast, and out to Upper Hutt, among other places; and they all merge into two rail lines before coming into the city rail station, creating congestion and delays. The other main PT programme in the Ngauranga to Airport Corridor is extending light rail from the train station to the Newtown growth node, including the region's main hospital. Exactly what path this light rail line will take, or even if it will be light rail, still remains to be determined. Brent Efford's view is that this will likely increase the usage of rail in the 
northern suburbs of Wellington because it will make rail more convenient - using Brian Baxter's definition of the word above.

The PT Plan defines the role of buses as to "provide for the safe and efficient movement of many people between many different origins and destinations" (p. 1) as well as to provide a feeder service to the rail network. The regional bus fleet consists of about 470 buses, 55 of which are electric trolley buses. Currently, there are approximately 87 bus routes - not including school buses - that operate in Greater Wellington (PT Plan p. 24-26). The bus network is set up with the electric trolleys at the core, running down all the main routes. Brian Baxter describes, "it's the ones that meander around the hills and go deeper into the suburbs that are run by diesel." The PT Plan also mentions that 61 new trolley buses will be operating in Wellington by November 2009 (p. 23).

Network reliability is the focus of the regional council's investment in attempting to increase PT mode share; with integrated ticketing and real time information systems coming later (PTOP p. 29; PTOP p. 31). One of the reasons for this is because the regional council has to play "catch-up" with the PT network (Brian Baxter, Joe Hewitt). "The sad reality is... that we had up to 20 years of nothing; of, in fact, the stripping of the assets, particularly of our rail network, under the failed privatization policies and there was no significant investment in infrastructure," says Peter Glensor.

"I think primarily it comes down to: where are we going to put our bucks in the short term," says Joe Hewitt. The short term is occupied with rail carriage improvements. "We're not spending that much on buses because at the moment the need is with the trains," adds Brian Baxter. Terry McDavitt also described the overall strategy for PT in Greater Wellington as catch-up from the prior lack of investment, laying the foundation for a better, more attractive service, and then moving on to a service which can meet the needs of more Wellington commuters. This is because, as Mr. McDavitt pointed out, expanding an unreliable, unimproved PT system is not productive because "you'd get modal shift and then lose it the next week."

The AA officer says his point of view is that modal shift is good in theory, but would not happen in practice barring a shock of some kind or taxation. There are not enough buses, in the AA's view, and the bus routes are not organized sufficiently to 
move tens of thousands of commuters, which is necessary for a PT system to effectively compete with private vehicles. His point is arguable, but the PTOP is taking steps to accommodate his critique. The two targets for route coverage (PTOP p. 8) are more than $90 \%$ of the region's population living within 400 meters - a 5 minute walk - of a bus stop or train station with at least a 30 minute service frequency, and at least three stops per kilometre in urban areas.

As mentioned before, 61 new trolley buses are scheduled to be added to the fleet by late 2009. It is unknown how many of the old buses will be decommissioned from now until 2016, so it is difficult to predict how much bus capacity will increase. The PTOP does call for an increase in service frequency and/or vehicle size on routes that are at or above $90 \%$ capacity at peak times (p. 9); however no specific targets are given (p. 10). Brian Baxter commented that the council decided to replace trolley buses with trolley buses - he later said that half of the trolley fleet was being refurbished, so it is difficult to determine when or if or how many of the old trolleys will be replaced - which will have air quality benefits. However, he added that there are no plans to extend the trolley's overhead wiring network onto new routes, so diesel buses will remain a significant portion of the bus fleet. "The top half-a-dozen routes in town are all electric so it's only the newer areas with less frequent services that are diesel," he says.

Modal shift is also made easier for commuters by integration of the various modes of transport. Page 43 of the RLTS has a chart that outlines what the regional council sees as "opportunities" to better integrate the various modes. Integrated ticketing is central, although that system is not a short-term priority. "The bus system is more or less designed to at least coordinate, if not integrate, with the rail system," explained Joe Hewitt. Brian Baxter noted that the feeder bus services are designed to arrive before the trains go and leave after they've arrived; which runs into problems if the trains or buses run late. There are also car parks near the train stations which integrate private vehicles and the trains. Mike Mellor referred to research done by the consulting group Opus when he said, "An awful lot of people drive very short distances to get to park-and-ride," and considering that modal shift away from private vehicles is an objective of the RLTS he continued: "and if you move park-and-ride further away from the station you actually get 
rid of an awful lot of that." However, this intervention does not appear in any implementation or corridor plan.

The integration of buses and trains with active modes of transport is less advanced. Currently, bicycles are not allowed on Greater Wellington buses. They are allowed on trains if there is room available for a $\$ 4$ charge - the same as an adult ticket (GWRC website, 14/3/08). The PTOP (p. 22) has a "park'n'ride" - presumably for cyclists provision in it where it states that the regional council will "continue to develop new and existing park'n'ride facilities and investigate opportunities for drop off facilities." Currently there are 146 cycle lockers at 12 rail stations in Greater Wellington (PT Plan p. 23). There are no targets set for the park'n'ride provisions. By contrast, Christchurch is trialling a bikes-on-buses system (Brian Baxter). Celia Wade-Brown views buses and bicycles as potentially more "complementary", in that if the bus route terminuses had good cycle storage facilities so people can leave their bicycles at the bus stop and then take the bus. The Regional Cycling Plan (RCP) has one action designed to "facilitate" PT integration with a small charge for cycle carriage at peak times, and free cycle carriage during the off-peak. The target and performance measure for this action is to be "specified in [a] new contract" (RCP p. 6).

The RLTS defines the role of cycling as "the safe and efficient movement of people between many origins and many destinations, over short to medium distances, as an alternative to private cars" (RLTS p. 41). Policy at the central government level is spelled out in the "Getting there - on foot, by cycle" report (2005) which encourages greater mode share for walking and cycling. The RCP does appear to be in line with the central government goals of community environments and transport systems that support walking and cycling, more people choosing to walk and cycle more often, and improved safety for pedestrians and cyclists (Getting there, p. 10). The RLTS targets for the regional strategic cycling network - which is different from a TA cycling network - is a $15 \%$ mode share for active modes by 2016, all the strategic cycle network providing an acceptable level of service, and fewer than 75 cyclists injured in the region per annum (RCP p. 1).

The RLTS sees walking as "the appropriate mode for short (less than $2 \mathrm{~km}$ ) local trips and for connections between modes and at either end of longer journeys by other 
modes" (RLTS p. 40). One of the desired outcomes is $75 \%$ modal share of all trips less than $1 \mathrm{~km}$ in length and $56 \%$ of trips less than $2 \mathrm{~km}$ (RPP p. 1). The two specific targets for the Regional Pedestrian Plan (RPP) are nearly all urban road frontages served by a footpath and fewer than 100 pedestrians injured per annum in Greater Wellington (RPP p. 1). There are only eight actions described in the RPP and most involve advocacy or reviews of current practice (RPP pp. 3-4). The RPP intends to implement the Public Transport Pedestrian Review Programme, which the regional council should have finished (RPP p. 3) but is not available on the regional council's website. As well, no progress reports or indicators are given in the RLTS.

The real problem, however, is the integration of the RCP and RPP with other programmes in the region. "I don't think they were well integrated," says Peter Glensor, "and part of the struggle that we're having at the moment is to get that integration going. We have a cycling strategy, we have a pedestrian strategy, they're all tied into the overall strategy, but in practice that's proving problematic." Specific walking and cycling measures are largely seen as issues the TAs are responsible for. "When it comes to the walking and cycling stuff," says Joe Hewitt, "[the regional] council has nothing to do with it. The RLTS says walking and cycling is good - we should have more." Celia Wade-Brown commented that "most of the implementation is left to the local authorities." This lack of integration between TAs is one of the key problems affecting modal shift to active modes. This may be one of the main reasons for the difficult practical integration of the modes, as noted by Peter Glensor.

The TDM Plan is another document that seeks to enable mode shift through various soft and hard measures. A soft measure is voluntary and includes the programmes under the travel behaviour change programme. These programmes include travel plans, awareness and marketing campaigns, ride sharing initiatives, variable work hours, and teleworking, teleconferencing, telebanking and teleshopping capabilities. Celia Wade-Brown gives the example that the WCC moved its morning meetings forward to 9:15 instead of 9:00, which puts them slightly behind the rush hour. "I remember there's an Eastbourne councillor who always drove in, but she said she couldn't believe the difference [for the better] it made having the meeting start at 9:15." 
Other measures mentioned in the TDM are hard measures, which involve regulating or pricing an activity. The latter include cordon charges - fees paid when a commuter enters a certain area, congestion pricing, tolls, High Occupancy Toll lanes that charge lower occupancy vehicles to use, as well as variable charges for area licences, distance or time based pricing, and parking charges (TDM p. 2-4). The regional LTCCP states that the regional council has calculated a congestion charge, but there is no legal framework to implement it (LTCCP policies doc., p. 38) suggesting a gap in the national transport legislative framework. One of the actions of the TDM Plan is to advocate to central government for the ability to do so (TDM p. 8). The AA officer objected to congestion charging in Wellington City, saying that there are few or no ways of getting around the priced streets. However, this appears to miss the point that pricing in Wellington City can still reduce vehicular traffic. Moreover, his critique does not seem consistent with his acknowledgement that congestion pricing may be a strong incentive for increased PT mode share. The 06/07 AMR concluded that the soft measures are expected to only change travel behaviour at the margins and "ultimately" hard pricing measures will be required to affect significant modal shift through direct economic incentives (p. 62). The new Land Transport Management Amendment Bill 2007 contains a provision for regional councils to levy fuel taxes, but there is no mention of congestion charging (Hon. A. King, 18/10/2007).

The second means of increasing accessibility is by increasing the proximity between places of living and work, and greater agglomeration through mixed-use urban design. Both are outside the brief of an RLTS (Joe Hewitt) and therefore the land use provisions mentioned in the RLTS all involve advocacy of more compact land use. Terry McDavitt says that the RLTS has "wishes" where transport and land use integration is concerned. A landmark case heard by the Environment Court was on a similar issue; it involved the Auckland Regional Council and the North Shore City Council (ARC vs. NSCC, 3 NZLR 18, 1995). It found that "Regional Plans [including the RLTS] couldn't have rules around land use, i.e. they could describe land use issues but couldn't have any land use rules or methods overriding local Councils" (Terry McDavitt).

Conscious of that, the Ngauranga to Airport Corridor Study seems to have been written to support the WCC Transport and Urban Development Strategies, mentioned on 
page 14 of the RLTS. There are two growth nodes along Adelaide Road in Newtown, near the hospital, and in Kilbirnie, that the Study outlines several proposals to better connect. Whether they are proposing the best approach to connecting them is debateable. Also of concern is severance between the city and its waterfront due to traffic. This more concentrated form of development is supported socially by the increasing attractiveness of inner city living and legally by the current RPS and the WRS which are concerned with reinforcing existing town centres (Joe Hewitt). The draft of the new RPS has a policy in it (Policy 53 p. 94) for "development that integrates land use with transportation" which appears to have more detail on this issue than the current RPS.

Celia Wade-Brown pointed out that in transport and urban design decisionmaking, long distance trips should not necessarily take precedence over local trips. Her example was Vivian Street in Wellington City, which is also SH 1: "the innocent pedestrian who might have chosen rationally to live near where they work has to wait for three minutes before they can get across, whereas a person who has driven in from Kapiti instead of catching the train gets priority." Reprioritising at pedestrian crossings can be another TDM means by which private vehicle use is discouraged while active transport modes are encouraged.

There does appear to be significant development in Greater Wellington that is taking up open space rather than being infill development. "It is fair to say that Porirua have plans to expand their footprint with relatively low-density development," says Joe Hewitt, referring to a recent discussion document released by Porirua City Council (PCC). The front page of the website (www.pcc.govt.nz) states that consultation on it has recently closed and therefore its final contents are not known as of this writing. Brian Baxter says that his department is working with the PCC on the timing of moving bus services into the new subdivisions. Celia Wade-Brown also comments that there is a lot of new low-density development around Lindale - just north of Paraparaumu - which she thinks will reduce accessibility for those people due to car dependence and a lack of nearby community facilities - despite the new Lindale train station which is part of the Western Corridor Plan. However, in the end, Joe Hewitt believes the urban form of Greater Wellington will remain much like it is currently, even thirty years down the road. 
"I don't think that our dispersed development is at a level which is unsustainable," he says.

Accessibility is broader than PT mode share and mixed-use urban design. "At the end of the day the roading network, like it or not, does most of the transport task for the region," says Joe Hewitt. Consequently, the Corridor Plans advocate for several road projects. The main projects are the Western Link Road, the Grenada to Gracefield project, and the Transmission Gully Motorway. There are also several potential roading projects outlined in the Ngauranga to Airport Corridor Study, with the most expensive ones being the Mt. Victoria and Terrace Tunnel duplications. Joe Hewitt says, "there's no traffic to speak of in Wainuiomata or Wairarapa, and in Upper Hutt there is relatively little traffic and there is a relatively large bypass." Therefore, the Wairarapa Corridor Plan and most of the Hutt Corridor Plan do not factor into this analysis.

The utility of roading projects in terms of accessibility goals is largely dependent on the extent to which road expansion will induce traffic growth. The purpose of the Western Link Road, as an arterial throughway, is to take local traffic off of SH 1 along the Kapiti Coast north of Paekakariki (Brian Baxter). However, as Mike Mellor pointed out, "experience shows that traffic expands to fill the space available." The map on page 2 of the Western Corridor Plan also suggests that as traffic increases along the Western Link Road community severance issues may become apparent. This illustrates why reducing the pressure on the road network is one of the primary reasons behind modal shift as a regional priority. The RLTS is "not unsupportive of roading... but it doesn't regard roading interventions as a first-choice by any measure. In fact, because of the expense and the community disruption they're usually the last choice," says Joe Hewitt.

The Grenada to Gracefield project is "one of the more logical roads that's promoted," according to Celia Wade-Brown. The odd thing about it, from the maps in the Western and Hutt Corridor Plans, is that it can be argued that the road does not connect Grenada and Gracefield. East-West connections in Greater Wellington are not sufficient (RLTS p. 16), and roads are most likely necessary to increase lateral connectivity. However, Terry McDavitt believes that there is a better solution than the road labelled Grenada to Gracefield to connect Lower Hutt to the Johnsonville area; and that the money allocated in the RLTS should be spent on finding a solution to the 
problem, "not that particular solution." East/West connections are not listed as a priority in the RLTS, and that is something that can be taken up in the next RLTS review. If Transmission Gully continues to be delayed, the regional council may want to consider upgrading State Highway 58 - another East/West connective road - a medium term priority instead of a long-term, post 2016 objective.

Transmission Gully Motorway is the most prominent single project in the RLTS. The motorway connects with SH 1 just east of Paekakariki and remerges at the southern suburbs of Porirua, near Linden (WCP p. 2). Its purpose is to reduce congestion on SH 1 and provide a lifeline to assist the evacuation from and relief effort to Wellington City in the case of "a big nasty event" (Joe Hewitt). At the projected cost of \$955 million (WCP p. 6), Transmission Gully can be expected to take traffic off of SH 1 around Porirua. "Transmission Gully... is likely to increase speed for private cars quite significantly," says Mike Mellor.

However, it most likely will not increase regional accessibility into and out of Wellington City. This is because Transmission Gully does not help abate congestion at the Ngauranga Gorge - the entrance of SH 1 to Wellington City - in fact, it most likely will increase the congestion pressure there. The lifeline argument is also dubious because Ngauranga Gorge will still have to be used to reach Transmission Gully from Wellington City.

The regional council performed an analysis of the 2016 business-as-usual morning peak without Transmission Gully or any other infrastructure improvements. It found that $72 \%$ of the commutes from Kapiti to Wellington City would be via PT (Joe Hewitt), "which is a pretty high ratio, much higher than you would expect." With the proposed rail improvements along the Western Corridor, depending on the light rail provisions that are implemented in Wellington City, that percentage should increase - if the figure turns out to be accurate. This would suggest that the vehicle travel demand might be manageable with only relatively modest improvements to the existing SH 1 . The increase in patronage from the new carriages on the Wairarapa Line also suggests that there might be suppressed PT demand in Greater Wellington. However, Joe Hewitt states that "the 'do PT only option' was certainly looked at... but found not to adequately address the needs of the community in terms of travel demand by car." 
The Environmental Performance Review noted that Transmission Gully is likely to improve the air quality along the SH 1 corridor because it reduces traffic in settled areas (Thomas, p. 10), a conclusion echoed by Peter Glensor. However, as Brent Efford pointed out, this is only true if the level of induced travel from the motorway is relatively low. "There seems to be a view that it will become a winding country road, which I find difficult to believe," says Mike Mellor. The other environmental concern with Transmission Gully - and the Grenada to Gracefield project as well - is that they will promote more development into greenspaces. The Porirua City Council is considering plans to build two new subdivisions along the proposed motorway route (PCC, p. 46). The officer from the AA said that people living in the Hutt Valley guard their environmental amenities "preciously." However, it is unknown if people living in the surrounding areas around Porirua feel the same.

\section{4: Low-Income Groups' Transport Affordability}

There are two forms of affordability relevant to this study: the affordability to the community, in terms of rates and other taxes, and the affordability to the users in the form of fares paid. Objective 6 of the RLTS (p. 23) is about affordability. It states that the RLTS is to "take account of the funding likely to be available, economic efficiency, and the impact of funding options on regional communities." It also states that the RLTS should "consider the affordability of transport options for all members of the community, including low income groups." Beneath this objective is outcome 1.3 which is concerned with making PT accessible "for all" and explicitly mentions low-income groups (RLTS p. 24). However, the targets attached to this related - or second-tier - outcome do not include a measure of affordability (RLTS p. 28). However, network management policy 8.1(n) is to "ensure the provision of PT services and concessions that recognise the needs of the transport disadvantaged" and also explicitly mentions low-income groups (RLTS p. 29).

Community affordability was a significant part of the RLTS development process since LTA section 175(2d) requires the RLTC to "take account of" funding availability (RLTS p. 64). The regional council spends about $\$ 60$ million a year in PT operating 
subsidies (Brian Baxter). When expanding the funding for PT between the draft and final forms of the RLTS, Joe Hewitt says, "There was an awful lot of work done with the Government to ensure that that level of investment was affordable." It also necessitates that trade-offs be made. "Integrated ticketing - fantastic idea," says Peter Glensor, "[fifteen"]* million dollars. So, how important is it? Is it worth [fifteen] million; and do you get that first, or do you hold that off?"

The RLTS identifies several funding gaps between the total likely funding and the planned costs (p. 53). The total funding gap is $\$ 416$ million, with $\$ 326$ million due to Transmission Gully costs and the other $\$ 90$ million related to the PT accessibility project. The two policies under section 8.6 (RLTS p. 31) describe how the regional council will attempt to make up the funding shortfall. Policy (a) is "advocate to government for increased funding and appropriate funding instruments." Policy (b) describes what these instruments might be: local fuel taxes, tolling new roads, road pricing existing roads, public/private partnerships, and LGA development contributions and RMA financial contributions. The RLTC also projects a further \$26 million per annum, over 35 years, of debt servicing if the money can be found (RLTS p. 52).

A cover story in the Dominion Post (8/02/2008) indicates that the regional council is looking into public/private partnerships to make up the Transmission Gully shortfall. Other projects identified in the RLTS (pp. 52-3) as having local funding issues are both stages of the Grenada to Gracefield link, for which the RLTC may request Land Transport NZ to raise the subsidy rate. Various Crown agencies are being approached to make up the funding shortfall of the PT accessibility project - PT access improvements in response to a Human Rights Commission Review (RLTS p. 52). The regional council's LTCCP has the transport rates increase by $8 \%$ per annum, part of which might be to pay for the enhanced PT spending in the RLTS.

The affordability of the PT fares was not a priority according to Joe Hewitt. Brian Baxter explained that the fares are meant to pay one half of the operating cost while subsidies from Land Transport NZ and the regional rate payers equally make up the rest. "Effectively, it's a cost transfer," says Joe Hewitt. Terry McDavitt points out that the only way of lowering PT fares in New Zealand is to raise the rates - to pay for the

* Corrected estimate cost supplied by Wayne Hastie, PT Divisional Manager, based on options available. 
concession subsidy - because that's how the funding system is organised. There has also been no effort to redraw the fare zones to benefit low-income communities as suggested in the literature and the Health Impact Assessment (Brian Baxter). The main concern, as far as low-income groups are concerned, was increased equity of physical access to the PT network (PTOP p. 8; Peter Glensor).

That does not mean that affordability concerns were ignored. There are, essentially, two methods of lowering fares via council intervention. The first is through a concessionary charge. The PTOP (p. 27) states that the concessions policy is currently under review with the aim of standardising the policy throughout the region. There are no targets attached to this policy to guide the review process. Currently, there are concession fares for the elderly and children, but none for low-income groups (Brian Baxter). The preferred method of making transport more affordable for low-income groups is to have low off-peak fares (Brian Baxter, Joe Hewitt, Terry McDavitt) since low-income groups tend to travel during off-peak times. This is the preferred policy because it is simpler to implement than a concessions fare which requires some form of identification check (Terry McDavitt).

"Because of the public funding element there's always a tension between affordability and level of service," says Joe Hewitt. However, Mike Mellor points out that it is all about patronage volumes. He says, "A high quality service [presumably with higher patronage volume]... can be cheaper per head." That would require the PT operators to lower fares, which Terry McDavitt believes is doubtful since they are profitoriented private businesses. These companies are very secretive about their revenues and costs, as well as some "fairly basic information" on PT habits of Wellingtonians, and often do not comply with regional council requests for that kind of information (Peter Glensor). The broader policy issue this raises is whether a private commercial fleet is compatible with community and fare affordability goals.

\section{5: Resilience and Adaptability}

The vision statement of the NZTS states that a transport system should be both resilient and adaptive (p. 4). The resilience and adaptability of a strategy like the RLTS 
is centred on adaptive governance processes. Risk of a deterioration of services has to be managed and change directed towards optimal outcomes. The literature is clear that a requisite variety of options and a governing structure with high adaptive capacity is best suited to properly manage a system as complex as a transport and land use system. Requisite variety, in this case, implies a well-functioning, multi-modal transport system in which demand ratios can smoothly shift from one mode to another. "If you're still mainly building road infrastructure but saying how there's a need to mode shift people onto trains, well, that's just not going to work," says Brent Efford. Without requisite variety future commuters will be locked into a sub-optimal transport system which will be less resilient to both slow and sudden changes. The process of developing the current RLTS involved modelling, consultation, policy planning, implementation, and monitoring phases.

The Wellington Transport Strategic Model (WTSM) was designed to assess possible infrastructural investment scenarios against the statutory objectives of an RLTS. The model incorporated empirical data on trends, such as a steady increase in vehicle ownership etc., in Greater Wellington (Joe Hewitt). Its purpose was to determine the differences between three options in the morning rush hour: Advanced Roading, Planned Investment, and Advanced Public Transport scenarios. "What we did is we went through a process and developed a balance programme - because that's where you're going to end up," explains Joe Hewitt. "Then we tested that balance programme if we move $10 \%$ of the roading investment to PT, what would that do? If we moved $10 \%$ the other way, what would that do?"

The model has come under quite intense criticism. Terry McDavitt described it as "inadequate" and "crude." Joe Hewitt defended the model, while admitting that it has serious shortcomings. The census data that was used was from 2001, and therefore out of date; active modes were not included in the model "in a very sophisticated way"; and in the important categories of reducing congestion, improved safety, greater PT mode share, and improved access and mobility "most of the programmes had very similar outcomes" (Joe Hewitt). This gives credibility to Brent Efford and Terry McDavitt's critique that the scenarios were merely three versions of a business-as-usual future. Backcasting methods and alternative trends for key drivers, such as vehicle ownership and petrol price, 
were also not employed in the modelling process. However, Joe Hewitt said that kind of analysis would be occurring in 2009 with an updated model employing the new 2006 census data. He added that the occurrence of shocks, like peak oil prices, would also be a part of the new modelling process. "We're looking to beef up our models so hopefully we'll use it a bit more because we'll have more faith in it," says Brian Baxter.

The Health Impact Assessment claimed that the draft RLTS, which adopted the Planned Investment scenario, actually was more 'advanced roading' than the scenario of the same name, with $67 \%$ of the funding going to roading projects over the Advanced Transport scenario's total of $66 \%$. Brent Efford also stated that he did not believe the Advanced PT scenario was nearly advanced enough, with regard to PT. Joe Hewitt confirmed that the Advanced PT scenario only "essentially put a light rail system from Johnsonville to Courtney Place, I think." The Advanced PT scenario was rejected as the planning basis for the draft RLTS because it did not meet the transport demand of the region (Joe Hewitt). However, the Advanced PT essentially ignored three out of the four corridor plans in its interventions. "That's the ultimate prediction of predict-andprovide," says Mike Mellor, "saying that there's this demand so therefore we have to meet it; and that isn't necessarily the case." There is also an element of predetermination shown in Joe Hewitt's remark that the scenarios were constructed by working from a balanced programme - the Planned Investment scenario - "because that's where you're going to end up," and then deriving the other scenarios from there.

"In my view the model probably had a lesser role in the outcomes of the strategy and the draft Programme than most people realize," says Joe Hewitt, adding that it only gives a frame of reference for deliberations and consultation. The consultation process itself for the RLTS and its component implementation and corridor strategies was rather comprehensive (Brent Efford). "I think it was good from the point of view of different transport mode users," says Celia Wade-Brown. "I felt Living Streets and Cycle Aware, and so on, had good opportunities." In fact, Joe Hewitt counted "up to about a dozen at one stage" public consultation periods.

The best evidence for the effect public consultations had on the process was the dramatic difference in PT spending from the draft and the final versions. "I think the consultation on the RLTS was effective insofar as the document was so radically changed 
as a result of the public input," says Brent Efford. Mike Mellor added that the number of submissions on the draft RLTS was quite large: "I think its 5- "n-a-half A4 folders of submissions." However, there are a few criticisms of the consultation process. "Sometimes you get people just defending their own patch," says Celia Wade-Brown. This can lead to negotiated knowledge. Peter Glensor also gave his opinion that the consultation process has become procedurally ritualistic and "bypass[es] the average person." He added that the sheer number of consultations on a myriad of programmes and plans under the RLTS umbrella can confuse people and stakeholder groups on where to concentrate their effort and resources to the greatest effect.

Effective consultation requires a knowledgeable community. The regional council does do an effective job at releasing council documents to the public. Attempts to educate the community are often seen as propagandising for a certain point of view (Brent Efford). Peter Glensor started a series of "conversations" early in 2008 in order to "put before people something of both the size of the issue, in terms of money and scale, and also the complexity of the issue." He promoted these conversations as a means of communicating the costs and benefits of various transport options to the public. With this simplified consultation process, he argues, the funding priorities will become more transparent and democratic. Jill Beck also mentioned that the regional council hosts quarterly cycle forums which bring TAs and cycle groups together to discuss issues and possible remedies. She later said that there was no complementary regional forum for pedestrians, as advocated by Celia Wade-Brown. "I think you probably have to rely, to some extent, on the community having enough awareness of some of these things," says Brent Efford.

The big critique that the AA officer made is that in both the modelling and consultation, the scope of the change necessary to have a world-class PT system was not adequately put across. Joe Hewitt earlier gave a possible explanation in that the RLTC was confined by the need to remain in the realm of affordability. That's why a "large scale urban renewal project" (Joe Hewitt) was not explicitly undertaken by the Committee. It is difficult to determine whether the scope of the implementation strategies will be enough to match the objectives of the RLTS, but it appears that they may not. This is because - with the exception of the PT Plan, the PTOP, and the 
Regional Transport Programme (RTP) - all the implementation and corridor plans were not updated for the new RLTS. The approval dates for the implementation and corridor plans range from December 2003 to July 2007. "The back half has very little connection with the front half," says Mike Mellor.

Joe Hewitt views this disconnect as a strength, because it means that during review periods the plans will be brought more in line with the current RLTS. He predicts that the RLTS objectives and outcomes will "be fairly robust and endure." It is the implementation plans that will change as new information becomes available and regional circumstances change. Brian Baxter says that, "by the end of their lifetime these documents get less and less relevant." The current RTP states that it only sets out the "expectations" of transport funding for the next 10 years (RTP p. 1). The adaptability of the RLTS is that implementation decisions are only made final in the annual plan budgeting processes.

The RLTS is a high level policy document and, like the RPS and WRS, is a guide to decision-making; it does not really decide for any intervention (Joe Hewitt). The roading network is also disaggregated into several projects at different scales - the planning for which is often done separately. Terry McDavitt commented that the definition of 'regional' in a NZ policy context does not include the local scale. "[There's] the Passenger Transport Programme which Greater Wellington does, the local roading programmes that the TAs do, and in the State Highway Programme that Transit does," says Joe Hewitt. In fact, the regional council only really controls public transport spending and fares, as well as the regional rates. Unlike the RPS and WRS, the RLTS does put together funding commitments. National, Regional, and Crown funds are all allocated by Land Transport NZ; and Local funds are allocated through the LTCCP and Annual Plans by the regional council and TAs (RLTS p. 51-52). This makes policy integration extremely important, which requires excellent communication.

The communication between the various policy and implementation offices in the regional council appears to be very solid. "We may operate as two separate departments but we're a division that acts collectively," says Jill Beck. The RLTS was delayed to take account of the WRS (RLTS p. 1), and the RPS is currently under review, with Joe Hewitt and the RLTC commenting on the various developmental drafts (Terry McDavitt). 
Transit, Land Transport NZ, the various offices of the regional council, and the TAs all make submissions on each other's proposals as well (Brian Baxter; Brent Efford; Joe Hewitt). However, often this is the only interaction between the different levels of government. "[At] the WCC district planning hearing we may have had a written submission from Greater Wellington, but I don't remember them coming in and [participating]" says Celia Wade-Brown.

Peter Glensor noted that there were difficulties in integrating walking and cycling measures in practice. Celia Wade-Brown's example of that are the cycling connections between Wellington and Petone. Coming in to Wellington on a bicycle is fine, but going from Wellington to Petone "along what looks like a cycle track, you get to the other end and suddenly find you're cycling contra-flow from everything on the motorway." Joe Hewitt's example of Porirua's expanding urban footprint is another case which may have to be reconciled with the WRS's urban development strategy, the NZTS, and the revised RPS. Terry McDavitt also mentioned that Treasury controls the rail funding, not Land Transport NZ; this has several integration issues attached to it since under a strict interpretation of the law, that rail money cannot be included in transport models or the RLTS planning stages.

Given a range of possibility between ignoring to implementing the RLTS, “you'd have to say that not inconsistent with is a fairly weak test," says Joe Hewitt. Celia WadeBrown added that, "most of the implementation is left to the local authorities but the funding doesn't necessarily go across." She went on to say, "if it's something where they [the TAs] have to decide to make some expenditure that's not covered, then they can disregard it, otherwise they wouldn't have any control over their own budgets." Peter Glensor also pointed out that both the regional council and TAs submit funding applications for transport projects and programmes to Land Transport NZ. There, a six member board makes the final decision on what the composition of the National Land Transport Programme will be. This is a system which lacks transparency since public consultations involve strategies and plans, not necessarily individual projects (Terry McDavitt).

Adaptability requires good monitoring and feedback mechanisms. The monitoring of the RLTS is in two forms. LTA section 182(1) mandates that an annual 
monitoring report (AMR) is published on the progress of RLTS implementation. In Greater Wellington, the AMR is due every 30 September (06/07 AMR p. 7). The other means is by quarterly reports that the TAs provide to the RLTC on their progress on a whole range of issues because the transport monitoring responsibility is shared between the regional council and TAs (Celia Wade-Brown). The AMR "takes the temperature at a point in time," says Joe Hewitt. It measures reported progress against a set of expectations and targets set in the RLTS (Joe Hewitt). Brent Efford says that he finds the latest AMR a helpful document. "I would say [the monitoring]'s well done," he added.

The quarterly reports are similar to the AMRs in that they measure progress set against expectations in the RLTS and other high level strategies and plans (Jill Beck). However, Celia Wade-Brown comments that "quite often you will see on a matrix "no report given' and the regional council [does not] seem to have a mechanism for actually contacting councils and ensuring that they do report." She says she does not notice much urgency amongst WCC officers to report back to the regional council. Other monitoring issues include Peter Glensor saying that the regional council has a very difficult time getting information from bus operating companies about "who is catching what buses, when, and trains, so that we can do some real monitoring... by getting a whole lot of information about costs and revenue."

The Land Transport Management Amendment Bill (the Bill) proposes some sweeping changes. The most significant ones in relation to this study are the new duties for the RLTC, the increased planning horizon, and changes to the monitoring schedule. Under the new legislation the RLTC will become a two tier committee where the upper tier creates the strategic plan and the lower tier creates the programme to implement that plan (Peter Glensor). This programme will replace the current RTP with a Regional Land Transport Programme, and the RLTC will decide what the constituent interventions will be. "Under the old system we put up a programme but in fact Land Transport New Zealand made those decisions," he says. This new committee system will create a "regional sieve" before funding requests go to central government (Peter Glensor). Mr. Glensor also notes that the RLTC will have more authority to demand information from the private PT operators. 
The AA officer says he believes the Bill will be "a disaster" because it limits public consultation by keeping the process within government and non-governmental organisations. However, page 57 of the Bill appears to refute that claim by mentioning the public in the list that the RLTC must consult. Peter Glensor also countered that currently Land Transport NZ, "in an even less accountable way" largely makes the funding decisions, and that all the current issue representatives will still be present at the upper tier meetings. There was near universal agreement that the extended planning horizon of 30 years was a positive. Celia Wade-Brown and Brent Efford both made the point that this was especially true with induced travel - which would now be more of a factor in the models. Joe Hewitt obliquely makes the same point when he says, "over the ten year analysis period... Transmission Gully frees things up quite nicely and so you're getting more efficient use" - when the opposite is more in line with world experience (Celia Wade-Brown). However, Peter Glensor did point out that it would be irresponsible to lock in decisions 30 years out because the numbers become too "soft." He added that he believes the 10 year planning cycle will continue, so that only the outlook will be 30 years ahead.

The Bill also changes the review and monitoring periods to six and three years respectively (Joe Hewitt). Mr. Hewitt says that, "from my point of view, we would still want to keep the annual monitoring report process" for reasons that relate to institutional memory and quality. Peter Glensor says that the RLTS and RTP will have to be rewritten under the Bill and that the Transport and Access Committee was projecting a "six figure" expense to do that. "Surely we can find a cheaper way of doing this rather than starting afresh when we've already got a Programme in place," he says. Therefore, it seems, beyond July 2008 the RLTS and its implementation and corridor plans have an even more uncertain future. 


\section{8: $\underline{\text { Discussion }}$}

The Discussion section that follows is meant to provide some commentary based on the details provided in the above Analysis. Any information that was not directly covered in the Analysis section is attributed to either the appropriate interviewee or document.

\section{1: Amenity and Amenity Access}

Amenity should most likely not be a priority for the RLTC. There are many amenity sites, and the plans that are in place likely will result in an increase of amenity in the transport system on their own. However, amenity and amenity access should not be an afterthought either. The RLTC's strategic objective of increasing mode share for PT and active modes can be well served by projects and programmes that increase the amenity values of the region. This is one of the areas where integration between transport and urban design can be very beneficial; however it takes strong and consistent leadership to make it work.

Currently, there is a conspicuous lack of emphasis on amenity values in the RLTS and the various implementation plans, and that could be addressed during the review processes of those documents. Going forward, specific projects undertaken to be consistent with the TDM, Cycling, and Pedestrian Plans could have increasing amenity values as an objective. Hopefully, more integrated urban design and transport will be a large part of regional investments going forward. In order to help ensure this, stakeholders such as Cycle Aware Wellington and Living Streets Aotearoa would be well advised to continue lobbying for increasing the amenity values of the transportation network and urban design of Greater Wellington.

\section{2: Air Quality}

The air quality in the Wellington region is quite good. The Environmental Performance Review indicated that the greatest gains in air quality will be through vehicle emission improvements, cleaner fuels, and the import of hybrid and other low 
emission technologies; therefore projected increases in vehicle use are likely not a threat to air quality. However, the air quality improvement policy in the RLTS is not directly integrated into any of the desired outcomes.

It can be argued that the encouragement of modal shift and reducing severe congestion outcomes would, as a natural consequence, positively influence air quality. However, there are no set targets to measure progress against and no stated goal to accomplish within the RLTS - it is included seemingly as an afterthought. The incorporation of the regional council's LTCCP target by the RLTS will increase the integration between it and the LTCCP; as well as support the air quality improvement policy of the RLTS. This can be done by adding improvements in air quality as an objective of projects and programmes within the various implementation plans.

As mentioned in the conceptual framework more evidence is beginning to be assembled suggesting that air pollutants can have both short and long term negative health effects at concentrations below WHO guidelines. The annual means of pollutant concentrations reported in the 06/07 AMR were low enough to suggest that this is not an issue. However, this conclusion can be misleading due to inadequacies in monitoring. GWRC does not monitor benzene levels and other VOCs, sulphur oxides, and ozone. The Ministry of Transport commissioned a study in 1996 which determined that approximately 400 people die prematurely due to vehicle emissions; Wellington City's contribution was calculated at around 56.

However, the GWRC disputes that number. "When we had a look at that, and in a different way of doing those calculations, we concluded that that number was actually about 6." It is outside the purview of this study to determine which calculation method is more appropriate. That would require a detailed empirical analysis of the air quality in Wellington City and the general region. Steps could be taken by the regional council, Ministry of Transport, and the Ministry of Health to determine the actual premature mortality rate brought on by vehicle emissions.

One of the themes of this discussion will be the notion of partnership that Celia Wade-Brown brought up in her interview. In this case, increasing the partnership between the regional council and WCC may involve reducing the tension on this issue between the two councils in order to test the air quality of Wellington City in a more 
systematic way. There may be some room to accomplish this since Celia Wade-Brown appeared supportive of more systematic monitoring and claims the air monitoring disputes did not involve the WCC councillors.

\section{3: Accessibility}

As the main focus of the RLTS, accessibility deserves a lot of attention. It is in this focus area that the greatest differences between the draft and final versions of the RLTS can be seen. Joe Hewitt remarked that the spending on PT more than doubled from about $\$ 50$ million per annum to $\$ 130$ per annum. However, this does not mean that Greater Wellington will have a top-of-the-line PT service anytime soon. The region has to play catch-up after two decades of under-investment. Therefore, it is entirely reasonable for the main focus of the RLTS to be concerned with increasing the reliability of the current PT network before any attempts are made to expand that coverage. Moreover, total PT investment is still less than roading, with over half the roading allocation going to Transmission Gully (RTP p. 4).

The natural consequence of this strategy is that modal shift will be more modest than several stakeholders may prefer. For PT to account for only $21 \%$ of the journey-towork modal share by 2016 does not make the PT service competitive with private vehicle use; although it may be in line with the desired national average in the Sustainable Transport discussion paper which updated the NZTS (p. 18). Also, a 15\% mode share for cycling and walking does not appear to be all that much of a "stretch" target, considering that the mode share was $13 \%$ in 2006 . In order to be consistent with the updated NZTS active mode target of $30 \%$ of total trips in urban areas by 2040 (Sustainable Transport $p$ 18), the next RLTS will have to be much more aggressive in pursuing active mode transport share. However, the low active mode targets may be a reflection of the fact that most of the investments of PT funds given in the RLTS are geared towards the rail and then the bus networks.

However, Celia Wade-Brown pointed out that different modes have different subsidy structures, called the Funding Assistance Rate. "I cannot see why road maintenance [and] new roads get one level of funding and new footpaths get nothing 
because they're considered to be purely a benefit within the area." This seems at odds with the walking and cycling language in the NZTS as well as the Land Transport Management Act, Urban Design Protocol, and the Sustainable Development for New Zealand Programme of Action. The regional council could consider means of advocating that central government ease the subsidy inequities between the different transport modes.

It is in Wellington City where modal shift can have its biggest impact. The Wellington CBD is the commercial hub of the region and the other three Corridor Plans are aimed at increasing accessibility to the City. With the growth node strategy seeking to concentrate development in existing centres, this gives the regional council and $\mathrm{WCC}$ a chance to dramatically increase the number of people using PT.

It should be noted that accessibility is not necessarily synonymous with PT usage or dense urban development. However, increasing modal choice to a wide range of possible destinations distributes the transport demand and makes congestion - which does reduce accessibility - less intense. As mentioned in the conceptual framework accessibility is often referred to as "walkability" in the literature. Communities can be well connected, and thus accessible, with new roading development. However, the number of negatives associated with new roading projects tend to be much greater than the negatives surrounding increased PT investment.

The vision for the Ngauranga to Airport Corridor Study says "public transport will be given priority through this corridor" (p. 4) and the WCC appears willing to implement that part of the vision (section a, p. 13). The consultation period ended February 22, 2008 (WCC, cover page) so the final decision is still pending as of this writing. A segregated busway - like light-rail but much cheaper (\$20 million for a busway and \$140 million for light rail; p. 12) - appears to be the preferred option over light rail in the document.

However, prior experience may justify a more bold approach to PT in Wellington City. The AA officer explained that SH 1 was not completely built in Wellington City; that construction was halted after the Terrace Tunnel. The bypass that was recently constructed is only half of what was recommended and is therefore only "expensive window-dressing" to the current congestion problem at the Terrace Tunnel. 
In light of this, having the proposed light rail system stop only halfway through the city at or near the hospital may be the system's Achilles Heal, similar to the partially completed SH 1. If the system is constructed all the way to the airport, which Brent Efford says is not difficult to conceptualise - even if it is considerably more expensive than other options - then the airport itself may be a significant draw. It will allow anyone riding the rail system into Wellington to have only one interchange from a heavy rail carriage to a light rail carriage. This will dramatically increase the accessibility and ease of travel to Wellington Airport - as well as Newtown and the hospital - and may possibly increase the business of the airport itself. Given that light rail requires certain densities to be economically viable (Brian Baxter, Joe Hewitt), if the airport is the terminus of the light rail system instead of the hospital this might alleviate some of the costs from a lack of density. This might make the light rail system more affordable than previously predicted by increasing the short term market for its service.

There is a strong risk of sprawl with the four new subdivisions being considered in Porirua, so it is comforting to know that the Public Transport Division of the regional council will be submitting comments and communicating with the PCC. However, if Transmission Gully is eventually completed, it is very likely that development pressure will continue to rise and Porirua and Kapiti's urban footprint will expand further. This new round of potential low-density sprawl could further erode accessibility in Porirua; which would be consistent with prior motorway induced development trends. There are also community severance issues that will have to be monitored by the regional council in any future development along Transmission Gully Motorway route.

It is likely that Joe Hewitt's assertion that the urban form of Greater Wellington will not significantly change in the coming decades is not entirely accurate. He may have meant that there will be no new towns in the region 30 years from now - which is likely. But his other statement that the urban footprint of the region is by and large sustainable will most likely be put to the test as new development - which, as he puts it, "still supports urban centres" - continues to advance over the hills. There are also accessibility and vehicle dependence concerns as these new subdivisions are built further and further away from central CBDs. 
It does appear that private vehicle use will be the main form of travel in the region for the foreseeable near future. That puts pressure on the RLTC to provide for that private vehicle use with more roading projects. The danger here, as Mike Mellor pointed out, is that roading projects become seen as solutions rather than sources of potential problems. This is true for all roading projects, and why new roads and expanded roadways must be well justified. Nowhere is this truer than with the Transmission Gully Motorway.

Despite the WRS and RPS provisions that new development should reinforce existing centres (policy 3.4, p. 253) new and dispersed development is likely to be introduced due to Transmission Gully, and possibly the Grenada to Gracefield project as well. The 2016 business-as-usual analysis mentioned before suggests that Transmission Gully may not be necessary to meet Wellington's transport needs. There are also funding considerations as well. It is alleged in a Dominion Post article (7/12/07) that Transmission Gully may face a funding battle with the roading provisions proposed in the Ngauranga to Airport Corridor Study. Further research into the business case made for Transmission Gully and its consistency with the NZTS would be beneficial to the region.

None of the accessibility reasons given for Transmission Gully appear to be valid. All the motorway would seem to do is better connect Paekakariki and beyond with the southern Porirua suburbs. Transmission Gully does not appear to improve accessibility for Wellington City because it ignores congestion at the Ngauranga Gorge. Going forward it is likely that Transmission Gully will increase congestion at the Gorge, despite the capacity-increasing measures described in the Ngauranga to Airport Corridor Study, or be a billion dollar motorway that people will underutilise due to the congestion at Ngauranga and the improved rail access to Wellington.

\section{4: Low-income Groups' Transport Affordability}

Low-income groups were part of a more general category of "transport disadvantaged" in the RLTS. The fare policy was worked out primarily in the Public Transport Division (Brian Baxter), and therefore was an issue that did not really rise to the RLTC level in any significant way (Brent Efford). This is probably a good thing 
since the Public Transport Division is more focused on PT activities than the RLTC. However, a higher level set of initiatives and guidelines might be appropriate to better integrate PT fare policy with overall regional objectives.

The AA officer had an interesting perspective on PT fares. He said that the regional council was using the wrong model in binding the PT fares to operating costs. He suggested that PT should be considered a public service and therefore the operating companies should be converted into Council Controlled Trading Organisations (CCTOs) under the regional council. It should be noted that this is not necessarily the position of the AA as an organisation. This way, the regional council can more easily keep fares low with subsidies by not having to negotiate with a private company whose objective is to profit from the PT service, as Peter Glensor described. Much of the PT infrastructure is already owned by four CCTOs (regional LTCCP p. 41). The counterargument is that competition between operators brings costs down. However, since there are only two bus companies operating in Greater Wellington, New Zealand Bus and Mana, there really is not much competition in Wellington. Toll Holdings under the Tranz Metro brand, another private operating company, runs all the trains in Wellington as a sanctioned local monopoly (Brian Baxter).

With a $\$ 416$ million shortfall, it also appears that the RLTC gave itself and the other regional transport committees a difficult task as far as community affordability goes. The RLTS clearly states that "projects will not proceed until full funding is allocated" (p. 53). This puts the implementation of several projects and programmes in jeopardy if more funding cannot be found in time.

There is also the issue of the regional fuel tax provision in the Land Transport Management Amendment Bill which could have a disproportionately negative impact on low-income groups. To avoid this, the regional council should use the current review of concessions policies to develop plans to mitigate any negative effects of the fuel tax on low-income groups. Low-income groups have mostly been ignored in prior concession fare policies. It would benefit the outcome of greater PT access for the transport disadvantaged if low-income groups were factored into concession fare policy. 


\section{5: Resilience and Adaptability}

The resilience and adaptability of the RLTS involves its sustainability as a strategic document and whether it is internally coherent and consistent. The answer to the second question is clear: no, it is not internally coherent or consistent. Most of the implementation and corridor plans were drafted prior to the development of the current RLTS and were not updated. It is also fair to say that roading projects still account for the majority of the funding $-\$ 1,330$ million for PT and $\$ 1,735$ million for roading (RTP p. 4) - despite central government strategies and the RLTS's own outcomes, targets and policies that promote modal shift to PT and active modes. However, this funding level is more in line with the Advanced Passenger Transport scenario and can be seen as a response to submissions made during public consultation.

The first question, about sustainability, is harder to answer. Transport and landuse infrastructure has a long lifespan and is very expensive to alter once it is in place. Therefore, being locked into sub-optimal options is a relatively large risk. The literature and international experience suggests that a resilient transport system is one that offers an array of transport choices and does not undervalue active modes. This facilitates a transport infrastructure that can cope with changing demand ratios between modes. The RLTS objectives and outcomes are in line with the literature; however the targets appear to be "modest", to use Brent Efford's term. This is most likely due to the trade-off made when focusing on improving the current PT system before expanding it. The model used, while it was only one input to the process, does not appear to have been very useful on the whole. Perhaps the model would have been more practical if each of the three scenarios were developed as stand-alones from each other and if assumptions on key drivers were more variable. It is hoped that the new model will be more valuable to the discussions around the new RLTS starting in July 2008.

There is also an element of predetermination in the selection of the Planned Investment scenario to base the draft RTP on. This appears in Joe Hewitt's statement on how the scenarios were constructed and in Mike Mellor's remark that "the consultation at the time was largely in favour of the Advanced Public Transport" scenario. However, this is speculative, and cannot be taken as fact-based analysis. 
The consultation process does appear to have been very broad, if somewhat overwhelming. Brent Efford praised Terry McDavitt for being generally responsive to public input. The issues with the consultation come in with Peter Glensor's opinion that the average person was "bypassed" with meetings where different advocacy groups defended their own point of view. The AA officer also noted that he believed the scope of change necessary to achieve a "world-class" PT network did not filter well into the consultations. Mr. Glensor's plan to hold "conversations" about cost, benefits, and issues of different transport options does appear to be helpful at opening the process up more to the general public and contributing to better understanding and knowledge in the wider community. This is also a good means of building trust amongst the various government and non-governmental stakeholders.

The integration of the plans seems to be hit or miss. As Joe Hewitt noted, not inconsistent with is a fairly weak test, although the language is progressively getting stronger (Brian Baxter). While the RLTS seems to be well integrated with the WRS and RPS, the implementation and corridor plans are lagging behind. While Jill Beck assures that the TDM Plan is well linked with the Cycling and Pedestrian Plans, they were all not updated to take the current RLTS into account. There are also issues with funding not coming through on objectives between the regional council and the TAs which are largely tasked with implementing the RLTS recommended projects and programmes.

The integration between the regional council and the TAs is also somewhat lacking. There does not seem to be a real effort to comply with the quarterly reporting process, and in practice the integrated implementation of the various plans is not going smoothly, as noted by Peter Glensor. "We need to get more into a partnership mode," says Celia Wade-Brown, "what are the areas where regional councils can help us, rather than tell us what to do... so we go in as a team." This partnership can also help ease tensions between the regional and local councils. Celia Wade-Brown says that the regional council sometimes gets funding from Land Transport NZ for a specific project or programme and then goes to the TAs with a "wish list" to implement it that is not in the TA's budget. Even if the TAs are sympathetic to the plan, they do not like appearing to "be on the back foot" (Celia Wade-Brown). 
Some of the reforms of the Bill tabled in Parliament can also increase council policy integration. Rather than the regional and local councils going to Land Transport NZ individually for funding, the RLTC will have the added responsibility of filtering the interventions. This may allow for greater integration between the interventions led by the regional council and the TAs. The process can also be made more transparent by ensuring the output from both tiers of the renovated RLTC is open to public consultation.

Most of the other reforms of the Bill do appear to be helpful. Expanding the planning horizon to 30 years will aid in making the RLTS more strategic because the long-term consequences of infrastructural capital projects may be more apparent depending on the quality of the upgraded model and how it is deployed. This will have positive benefits in tracking induced traffic, energy prices, and long-term health effects like obesity. The greater ability of the regional council to obtain information from private operators on usage trends and costs of PT can also be helpful in making the WTSM more accurate and provide more information for the implementation and corridor plan reviews.

However, there are negatives to the Bill. As Joe Hewitt pointed out, a 3 yearly monitoring cycle is not robust enough, and the regional council is encouraged to maintain the annual monitoring cycle. Also, since the RLTS was recently approved as of July 2007, the need to start the development process over again in July 2008 seems unnecessary - as well as expensive. The greatest good this new development cycle can foster in the short-term is a focus on renewing the implementation and corridor plans to make them more consistent with the new outcomes, targets, and polices of the RLTS 2007-2016. The Bill also lacks legal reforms which will allow regional councils to implement congestion charging policies. 


\section{9: Conclusion}

Transport and land use issues have a great effect on society and the economy. An efficient transport system lowers transaction costs and better connects communities. A mixed-use, agglomerated urban form and transport infrastructure increases choices in travel modes and makes life in the streets more vibrant and inviting. The Wellington RLTS is a high level strategy that seeks to guide transport funding in the Wellington region for the next 10 years -2007 to 2016 . The focus areas analysed are amenity and amenity access, air quality, accessibility, low-income groups' transport affordability, as well as its resilience and adaptability. The objective of this study has been to determine how well the RLTS balances key environmental, economic and social outcomes, how resilient and adaptable it is to a range of future circumstances, and whether it is internally coherent and consistent. In other words, how strategic is the Wellington Regional Land Transport Strategy?

Amenity values are important to a region for the various environmental, social, and economic benefits they provide to regional quality of life. The key factors for amenity include access to well-maintained greenspaces, such as botanical gardens, and facilities such as Wellington Hospital, schools, CBDs, and the airport. Also important is the condition of the infrastructure: streets, trains, and buses; whether they meet the definition of amenity in the RMA of contributing "to people's appreciation of its pleasantness, aesthetic coherence, and cultural and recreational attributes." Clean and comfortable buses and train carriages tend to increase patronage and aid in the RLTS's accessibility outcomes. Amenity and amenity access were secondary concerns in the RLTS. This is reasonable since urban form amenity interventions in NZ are considered more a local TA responsibility. However, given that amenity values have a demonstrated ability to increase PT and active mode share, and that the regional council is directly responsible for the PT system, adding policies to the RLTS for increasing amenity values throughout the region would be beneficial.

The level of air pollution for any given area is dependent on a host of factors. Nevertheless, the use of transport networks is a significant contributor to that air pollution. This pollution has both short-term and long-term health effects which reduces quality of living for the people exposed, especially children. There are also significant effects on 
the economy from increased health care costs and restricted activity days. Greater Wellington currently does not have any transport-induced air quality problems on the regional scale, and therefore, there are few air quality policies in the RLTS. Concerns have been raised over the lack of monitoring of local air quality where human exposure to vehicle exhaust pollution is the greatest. Greater partnership between the regional council and the TAs to increase the monitoring of air quality in local areas is a start to better monitoring procedures which can lead to more effective policy.

Accessibility, as defined in this study, is an umbrella term encompassing the concepts of mobility and connectivity. It is also determined by the level of proximity and agglomeration of a community's urban form. Sprawl and congestion have a negative effect on accessibility. A lack of accessibility has many environmental, social, and economic costs associated with it. Multi-modal measuring techniques for connectivity mean that the diversity of destinations within easy travelling distances and times of PT, cycling, and walking are key factors in determining the connectivity - and thus the accessibility - of a given area. However, feedback loops that accentuate sprawl and congestion by under-pricing private vehicle use and undervaluing alternative modes are still not fully accounted for in Greater Wellington's transport and urban design models.

Accessibility was the primary driver of the RLTS investments and interventions. The RLTS outcomes do promote greater choice in transportation in general; however the targets appear to be modest. This is partially a natural consequence of the investment strategy which focuses on catching-up with approximately 25 years of under-investment in PT, especially rail. However, due to the modest targets set in the RLTS, a PT network that is competitive with private vehicle use is still a long way off. As well, despite provisions in the WRS and RPS designed to reduce sprawl and promote infill development, the Porirua City Council and the Kapiti District Council, at least, appear to have plans to expand their urban footprints into surrounding greenspaces.

The affordability of a transport network is crucial to the equitable distribution of services and benefits that an urban community produces. Public transport is often designed around the needs of middle to upper income groups and limited in scope to peak travel times. This type of planning can disenfranchise low-income groups by limiting their access to public transport facilities and services. Transport costs take up a large 
percentage of budgets for low-income groups, who also tend to make shorter trips because of this. Land use policies, therefore, play a big role in the affordability of a transport network.

There are two affordability criteria in the RLTS: affordability to the community in terms of rates and taxes, and affordability for users, especially the 'transport disadvantaged' - which includes low-income groups. The community affordability objective of the RLTS was not well adhered to, resulting in almost $\$ 400$ million in unpaid costs. Fare policy affordability, especially for low-income groups, is not nearly as important a strategic priority as it could have been. There are several means to increase low-income groups' transport affordability, through fare boundaries and concessions policies, that the RLTC can incorporate into review and revision periods for the RLTS and its implementation and corridor plans. Any new regional fuel tax authorised by the Regional Land Transport Management Amendment Bill should have a concessions policy attached to it designed to mitigate any adverse effect on accessibility for low-income groups and a deliberate PT offset. However, the regional council's preferred method for increasing low-income groups' transport affordability is through low off-peak fares which are easier to implement.

The resilience and adaptability of a transportation and land use system are centred on its ability to withstand and cope with risk and change. The same thing is true with a policy strategy concerning the transportation and land use system. The development of a resilient and adaptable strategy is more likely with a high degree of participation from all stakeholders which is founded upon good, healthy communication and trust between the stakeholders. Implementation of the strategy requires a high degree of compliance and policy flexibility, which is generally attained through more democratic planning stages and a firm grasp by the implementation agencies of the facts on the ground. Monitoring of the facts on the ground and the progress of implementation need to be constant; and the responsible agencies need to be sensitive to the results of that monitoring. However, this monitoring can be difficult and time consuming.

The objectives and outcomes of the RLTS do appear to promote a more resilient and adaptive transport and land use system, even if the targets are rather modest and the PT/roading funding split is still favoured towards roading. Again, the 20+ years of 
underinvestment is slowing progress towards a PT system which can adequately compete with private vehicles, which is likely why the full scope of interventions needed to produce such a PT network is not present in the RLTS. The model used by the regional council was substandard and the three scenarios used in the model did not adequately reflect the range of possibility for the region. A more adaptable model with variable trends and updated census data would make the model more useful to future policy development processes. The public consultation was broad and deep, in that several consultation periods were conducted for the RLTS and a few of its subsidiary plans. However, the consultation was perhaps too formalised, overbearing and confusing in its implementation. Although, the amount of information made public by the regional council did make the process relatively transparent to the public. Efforts to increase trust, communication, and monitoring compliance between the regional council and the TAs as well as trust and communication amongst the various stakeholders and the general public - would probably well serve future strategic development.

There are problems with the integration of the implementation plans. However, the implementation process of the RLTS does appear to be rather adaptable in that the monitoring process and funding allocations are on an annual basis. Although, with this yearly funding process strong and visionary leadership is needed to ensure multiyear projects and programmes retain the funding they require to be effective. However, the Land Transport Management Amendment Bill currently requires that the RLTS and RTP be rewritten. While this increases uncertainty going forward, it is unlikely that the RLTS objectives and outcomes will change considerably. The implementation and corridor plans are likely to be more dramatically altered. This is due to the fact that most of the implementation and corridor plans were not updated for the current RLTS. Therefore, the current RLTS is not internally coherent and consistent.

As a strategy, then, considering the context of the present transport network in the Wellington region, the RLTS does appear to be adequate to its task. The priorities of the Strategy do appear to focus on the most pressing issues - namely PT and active modes share. The caveat to that conclusion is the imbalanced PT/roading funding split. The RLTS does balance the four out of five of the focus areas of this study relatively well, the exception being low-income groups' transport affordability. When the RLTS is next 
reviewed, it is unlikely that the objectives and outcomes contained within the Strategy will be altered to a considerable degree. This is a sign that the RLTS is a resilient document. Flexibility within the RLTS is a product of the 3 yearly review process which allows for the inclusion of new information to be regularly incorporated into the RLTS. Separate procedures for updating the Implementation and Corridor Plans also lead to greater flexibility in the efforts to realise the rather robust objectives and outcomes of the RLTS. However, this can also lead to a lack of consistency between the Strategy and the various Plans drafted to see it through. The internal coherence and consistency, therefore, needs to be improved. 


\section{$\underline{\text { References }}$}

\section{Policy References}

GWRC, Long-Term Council Community Plan 2006-2016

GWRC, Passenger Transport Operational Plan 2007

GWRC, Regional Cycling Plan 2004

GWRC, Regional Land Transport Strategy 2007-2016

GWRC, Regional Passenger Transport Plan 2007

GWRC, Regional Pedestrian Plan 2004

GWRC, Regional Policy Statement, 1995

GWRC, Regional Transport Programme 2007/08-2016

GWRC, Travel Demand management Plan 2005

GWRC, Wellington Regional Strategy - Internationally Competitive Wellington, 2007

GWRC, Western Corridor Plan 2006

Land Transport Act 1998

Land Transport Management Act 2003

Resource Management Act 1991

New Zealand Transport Strategy 2002

WCC, Help us keep Wellington on the move, 2007

\section{Introduction}

GWRC, The facts about the region. http://www.gw.govt.nz/section682.cfm? (accessed $10 / 2 / 08)$.

GWRC, Introducing the draft Regional Policy Statement. http://www.gw.govt.nz/story26549.cfm? (accessed 13/3/08).

Kemp, René; Loorbach, Derk; Rotmans, Jan. (2007). "Transition management as a model for managing processes of co-evolution towards sustainable development." International Journal of Sustainable Development and World Ecology 14(1): 7891.

\section{Amenity}

Bell, Karen; Glasson, Peter; Hill, Fiona. (2000). Key Urban Amenity Approaches. Environmental Performance Indicators Programme, Ministry for the Environment.

Burgess, Jacquelin; Harrison, Carolyn M.; Limb, Melanie. (1988). "People, parks and the urban green: A study of popular meanings and values for open spaces in the city." Urban Studies 25: 455-473.

Carmona, Matthew; Magalhaes, Claudio de. (2006). "Public space management: Present and potential." Journal of Environmental Planning and Management 49(1): 75-99.

Coppack, Philip M. (1988). "Reflections on the role of amenity in the evolution of the urban field." Geografiska Annaler. Series B, Human Geography 70(3): 353-361. 
Dwyer, John F.; Childs, Gina M. (2004). "Movement of people across the landscape: A blurring of distinctions between areas, interests, and issues affecting natural resource management." Landscape and Urban Planning 69: 153-164.

Ellaway, Anne; Macintyre, Sally; Kearns, Ade. (2001). "Perceptions of place and health in socially contrasting neighbourhoods." Urban Studies 28(12): 2219-2316.

Freitas, H.; Prasad, M.N.V.; Pratas, J. (2004). "Plant community tolerant to trace elements growing on the degraded soils of Sao Domingos mine in the south east of Portugal: environmental implications.” Environmental International 30: 65-72.

Giles-Corti, Billie; Broomhall, Melissa H.; Knuiman, Matthew; Collins, Catherine; Douglas, Kate; Ng, Kevin; Lange, Andrea; Donovan, Robert J. (2005). "Increasing walking: How important is distance to, attractiveness, and size of public open space?" American Journal of Preventive Medicine 28(2S2): 169-176.

Hayward, D. Geoffrey; Weitzer, William H. (1984). "The public's image of urban parks: past amenity, present ambivalence, uncertain future." Urban Ecology 8: 243268.

Jim, C.Y. (2004). "Green-space preservation and allocation for sustainable greening of compact cities." Cities 21(4): 311-320.

Jim, C.Y.; Chen, Wendy, Y. (2006). "Recreation-amenity use and contingent valuation of urban greenspaces in Guangzhou, China." Landscape and Urban Planning 75: 8196.

Lafforgue, Gilles. (2005). "Uncertainty and amenity values in renewable resource economics.” Environmental \& Resource Economics 31: 369-383.

Living Streets Wellington. (2006). Submission from Living Streets Wellington - Draft Wellington Regional land Transport Strategy 2007-2016. Living Streets Aotearoa.

Mallawaarachchi, Thilak; Morrison, Mark D.; Blamey, Russell K. (2006). "Choice modeling to determine the significance of environmental amenity and production alternatives in the community value of peri-urban land: Sunshine Coast, Australia." Land use Policy 23: 323-332.

Marcouiller, David W.; Kim, Kwang-Koo; Deller, Steven C. (2004). "Natural amenities, tourism and income distribution." Annals of Tourism Research 31(4): 10311050 .

McCarthy, John. (2006). "The application of policy for cultural clustering: Current practice in Scotland.” European Planning Studies 14(3): 397-408. 
Netusil, Noelwah R. (2005). "The effect of environmental zoning and amenities on property values: Portland, Oregon." Land Economics 81(2): 227-246.

Newman, Peter; Bachels, Mark; Chapman, Ralph. (2005). "Sustainable transport for sustainable cities: policy implications for managing development in New Zealand cities." Public Sector 28(3): 10-16.

Quigley, Robert; Cunningham, Ruth; Ward, Martin; de Boar, Marty; Conland, Catherine. (2006). The Greater Wellington Regional Land Transport Strategy Health Impact Assessment. Wellington: Greater Wellington Regional Council.

Resource Management Act 1991. Wellington

Schmidt, Lucie; Courant, Paul N. (2006). "Sometimes close is good enough: the value of nearby environmental amenities." Journal of Regional Science 46(5): 931-951.

Smith, V. Kerry; Poulos, Christine; Kim, Hyun. (2002). "Treating open space as an urban amenity." Resource and Energy Economics 24: 107-129.

Solecki, William D. and Welch, Joan M. (1995). "Urban parks: green spaces or green walls?" Landscape and Urban Planning 32: 93-106.

Wilby, R.; Perry, GLW. (2006). "Climate change, biodiversity and the urban environment: a critical review based on London, UK." Progress in Physical Geography 30(1): 73-98.

Willis, K. G.; Powe, N. A.; Garrod, G. D. (2005). "Estimating the value of improved street lighting: A factory analytical discrete choice approach." Urban Studies 42(12): 2289-2303.

Woolley, Helen; Rose, Sian; Carmona, Matthew; Freedman, Jonathan. (2004). The Value of Public Space: How high quality parks and public spaces create economic, social, and environmental value. London: CABE Space.

\section{Air Quality}

Beverland, Iain J.; Tunes, Trygve; Sozanska, Malgorzata; Elton, Robert A.; Agius, Raymond M.; Heal, Mathew R. (2000). "Effect of long-range transport on local $\mathrm{PM}_{10}$ concentrations in the UK." Inertnational Journal of Environmental Health Research 10: 229-238.

Bose, Ranjan Kumar and Srinivasachary, V. (1997). "Policies to reduce energy use and environmental emissions in the transport sector, A case of Delhi city." Energy Policy 25(14-15): 1137-1150. 
Calef, David and Goble, Robert. (2007). "The allure of technology: How France and California promoted electric and hybrid vehicles to reduce urban air pollution." Policy Sci 40: 1-34.

Chaaban, F.B.; Nuwayhib, I.; Djoundourian, S. (2001). "A study of social and economic implications of mobile sources on air quality in Lebanon." Transportation Research Part D 6: 347-355.

Chan, M.Y. (2005). "Commuters' exposure to carbon monoxide and carbon dioxide in air-conditioned buses in Hong Kong." Indoor Built Environment 14(5): 397-403.

Chang, Shuenn-Chin and Lee, Chung-Te. (2007). "Secondary aerosol formation through photochemical reactions estimated by using air quality monitoring data in Taipei City from 1994 to 2003.” Atmospheric Environment 41: 4002-4017.

Chow, Judith C. and Watson, John G. (2002). "Review of $\mathrm{PM}_{2.5}$ and $\mathrm{PM}_{10}$ apportionment for fossil fuel combustion and other sources by the Chemical Mass Balance Receptor Model.” Energy \& Fuels 16: 222-260.

Diana, Marco; Quadrifoglio, Luca, Pronello, Cristina. (2007). "Emissions of demand responsive services as an alternative to conventional transit systems." Transportation Research Part D 12: 183-188.

Fisher, G.; Kjellstrom, S.; Kingham, S.; Hales, S.; Shrestha, R. (2007). Health and Air Pollution in New Zealand: Final Report. http://www.hapinz.org.nz/index.shtml.

Guest, Charles S.; Morgan, Philip; Moss, John R.; Woodward, Alistair J.; McMichael, Anthony J. (1996). "Abatement of tropospheric ozone: effects of strategies to improve air quality on public health and other sectors." Australian and New Zealand Journal of Public Health 20(3): 301-308.

Hidy, G.M. (2002). "Multiscale impact of fuel consumption on air quality." Energy \& Fuels 16: 270-281.

Hutchinson, Emma J. and Pearson, Peter J. G. (2004). "An evaluation of the environmental and health effects of vehicle exhaust catalysts in the United Kingdom." Environmental Health Perspectives 112(2): 132-141.

Jakob, Astrid; Craig, John L.; Fisher, Gavin. (2006). "Transport cost analysis: a case study of the total costs of private and public transport in Auckland." Environmental Science \& Policy 9: 55-66.

Lopez, J.M.; Callén, M.S.; Murillo, R.; García, T.; Navarro, M.V.; de la Cruz, M.T.; Mastral, A.M. (2005). "Levels of selected metals in ambient air PM10 in an urban site of Zaragoza (Spain).” Environmental Research 9: 58-67. 
Ministry of Transport. (1996). Land transport pricing study: Environmental externalities discussion paper. 179 p. Wellington, New Zealand.

Potoglou, Dimitris and Kanaroglou, Pavlos S. (2005). "Carbon monoxide emissions from passenger vehicles: predictive mapping with an application to Hamilton, Canada." Transportation Research Part D 10: 97-109.

Seagriff, Elaine. (1995). "Southern California air quality plans in the 1990s and the effects on transport policy." Transport Reviews 15(2): 141-165.

Taylor, George E.; Johnson, Dale W.; Andersen, Christian P. (1994. "Air pollution and forest ecosystems: A regional to global perspective." Ecological Applications 4(4): 662-689.

\section{Accessibility}

André, Michel; Villanova, André. (2004). "Characterisation of an urban bus network for environmental purposes." Science of the Total Environment 334-335: 85-99.

Artimy, Maen. (2007). "Local density estimation and dynamic transmission-range assignment in vehicular ad hoc networks." IEEE Transactions on Intelligent Transportation Systems 8(3): 400-412.

Bengston, David N.; Yeo-Chang Youn. (2006). "Urban containment policies and the protection of natural areas: The case of Seoul's greenbelt." Ecology and Society 11(1): 3 http://www.ecologyandsociety.org/vol11/iss1/art3/.

Cerin, Ester; Macfarlane, Duncan J.; Ko, Hin-Hei; Chan, Kwok-Cheung A. (2007). "Measuring perceived neighbourhood walkability in Hong Kong." Cities 24(3): 209-217.

Chatterjee, Kiron; Gordon, Andrew. (2006). "Planning for an unpredictable future: Transport in Great Britain in 2030.” Transport Policy 13: 254-264.

Chen, Haiyan; Ganesan, S.; Jia, Seisi. (2005). "Environmental challenges of post-reform housing development in Beijing." Habitat International 29: 571-589.

de Cea, Joaquín; Fernández, J. Enrique; Dekock, Valérie; Soto, Alexandra. (2005). "Solving network equilibrium problems on multimodal urban transportation networks with multiple user classes." Transport Reviews 25(3): 293-317.

de Corla-Souza, Patrick; Cohen, Harry. (1999). "Estimating induced travel for evaluation of metropolitan highway expansion." Transportation 26: 249-262.

de Palma, André; Robin, Lindsey; Proost, Stef. (2006). "Research challenges in modeling urban road pricing: An overview." Transport Policy 13: 97-105. 
Downs, Anthony. (1999). "Some realities about sprawl and urban decline." Housing Policy Debate 10(4): 955-974.

Dunphy, Robert T. (no date). Shaping Land Use as if Transportation Mattered. Interdisciplinary Ph.D. Program in urban Design and Planning Annual Symposium on "Rethinking Growth Management". Washington, D.C.

Farmer, Dennis; Fink, Camille. (2002). Tackling Traffic Congestion. The Transportation, Land Use, Environment Connection, Lake Arrowhead, California, UCLA Extension Public Policy Program.

Frank, Lawrence D.; Sallis, James F.; Conway, Terry L.; Chapman, James E.; Saelens, Brian E.; Bachman, William. (2006). "Many pathways from land use to health Associations between neighborhood walkability and active transportation, body mass index, and air quality." Journal of the American Planning Association 72(1): 75-87.

Frank, Lawrence D. (2000). "Land use and transportation interaction - Implications on public health and quality of life." Journal of Planning Education and Research 20: 6-22.

Gayle, Steven B. (2003). "Looking at transportation planning with an operations perspective.” Institute of Transportation Engineers, ITE Journal 73(12): 22-26.

Hensher, David A.; Puckett, Sean M. (2005). "Refocusing the modelling of freight distribution: Development of an economic-based framework to evaluate supply chain behaviour in response to congestion charging." Transportation 32: 573-602.

Hess, Stephane; Polak, John W.; Daly, Andrew. (2007). "Flexible substitution patterns in models of mode and time of day choice: New Evidence from the UK and the Netherlands." Transportation 34: 213-238.

Horner, Mark W.; Murray, Alan T. (2003). "A multi-objective approach to improving regional jobs-housing balance.” Regional Studies 37(2): 135-146.

Lam, Soi Hoi; Toan, Trinh Dinh. (2006). "Land transport policy and public transport in Singapore." Transportation 33: 171-188.

Litman, Todd. (1997). "Full cost accounting of urban transportation: implications and tools." Cities 14(3): 169-174.

Litman, Todd. (2005). Win-Win Emission Reductions, Victoria Transport Policy Institute. 
Litman, Todd. (2006). Re-evaluating the Role of Highway Expansion for Improving Urban Transportation. Smart Transportation Investments, Victoria Transport Policy Institute.

LSA (2006). Submission from Living Streets Aotearoa - To: Secretary, Health Select Committee, Parliament. Inquiry into Obesity and Type Two Diabetes in New Zealand. Living Streets Aotearoa.

Marchetti, Cesare. (1994). "Anthropological invariants in travel behavior." Technological Forecasting and Social Change 47: 75-88.

Matthews, John W.; Turnbull, Geoffrey K. (2007). "Neighborhood Street Layout and Property Value: The Interaction of Accessibility and Land Use Mix." Journal of Real Estate Financial Economy 35: 111-141.

Newman, Peter; Bachels, Mark; Chapman, R. (2005). "Sustainable transport for sustainable cities: Policy implications for managing development in New Zealand cities." Public Sector 28(3): 10-16.

OECD. (2000). Synthesis Report of the OECD Project on Environmentally Sustainable Transport EST. EST! environmentally sustainable transport futures, strategies and best practices. Vienna, Organisation of Economic Co-operation and Development.

Perkins, Alan; Hamnett, Stephen. (2005). The Significance of Urban Form in Creating More Greenhouse-Friendly Cities. $8^{\text {th }}$ International Conference of the Asian Planning Schools Association.

Safirova, Elena; Gillingham, Kenneth; Houde, Sébastien. (2007). "Measuring marginal congestion costs of urban transportation: Do networks matter?" Transportation Research Part A 41: 734-749.

Schlossberg, Marc; Greene, Jessica; Phillips, Page Paulsen; Johnson, Bethany; Parker, Bob. (2006). "School trips: Effects of urban form and distance on travel mode." Journal of the American Planning Association 72(3): 337-346.

Schreyer, Christoph; Schneider, Christian; Maibach, Markus; Rothengatter, Prof. Werner; Doll, Claus; Schmedding, David. (2004). The External Costs of Transport Update Study, IWW, University of Karlsruhe INFRAS.

Shiftan, Yoram; Kaplan, Sigal; Hakkert, Shalom. (2003). "Scenario building as a tool for planning a sustainable transportation system." Transportation Research Part D 8: 323-342.

Silva, Ricardo Toledo. (2000). "The Connectivity of Infrastructure Networks and the Urban Space of São Paulo in the 1990s." International Journal of Urban and Regional Research 24(1): 139-164. 
Song, Yan. (2005). "Smart Growth and urban development pattern: A comparative study." International Regional Science Review 28(2): 239-265.

Song, Yan; Knaap, Gerrit-Jan. (2004). "Measuring urban form - Is Portland winning the War on Sprawl?" Journal of the American Planning Association 70(2): 210-225.

Sultana, Selima; Weber, Joe. (2007). "Journey-to-work patterns in the Age of Sprawl: Evidence from two midsize southern metropolitan areas." The Professional Geographer 59(2): 193-208.

Vuchic, Vukan R. (1999). Transportation for Livable Cities. New Brunswick, Center for Urban Policy Research

Waddell, Paul; Ulfarsson, Gudmundur F.; Franklin, Joel P.; Lobb, John. (2007). "Incorporating land use in metropolitan transportation planning." Transportation Research Part A 41: 382-410.

Willson, Richard W. (1995). "Suburban parking requirements - A tacit policy for automobile use and sprawl." Journal of the American Planning Association 61(1): $29-42$.

\section{Affordability}

Behrens, Roger. (2004). "Understanding travel needs of the poor: Towards improved travel analysis practices in South Africa." Transport Reviews 24(3): 317-336.

Berg, Charlotte. (2007). "Household transport demand in a CGE-framework." Environmental \& Resource Economics 37: 573-597.

Bostock, Lisa. (2000). "Pathways of disadvantage? Walking as a mode of transport among low-income mothers." Health and Social Care in the Community 9(1): 1118.

Burton, Elizabeth. (2000). "The compact city: Just or just compact? A preliminary analysis." Urban Studies 37(11): 1969-2001.

Câmara, Paulo; Banister, David. (1993). "Spatial inequalities in the provision of public transport in Latin American cities.” Transport Reviews 13(4): 351-373.

Charoentrakulpeeti, Wanpen; Sajor, Edsel; Zimmermann, Willi. (2006). "Middle-class travel patterns, predispositions and attitudes, and present-day transport policy in Bangkok, Thailand.” Transport Reviews 26(6): 693-712.

Eliasson, Jonas; Mattsson, Lars-Göran. (2006). "Equity effects of congestion pricing quantitative methodology and a case study for Stockholm." Transportation Research Part A 40: 602-620. 
Fouracre, P.R.; Sohail, M.; Cavill, S. (2006). "A participatory approach to urban transport planning in developing countries." Transportation Planning and Technology 29(4): 313-330.

Gray, David; Farrington, John; Shaw, Jon; Martin, Suzanne; Roberts, Deborah. (2001). "Car dependence in rural Scotland: Transport policy, devolution and the impact of the fuel duty escalator." Journal of Rural Studies 17: 113-125.

Hensher, David. A. (2007). "Sustainable public transport systems: Moving towards a value for money and network-based approach and away from blind commitment." Transport Policy 14: 98-102.

Jarvis, Helen. (2005). "Moving to London Time: Household co-ordination and the infrastructure of everyday life." Time \& Society 14(1): 133-154.

Lau, Joseph Cho-Yam. (1997). "The performance of public transport operations, land-use and urban transport planning in Hong Kong." Cities 14(3): 145-153.

Lau, Joseph Cho-Yam; Chiu, Catherine C.H. (2003). "Accessibility of low-income workers in Hong Kong." Cities 20(3): 197-204.

Metz, David. (2003). “Transport policy for an ageing population.” Transport Reviews 23(4): 375-386.

Speck, Stefan. (1999). "Energy and carbon taxes and their distributional implications." Energy Policy 27: 659-667.

Tiwari, Geetam. (2002). "Urban transport policies: Meeting the challenge of socioeconomic diversity in cities, a case study of Delhi, India." Cities 19(2): 95-103.

Whitley, Rob; Prince, Martin. (2005). "Fear of crime, mobility and mental health in inner-city London, UK." Social Science \& Medicine 61: 1678-1688.

\section{Resilience and Adaptability}

Adger, W. Neil. (2006). "Vulnerability." Global Environmental Change. 16: 268-281.

Brock, William A.; Carpenter, Stephen R. (2007). "Panaceas and diversification of environmental policy." Proceedings of the National Academy of Sciences of the United States of America 104(39): 15206-15211.

Brooks, Nick; Adger, W. Neil; Kelly, P. Mick. (2005). "The determinants of vulnerability and adaptive capacity at the national level and the implications for adaptation." Global Environmental Change 15: 151-163. 
Bryner, Gary. Review. (2006) “Adaptive Governance: Integrating Science, Policy, and Decision Making.” Ronald D. Brunner, Toddi A. Steelman, Lindy Coe-Juell, Christina M. Crowley, Christine M. Edwards and Donna W. Tucker. New York: Columbia University Press, 2005. 319 pg. In Governance: An International Journal of Policy, Administration, and Institutions 19(4): 673-675.

Dietz, Thomas; Ostrom, Elinor; Stern, Paul C. (2003). "The struggle to govern the commons." Science 302: 1907-1912.

Fang, Qinhua; Zhang, Luoping; Hong, Huasheng. (2006). "Towards adaptive town environmental planning: The experience of Xiamen, China.” Environment \& Urbanization 18(1): 87-101.

Folke, Carl; Carpenter, Steve; Elmqvist, Thomas; Gunderson, Lance; Holling, CS; Walker, Brian. (2002). "Resilience and sustainable development: Building adaptive capacity in a world of transformations." Ambio 31(5): 437-440.

Folke, Carl; Hahn, Thomas; Olsson, Per; Norberg, Jon. (2005). "Adaptive governance of social-ecological systems." Annual Review of Environment and Resources 30: 441-473.

Folke, Carl; Pritchard, Lowell Jr.; Berkes, Fikret; Colding, Johan; Svedin, Uno. (2007). "The problem of fit between ecosystems and institutions: Ten years later." Ecology and Society 12(1).

Geurs, K. T.; van Wee, G. P. (2000). Environmentally Sustainable Transport: Implementation and Impacts for the Netherlands for 2030. Phase 3 report of the OECD project "Environmentally Sustainable Transport" RIVM report 773002013.

Kemp, René; Loorbach, Derk; Rotmans, Jan. (2007). "Transition management as a model for managing processes of co-evolution towards sustainable development." International Journal of Sustainable Development and World Ecology 14(1): 7891.

Kemp, René; Parto, Saeed; Gibson, Robert B. (2005). "Governance for sustainable development: Moving from theory to practice." International Journal of Sustainable Development 8(1/2): 12-30.

Lejano, Raul P.; Ingram, Helen M.; Whiteley, John M.; Torres, Daniel; Agduma, Sharon J. (2007). "The importance of context: Integrating resource conservation with local institutions." Society and Natural Resources 20: 177-185.

Nooteboom, Sibout. (2007). "Impact assessment procedures for sustainable development: A complexity theory perspective." Environmental Impact Assessment Review 27: 645-665. 
Olsson, Per; Folke, Carl; Berkes, Fikret. (2004). “Adaptive comanagement for building resilience in social-ecological systems." Environmental Management 34(1): 7590.

Plummer, Ryan; Armitage, Derek. (2007). “A resilience-based framework for evaluating adaptive co-management: Linking ecology, economics and society in a complex world." Ecological Economics 61: 62-74.

Schoemaker, Paul J.H. (1995). “Scenario Planning: A tool for strategic thinking.” Sloan Management Review Winter: 25-40.

Shindler, Bruce; Cheek, Kristin Aldred; Stankey, George H. (1999). Monitoring and evaluating citizen-agency interactions: a framework developed for adaptive management. Gen. Tech. Rep. PNW-GTR-452. Portland, OR: U.S Department of Agriculture, Forest Service, Pacific Northwest Research Station. 38 pg.

Young, Oran. (2006). "Vertical interplay among scale-dependent environmental and resource regimes." Ecology and Society 11(1).

Analysis and Discussion

GWRC, "2006/2007 Annual Monitoring Report on the Regional Land Transport Strategy." September 2007: GWRC.

GWRC, “A Sustainable Region: policies document.” Amended June 2007: GWRC.

GWRC, Cycles on trains, buses, and ferries. http://www.gw.govt.nz/story14785.cfm? (accessed 14/3/08).

Kay, Martin. (8/02/2008) Private funds may help pay for Gully. The Dominion Post. Wellington.

KCDC. “Western Link Road.” http://www.kapiticoast.govt.nz/GettingAbout/ WesternLInkRoad.htm. (accessed 27/2/08).

King, Hon. Annette; Press Release, 18/10/2007. “Land Transport Management Amendment Bill 2007." http://www.beehive.govt.nz/node/31036. (last accessed 27/2/08).

Ministry of Transport. “Getting there - on foot, by cycle.” February 2005: MoT.

Ministry of Transport. “Sustainable Transport: discussion paper.” December 2007: MoT.

PCC, Porirua Development Framework: Discussion Document, 2007. 
Report 08.41. Hastie, Wayne. Divisional Manager's Report. Transport \& Access Committee, GWRC, 30 January 2008. File E/06/29/03.

Thomas, P. (2006) Draft Wellington Regional Land Transport Strategy: Environmental Performance Review. Environment Management Services Ltd.: Wellington.

Williamson, Kerry. (07/12/2007). Tunnels may come at cost of Gully route. The Dominion Post. Wellington. 


\section{$\underline{\text { Appendix }}$}

\section{Human Ethics Committee}

\section{Contents}

List of Interview Participants........................100

Information for Research Participants...............101

Research Participant Consent........................103

Waiver of Confidentiality..........................105

Interview Permission Letter to GWRC..............106

Human Ethics Application.......................................107 


\section{$\underline{\text { List of Interview Participants }}$}

Joe Hewitt: GWRC

Mike Mellor: GWRC

Brent Efford: Transport 2000+; former GWRC

Terry McDavitt: former GWRC

Brian Baxter: GWRC

Celia Wade-Brown: WCC

Peter Glensor: GWRC; Hutt Valley District Health Board Jill Beck: GWRC 


\title{
The Strategic Nature of the Wellington Regional Land Transport Strategy 2007-2016
}

\author{
Principal Researcher: \\ Telephone: \\ Patrick Farrell \\ 044632115 \\ and \\ Email: \\ farrelpatr@student.vuw.ac.nz \\ Supervisor: \\ Telephone: \\ Email:
Assoc. Prof. Ralph Chapman
044635163 \\ Ralph.Chapman@vuw.ac.nz
}

\author{
Environmental Studies Programme \\ School of Geography, Environment \\ Earth Sciences \\ Victoria University of Wellington \\ PO Box 600, Wellington, NZ \\ Telephone: 044636108
}

\section{Research Participant Consent}

\section{Introduction}

The researcher is undertaking a Master's thesis project in the Environmental Studies programme at Victoria University of Wellington. Victoria University requires a student obtain ethical approval when research involves human subjects. Participation in the research must be voluntary and obtained through informed consent. This consent form is part of that process.

\section{Purpose of research}

The study aims to determine how strategic the Wellington Regional Land Transport Strategy (RLTS) is in terms of land use and transport issues. This project looks into the resilience and adaptability of the strategy in relation to three interrelated areas: environmental, economic and social outcomes. Specifically, the environmental outcomes of concern are access to amenity and air quality. The focus of the economic outcomes is on accessibility and mobility/congestion reduction. The social outcome considered is low-income groups' transport affordability.

\section{Research format}

The main focus of the interviews will be to determine the participants' professional views on the extent to which the issues identified above were addressed in the drafting and finalization of the RLTS. In so doing, it is the intent of the researcher to use these interviews to determine how strategic the RLTS is in relation to these issues. Strategic in this sense means, in brief, how well the RLTS will function under a range of potential future circumstances and whether it is internally coherent and consistent. My intention is to record all discussions and interviews using a digital recording device. If consent is given, follow-up telephone calls or e-mails may be used as needed to clarify specific information left outstanding from the interviews.

\section{Declaration of consent}

\section{Information}


I have been given, read and understood the 'Information for research participants' pertaining to this research project. I have had an opportunity to ask questions and have them answered to my satisfaction.

\section{Right of withdrawal}

I understand that participation in the research project is entirely voluntary and that I may withdraw myself and any information I have provided from this project within 2 months of the date of the interview without having to give an explanation or without disadvantaging myself in any way. I will need to inform the researcher at the time.

Confidentiality and use of data (delete one)

\section{a) Confidentiality required}

I understand that my identity will be kept confidential to the researcher and the supervisor. I understand that the published results will not use my name and that no opinions will be attributed to me in any way that will identify me.

\section{b) Confidentiality not required}

I consent to information or opinions which I have given, being attributed to me in any reports on this research and have signed the separate 'Waiver of Confidentiality' form. I understand that I will have the opportunity to check the transcripts of the interviews before publication. If I do not reply to the researcher within 30 days of receiving the transcripts, they may be used as stated in this consent.

\section{Follow-up Communication}

I consent to being contacted anytime within reasonable hours from the date of the interview to the completion of the thesis in order to clarify any statements given during the interview. (Y / N)

\section{Access to research results}

I understand that the information I provide will be published in a Master's thesis at Victoria University of Wellington. The information may also feature in academic, industry or local government publications and/or be presented at academic or professional conferences. I understand that the data I provide will not be used for any other purpose or released to others without my further written consent.

\section{Declaration}

I consent to participating in this research project.
Name
Signed
Date

Research participant:

Researcher: Patrick Farrell 


\title{
The Strategic Nature of the Wellington Regional Land Transport Strategy 2007-2016
}

\author{
Principal Researcher: \\ Patrick Farrell \\ 044632115 \\ and \\ Email: $\quad$ farrelpatr@student.vuw.ac.nz \\ Environmental Studies Programme
School of Geography, Environment \\ Earth Sciences \\ Victoria University of Wellington \\ Supervisor: \\ Assoc. Prof. Ralph Chapman \\ PO Box 600, Wellington, NZ \\ Telephone: \\ 044635163 \\ Email: \\ Ralph.Chapman@vuw.ac.nz \\ Telephone: 044636108
}

\section{Information for research participants}

\section{Introduction}

I am a Master's student in Environmental Studies at Victoria University of Wellington and this research is being undertaken as part of a Master's thesis. I anticipate that my thesis will be completed in February 2008.

\section{Purpose of research}

The study aims to determine how strategic the Wellington Regional Land Transport Strategy (RLTS) is in terms of land use and transport issues. This project looks into the resilience and adaptability of the strategy in relation to three interrelated areas: environmental, economic and social outcomes. Specifically, the environmental outcomes of concern are access to amenity and air quality. The focus of the economic outcomes is on accessibility and mobility/congestion reduction. The social outcome considered is low-income groups' transport affordability.

\section{Research format}

A literature review of the relevant areas of focus of this project will provide a scientific backdrop for the interviews of policy experts and key stakeholders to follow.

The main focus of the interviews will be to determine the participants' professional views on the extent to which the issues identified in the literature review and subsequent analysis are addressed in the drafting of the RLTS. In so doing, it is the intent of the researcher to use these interviews to determine how strategic the RLTS is in relation to these issues. Strategic in this sense means, in brief, how well the RLTS will function under a range of potential future circumstances and whether it is internally coherent and consistent.

The focus areas will be disclosed to the participants before any discussions/interviews take place. Specific questions in all the focus areas the researcher intends to discuss with the participant will also be made available beforehand. 
My intention is to record all discussions and interviews using a digital recording device. If consent is given, follow-up telephone calls or e-mails may be used as needed to clarify specific information left outstanding from the interviews.

\section{Confidentiality and use of data}

Participation in the research project is entirely voluntary. Research participants will be asked to sign a consent form. Your identity will be kept confidential and no information will be attributed to you unless a separate 'Waiver of Confidentiality' form is also signed. If you do not require your identity to remain confidential, you will have the opportunity to review and edit or withdraw the transcript of our discussion/interview(s).

All data will be kept secure with access restricted to the researcher and supervisor. All data will be destroyed one year after the project is complete. During the research project and this one year period it is anticipated that research findings will be used in publications such as academic journals, industry or local government publications and/or presented at professional or academic conferences.

\section{Right of withdrawal}

Should you feel the need to withdraw from the project, you may do so at any time within 2 months of the date of the interview. Please let me know at the time.

\section{Access to research results}

Research findings will form the basis of a Master's thesis which will be submitted to the School of Geography, Environment and Earth Sciences with copies deposited in Victoria University of Wellington libraries. At the completion of my thesis a research summary can be made available to you on request.

If you have any questions or would like further information about the project, please contact either myself or my supervisor, Associate Professor Ralph Chapman, as above.

Thank you,

\section{Patrick Farrell}

Master's student, Environmental Studies

Victoria University of Wellington 


\section{Research Project: “The Strategic Nature of the Wellington Regional Land Transport Strategy 2007-2016"}

\section{Waiver of Confidentiality}

$\mathrm{I}$, have been interviewed by Patrick Farrell as part of the "The Strategic Nature of the Wellington Regional Land Transport Strategy 2007-2016" research project. I have chosen that my identity will not remain confidential.

Patrick Farrell, Victoria University of Wellington, and any publications which use material from this research project have my permission to publicly identify me by name and use the transcript of the interview with me (after I have had the opportunity to review and modify it) as an accurate representation of what I have said.

Signature:

Name:

Date: 
Patrick Farrell

Apt. 88, Stafford House

P.O. Box 8050

Wellington, 6143

Cell: [removed]

28/9/07

David Benham

Chief Executive

Greater Wellington

142 Wakefield Street

Wellington 6011

Re: Student requesting permission to interview managers and employees of the GWRC

Dear Mr. Benham,

My name is Patrick Farrell, a Master's student in Environmental Studies at Victoria University of Wellington working on my thesis. The title is "The Strategic Nature of the Wellington Regional Land Transport Strategy 2007-2016".

I am writing to request permission to interview managers and employees of Greater Wellington in order to complete my thesis. This is part of my Victoria University Human Ethics Committee requirements, and accordingly, all rules of confidentiality required by the Committee will apply. Included is a copy of the consent form I plan to distribute if you assent.

My project looks into five interrelated areas: environmental, economic and social outcomes, the resilience and adaptability of the strategy, and the policy process. Specifically, the environmental outcomes of concern are access to amenity and air quality. The economic outcomes will be mobility/congestion reduction and accessibility/connectivity issues. The social outcomes considered are health and well-being, as well as low income groups' transport affordability. The focus of the process section concerns futures thinking methods and models, horizontal integration among focus areas, transparency, the consultation process, and issues surrounding the implementation of the RLTS.

The purpose of the interviews will be to determine the participants' professional views on the extent to which the subjects identified above are addressed in the RLTS. In so doing, it is my intent to use these interviews to help determine how strategic the RLTS is in relation to these subjects. Strategic in this sense means, in brief, how well the RLTS will function under a range of potential future circumstances and whether it is internally coherent and consistent.

If you have any questions or concerns, please do not hesitate to get in touch with me via phone or e-mail. The phone number of my university office is 472.1000 extension 8368 .

Sincerely,

Patrick Farrell 


\section{VICTORIA UNIVERSITY OF WELLINGTON \\ Te Whare Wananga o te Upoko o te Ika a Maui}

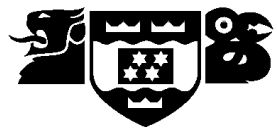

\section{HUMAN ETHICS COMMITTEE}

\section{Application for Approval of Research Projects}

Please write legibly or type if possible. Applications must be signed by supervisor (for student projects) and Head of School

Note: The Human Ethics Committee attempts to have all applications approved within three weeks but a longer period may be necessary if applications require substantial revision.

\section{NATURE OF PROPOSED RESEARCH:}

(a) Student Research

(b) If Student Research $\quad$ Degree MEnvStud Course Code ENVI593

(c) Project Title: The Strategic Nature of the Wellington Regional Land Transport Strategy 2007-2016

\section{INVESTIGATORS:}

(a) Principal Investigator

Name Patrick Farrell

e-mail address farrelpatr@student.vuw.ac.nz

School/Dept/Group School of Geography, Environment and Earth Sciences Environmental Studies

(b) Other Researchers $\quad$ Name Position

$N / A$

(c) Supervisor (in the case of student research projects)

Dr Ralph Chapman, Associate Professor, Environmental Studies 
(a) Proposed starting date for data collection 1 October 2007 (Note: that NO part of the research requiring ethical approval may commence prior to approval being given)

(b) Proposed date of completion of project as a whole 31 January 2008

\section{PROPOSED SOURCE/S OF FUNDING AND OTHER ETHICAL CONSIDERATIONS}
(a) Sources of funding for the project
Please indicate any ethical issues or conflicts of interest that may arise because of sources of funding
e.g. restrictions on publication of results

N/A

(b) Is any professional code of ethics to be followed

name

(c) Is ethical approval required from any other body

If yes, name and indicate when/if approval will be given

\section{DETAILS OF PROJECT}

Briefly Outline:

(a) The objectives of the project

1. To analyse how strategic the Wellington RLTS is considering 5 focus areas:

- environmental outcomes (amenity access, air quality)

- economic outcomes (mobility/congestion, accessibility/connectivity)

- social outcomes (health/well-being, transport affordability for low-income

groups)

- resilience and adaptability

- policy process (futures thinking/models, horizontal integration, transparency, consultation, implementation)

(b) Method of data collection 


\section{Policy document analysis (existing and developing policy)}

\section{Analysis of existing scientific literature relevant to focus areas}

3. Semi-structured interviews with land transport and land use policy advisors, policy makers, and relevant stakeholders to determine their professional views

- Individual interviews will focus on, but not exclude, separate outcomes

- Resilienceladaptability and process issues will be covered in all interviews

4. Follow-up communications (telephone or e-mail) to clarify any outstanding matters

(c) The benefits and scientific value of the project

The research will provide insights into the resilience and strategic nature of transport planning methods in a regional New Zealand setting, and a picture of the perceptions of participants and stakeholders concerning a significant strategic planning process.

(d) Characteristics of the participants

Policy advisors, policy makers, and stakeholder parties with an active interest in transport issues and land use. Participants will primarily work at the regional council level, however city/district council members and employees may be contacted if deemed necessary by the researcher or supervisor.

(e) Method of recruitment

Participants will be recruited by the process of purposive sampling. The researcher will select a range of interviewees in a manner that covers the key strategic focus issues in this study. This will be done via contact with the Greater Wellington Regional Council and the researcher's supervisor is familiar with key stakeholders. An endeavour will be made to cover the range of key stakeholders and Regional Council employees at various levels. Others may be recruited based on referrals to the researcher during preliminary discussions and interviews.

(f) Payments that are to be made/expenses to be reimbursed to participants 
N/A

(g) Other assistance (e.g. meals, transport) that is to be given to participants

$N / A$

(h) Any special hazards and/or inconvenience (including deception) that participants will encounter

$N / A$

(i) State whether consent is for (delete where not applicable):

(i) the collection of data

(ii) attribution of opinions or information*

(iii) f da

(iv) use for a conference report or a publication

(v) use for some particular purpose (specify)

The data will contribute to a Master's thesis which will be deposited in VUW libraries. * Confidentiality will be the default unless a separate waiver of confidentiality is signed.

Attach a copy of any questionnaire or interview schedule to the application

(j) How is informed consent to be obtained (see sections 4.1, 4.5(d) and 4.8(g) of the Human Ethics Policy)

(i) the research is strictly anonymous, an information sheet is supplied and informed consent is implied by voluntary participation in filling out a questionnaire for example (include a copy of the information sheet)

$N$

(ii) the research is not anonymous but is confidential and informed consent will be obtained through a signed consent form (include a copy of the consent form and information sheet)

$Y^{*}$

(iii) the research is neither anonymous nor confidential and informed consent will be obtained through a signed consent form (include a copy of the consent form and information sheet)

$N$ 
(iv) informed consent will be obtained by some other method (please specify and provide details)

* Confidentiality will be the default unless a separate waiver of confidentiality is signed.

With the exception of anonymous research as in (i), if it is proposed that written consent will not be obtained, please explain why

$N / A$

(k)If the research will not be conducted on a strictly anonymous basis state how issues of confidentiality of participants are to be ensured if this is intended. (See section 4..1(e) of the Human Ethics Policy). (e.g. who will listen to tapes, see questionnaires or have access to data). Please ensure that you distinguish clearly between anonymity and confidentiality. Indicate which of these are applicable.

(i) access to the research data will be restricted to the investigator

$N$

(ii) access to the research data will be restricted to the investigator and their supervisor (student research)

(iii) all opinions and data will be reported in aggregated form in such a way that individual persons or organisations are not identifiable

$Y^{*}$

(iv) Other (please specify)

$N / A$

* Confidentiality will be the default unless a separate waiver of confidentiality is signed.

(1) Procedure for the storage of, access to and disposal of data, both during and at the conclusion of the research. (see section 4.12 of the Human Ethics Policy). Indicate which are applicable:

(i) all written material (questionnaires, interview notes, etc) will be kept in a locked file and access is restricted to the investigator 
(ii) all electronic information will be kept in a password-protected file and access will be restricted to the investigator

(iii)all questionnaires, interview notes and similar materials will be destroyed:
(a) at the conclusion of the research

$N$

or (b) __ 1__ years after the conclusion of the research

(iv) any audio or video recordings will be returned to participants and/or electronically wiped

(v) other procedures (please specify):

$N / A$

If data and material are not to be destroyed please indicate why and the procedures envisaged for ongoing storage and security

Data will be stored for up to one year (to enable further writing and publication) after which time it will be destroyed. Hard-copy data will be kept in a locked file and electronic data will be kept in a password-protected file, both with restricted access.

(m) Feedback procedures (See section 7 of Appendix 1 of the Human Ethics Policy). You should indicate whether feedback will be provided to participants and in what form. If feedback will not be given, indicate the reasons why.

Signed consent to participate in the research will guarantee the participant receives their transcribed comments for approval or correction.

(n) Reporting and publication of results. Please indicate which of the following are appropriate. The proposed form of publications should be indicated on the information sheet and/or consent form.

(i) publication in academic or professional journals

(ii) dissemination at academic or professional conferences

(iii) deposit of the research paper or thesis in the University Library (student research)

$\boldsymbol{Y}$

(iv) other (please specify)

$Y^{*}$

* Other publications such as industry publications or reports. 
Signature of investigators as listed on page 1 (including supervisors) and Head of School.

NB: All investigators and the Head of School must sign before an application is submitted for approval

Date

Date

Date

Head of School:

Date 


\section{APPLICATIONS FOR HUMAN ETHICS APPROVAL}

\section{CHECKLIST}

- Have you read the Human Ethics Policy?

- Is ethical approval required for your project?

- Have you established whether informed consent needs to be obtained for your project?

- In the case of student projects, have you consulted your supervisor about any human ethics implications of your research?

- Has your supervisor read and signed the application?

- Have you included an information sheet for participants which explains the nature and purpose of your research, the proposed use of the material collected, who will have access to it, whether the data will be kept confidential to you, how anonymity or confidentiality is to be guaranteed?

- Have you included a written consent form?

- If not, have you explained on the application form why you do not need to get written consent?

- Are you asking participants to give consent to:

- collect data from them

- attribute information to them

- release that information to others

- use the data for particular purposes

- Have you indicated clearly to participants on the information sheet or consent form how they will be able to get feedback on the research from you (e.g. they may tick a box on the consent form indicating that they would like to be sent a summary), and how the data will be stored or disposed of at the conclusion of the research?

- Have you included a copy of any questionnaire or interview checklist you propose using?

- Has your application been seen by the head of your school or department (or the person given responsibility to consider applications on behalf of the head (see section 4.5(b) of the Human Ethics Policy). 